University of Louisville

ThinkIR: The University of Louisville's Institutional Repository

Electronic Theses and Dissertations

$12-2015$

\title{
Evaluation of two-phase evaporation pressure drop correlations for low refrigerant mass flux.
}

Anna Fenko

Univeristy of Louisville

Follow this and additional works at: https://ir.library.louisville.edu/etd

Part of the Energy Systems Commons, Heat Transfer, Combustion Commons, and the Manufacturing Commons

\section{Recommended Citation}

Fenko, Anna, "Evaluation of two-phase evaporation pressure drop correlations for low refrigerant mass flux." (2015). Electronic Theses and Dissertations. Paper 2292.

https://doi.org/10.18297/etd/2292

This Master's Thesis is brought to you for free and open access by ThinkIR: The University of Louisville's Institutional Repository. It has been accepted for inclusion in Electronic Theses and Dissertations by an authorized administrator of ThinkIR: The University of Louisville's Institutional Repository. This title appears here courtesy of the author, who has retained all other copyrights. For more information, please contact thinkir@louisville.edu. 


\title{
EVALUATION OF TWO-PHASE EVAPORATION PRESSURE DROP CORRELATIONS FOR LOW REFRIGERANT MASS FLUX
}

\author{
By \\ Anna Fenko \\ B.S., University of Florida, 2012

\begin{abstract}
A Thesis
Submitted to the Faculty of the University of Louisville

J.B. Speed School of Engineering

In Partial Fulfillment of the Requirements
\end{abstract}

For the Degree of

Master of Science in Mechanical Engineering

\author{
Department of Mechanical Engineering \\ University of Louisville \\ Louisville, KY
}

December 2015 



\section{EVALUATION OF TWO-PHASE EVAPORATION PRESSURE DROP CORRELATIONS FOR LOW REFRIGERANT MASS FLUX}

Submitted by:

\begin{tabular}{c} 
Anna Fenko \\
A Thesis Approved On \\
November $30^{\text {th }}, 2015$ \\
By the Thesis Committee: \\
\hline Dr. Ellen Brehob \\
\hline Dr. Sam Park \\
\hline Dr. Andrea Kelecy \\
\hline Dr. Kihwan Bae
\end{tabular}




\section{DEDICATION}

This thesis is dedicated to my family, who provided their unconditional love and support. 


\section{ACKNOWLEDGEMENTS}

I would like to thank my advisors Dr. Ellen Brehob, Dr. Sam Park, and Dr. Andrea Kelecy for their help and guidance throughout this project. My specials thanks to Brent Junge and Mike Kempiak for helping me build the testing fixture and guiding me through data collection. My gratitude for Scott Welham, Tim Oconnell, and Ron Foster, and my work team for allowing me to do research and giving me all the support. 


\begin{abstract}
EVALUATION OF TWO-PHASE EVAPORATION PRESSURE DROP CORRELATIONS FOR LOW REFRIGERANT MASS FLUX
\end{abstract}

\begin{abstract}
Anna Fenko
November $30^{\text {th }}, 2015$

This study was conducted to evaluate three currently popular two-phase pressure drop models for extremely low velocity refrigerant flow through smooth circular evaporators in household refrigeration systems. Experimental data was taken at mass fluxes under 70 $\mathrm{kg} / \mathrm{m}^{2} \mathrm{~s}$ for two refrigerants, R134A and R600A, internal diameters of aluminum evaporators ranging from 0.186 to 0.317 inches, U-bend internal radii ranging from 0.342 to 0.750 inches in horizontal and vertical orientations of evaporators. The geometry of the samples closely resembled a commonly used serpentine shape with multiple U-bends experiencing both, up- and down-flow of the refrigerant. Two empirical models, MüllerSteinhagen \& Heck (1986) and Grönnerud (1979), as well as one phenomenological model, Silva Lima \& Thome (2012), were compared to experimental data and all performed very well for horizontally oriented samples. However, in vertical orientation only $60.6 \%, 63.3 \%$ and $75.8 \%$ data fell within $\pm 30 \%$ accuracy band for Grönnerud, Silva Lima \& Thome and Müller-Steinhagen \& Heck correlations, respectively. The predicted values showed what steps could be taken to improve the performance of all models, which could be accomplished with future work.
\end{abstract}




\section{TABLE OF CONTENTS}

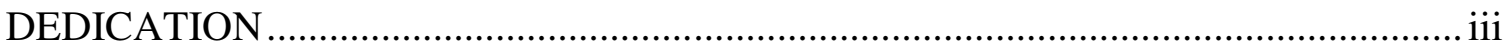

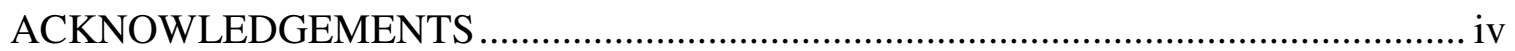

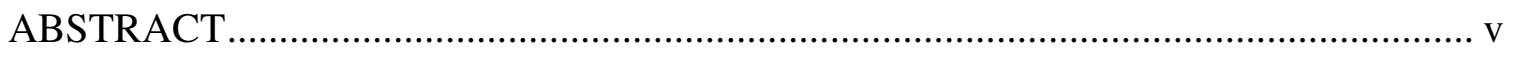

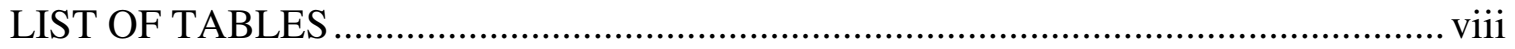

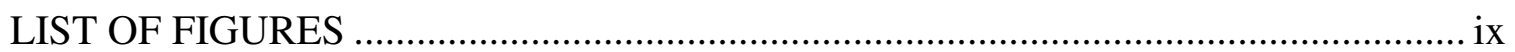

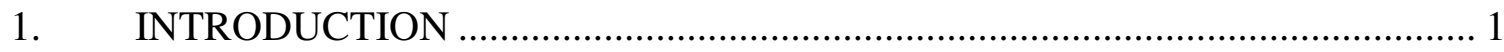

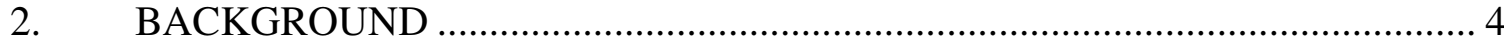

2.1 Two-Phase Pressure Drop Components................................................................ 6

2.2 Two-Phase Frictional Pressure Drop in Straight Tubes......................................... 7

2.2.1 Müller-Steinhagen \& Heck Empirical Model .......................................................10

2.2.2 Grönnerud Empirical Model ........................................................................12

2.2.3 Silva Lima \& Thome Phenomenological Model .................................................13

2.6 Two-Phase Frictional Pressure Drop in U-bends................................................... 18

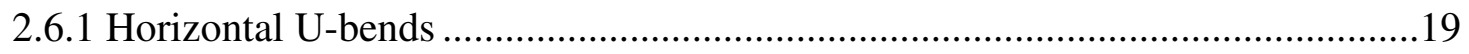

2.6.2 Vertical U-bends ............................................................................................24

2.6.3 Two-Phase Pressure Drop Models for U-bends ................................................26

2.6.4 Silva Lima \& Thome Model for U-bends ................................................................

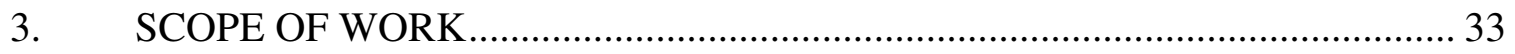

4. TEST FIXTURE AND EXPERIMENTAL CONDITIONS …………………..... 36

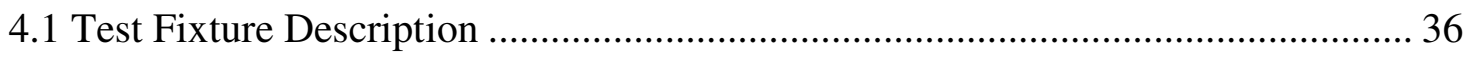

4.2 Test Configurations ...................................................................................... 41

4.3 Experimental Conditions and Control ................................................................ 44

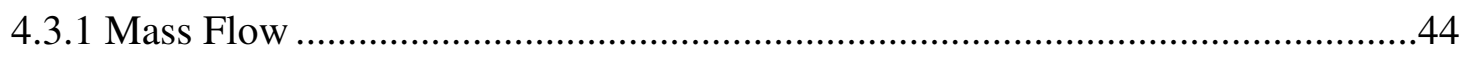

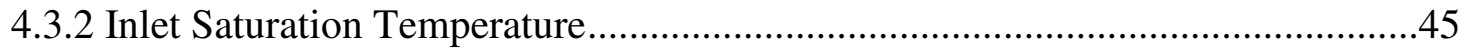




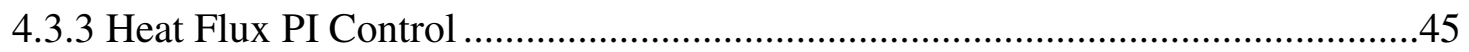

4.4 Instrumentation and Data Acquisition .............................................................. 46

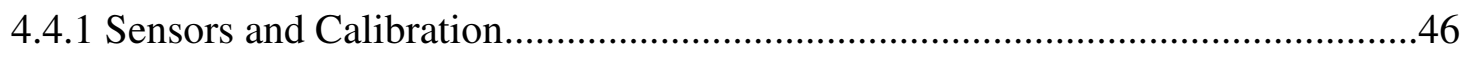

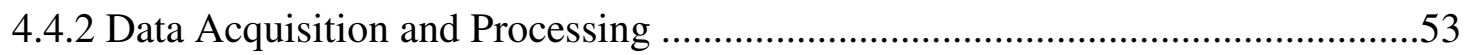

4.5 R134A and R600A Physical and Chemical Properties Comparison ...................... 53

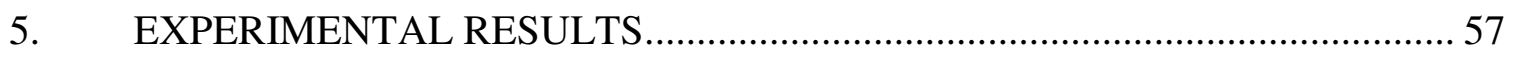

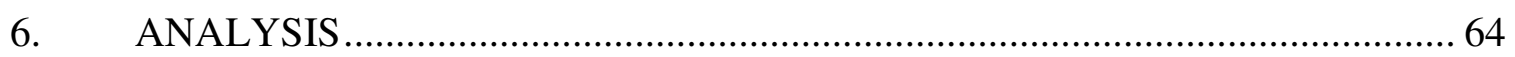

6.1 Horizontal orientation and double U-bends study (Data sets 14-17) ......................64

6.2 Vertical curvature ratio study (Data sets 9-13) .....................................................79

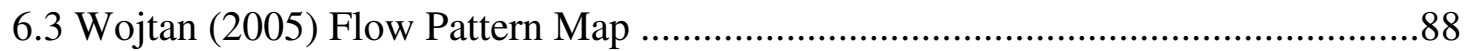

6.4 Silva Lima \& Thome (2012) Frictional Pressure Drop, Horizontal Orientations...93

6.5 Vertical Orientation Study (Data sets 1-8) ............................................................103

7. CONCLUSION AND FUTURE WORK ……………………..................... 117

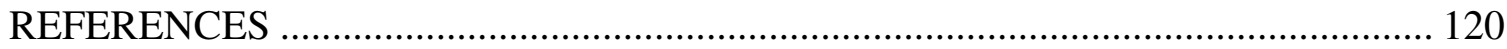

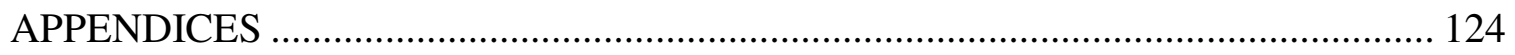

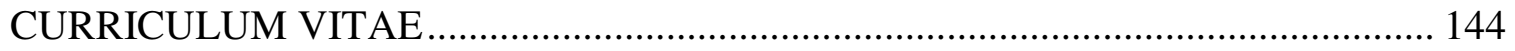




\section{LIST OF TABLES}

Table 1: Comparison of popular correlations by Müller-Steinhagen \& Heck (1986) ........ 8

Table 2: Segregated experimental values by flow regime using Wojtan et al. flow pattern map (Moreno Quibèn \& Thome, 2007a) ...................................................................... 17

Table 3: Domanski and Hermes (2006) coefficients used to calculate multiplier K for original Müller-Steinhagen \& Heck model................................................................ 27

Table 4: Paliwoda (1992)friction factor coefficients based on the curvature ratio, D/d... 28

Table 5: Databank description .......................................................................... 35

Table 6: Temperature Measurements Uncertainty ................................................... 48

Table 7: Absolute Pressure Measurements Uncertainty ............................................... 50

Table 8: Differential Pressure Measurements Uncertainty .......................................... 51

Table 9: R134A and R600A physical (at $-11^{\circ} \mathrm{F}$ ), ecological and safety properties......... 54

Table 10: Property gradients in operating pressure range (16 to $14.8 \mathrm{psi}$ ) along evaporator 71

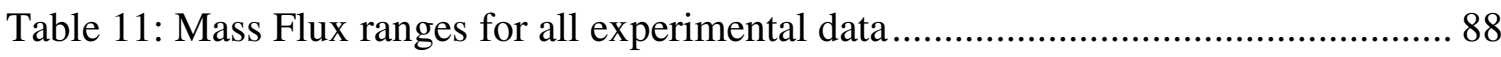

Table 12: Wojtan flow pattern map graphical representations ...................................... 89

Table 13: Data sets plotted on Figures 48(A-B)-49(A-B) and Figures 50(A-B)-51(A-B) 


\section{LIST OF FIGURES}

Figure 1: Example of Wojtan flow pattern map as a function of vapor quality and in terms of mass velocity (mass flux) 14

Figure 2: Peripheral and axial relative pressure distribution along the pipeline containing a horizontal U-bend (Ito, 1960) 20

Figure 3: Impact of the U-bend frictional pressure drop on the total frictional pressure drop for R134a at $41^{\circ} \mathrm{F}$ flowing at $300 \mathrm{~kg} / \mathrm{m} 2 \mathrm{~s}$ in different test sections based on (a) mass flux $\mathrm{G}$, (b) curvature ratio D/d, and (c) tube internal diameter d (Silva Lima \& Thome, Part 1, 2012)

Figure 4: Ratio between U-bend frictional pressure gradient and that at the inlet of the straight tube (-141d) for R134A at $41^{\circ} \mathrm{F}$ with tube ID $=0.527 \mathrm{in}$, U-bend $\mathrm{R}=1.5$ in for different orientations: (a) horizontal, (b) vertical downflow, and (c) vertical upflow (Silva Lima \&Thome, 2012b )

Figure 5: Comparison between the experimental data and prediction from existing models for horizontal flow based on Silva Lima \& Thome study (Silva Lima \& Thome,Part 2, 2012), including models of: (a) Geary, (b) Paliwoda, (c) Chen, (d) Domanski and Hermes a, and (e) Domanski and Hermes b........................................................................... 29 Figure 6: Experimental Fixture Diagram .................................................................. 36

Figure 7: Experimental Fixture Photo (left-side view) ............................................... 39

Figure 8: Experimental Fixture Photo (right-side view) ............................................. 39

Figure 9: Pressure Sensors: (a) Differential pressure transducers in parallel across

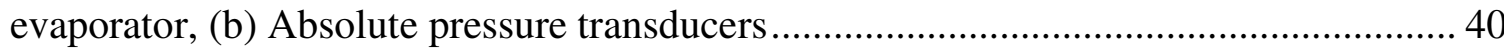

Figure 10: (a) Coriolis flowmeter and transducer, (b) Main (top) and secondary (bottom) compressors.

Figure 11: Twelve vertical and one horizontal U-bends in vertical evaporator orientation (samples 1-7 in Table 5)

Figure 12: 13 horizontal U-bends in horizontal evaporator orientation (sample 8 in Table 5)

Figure 13: 26 horizontal U-bends in horizontal evaporator orientation (sample 9 in Table 5) 
Figure 14: RTD error probability density versus calibration error (FS): (a) Evaporator Inlet RTD, (b) Evaporator Outlet RTD, (c) Condenser Outlet RTD. (FCS -full calibration scale of $\left.150^{\circ} \mathrm{F}\right)$. 48

Figure 15: Pressure transducers error probability density versus calibration error (FS): (a) Evaporator inlet pressure, (b) Evaporator outlet pressure, (c) Condenser outlet pressure. (FS -full scale)

Figure 16: Differential Pressure Transducer 3-Valve Manifold Assembly .... 52

Figure 17: Vertical evaporator orientation study with 12 Vertical and 1 Horizontal Ubends per data sets 1-12 from Table 5 (see Figure 11 for photos of installation)...

Figure 18: Vertical evaporator orientation study with 12 Vertical and 1 Horizontal Ubends per data sets 9-13 from Table 5 (see Figure 11 for photos of installation).

Figure 19: Horizontal evaporator orientation study with 13 Horizontal U-bends per data sets 14-15 and Double U-bend horizontal evaporator study with 26 Horizontal U-bends per data sets 16-17 in Table 5 (See Figure 12 and 13 for photos of installation)

Figure 20: Under-prediction of the total pressure drop as the result of ignoring momentum pressure drop contribution while using MS\&H correlation for Data sets 1417: Horizontal orientation study. 66

Figure 21:Under-prediction of the total pressure drop as the result of ignoring momentum pressure drop contribution while using Grönnerud correlation for Data sets 14-17:

Horizontal orientation study.

Figure 22: Under-prediction of the total pressure drop as the result of ignoring refrigerant property changes with decrease of pressure along the tube while using MS\&H correlation for Data sets 14-17: Horizontal orientation study. 69

Figure 23:Under-prediction of the total pressure drop as the result of ignoring refrigerant property changes with decrease of pressure along the tube while using Grönnerud (1979) correlation for Data sets 14-17: Horizontal orientation study.

Figure 24: Experimental two-phase refrigerant pressure drop and prediction using MS\&H (1986) correlation for Data sets 14-17: Horizontal orientation study.

Figure 25: Ratio of predicted two-phase refrigerant pressure drop using MS\&H (1986) correlation to experimental data for Data sets 14-17: Horizontal orientation study......... 73

Figure 26: Experimental two-phase refrigerant pressure drop and prediction using Adjusted MS\&H (1986) correlation for Data sets 14-17: Horizontal orientation study... 75 Figure 27: Ratio of predicted two-phase refrigerant pressure drop using Adjusted MS\&H (1986) correlation to experimental data for Data sets 14-17: Horizontal orientation study. 
Figure 28: Experimental two-phase refrigerant pressure drop and prediction using Grönnerud (1979) correlation for Data sets 14-17: Horizontal orientation study. 77

Figure 29: Ratio of predicted two-phase refrigerant pressure drop using Grönnerud (1979) correlation to experimental data for Data sets 14-17: Horizontal orientation study.

Figure 30: Location of property calculation for static pressure drop across a single vertical U-bend.

Figure 31: Calculated static pressure drop contribution for each of twelve vertical Ubends for $7.14 \mathrm{lbm} / \mathrm{hr}$ mass flow rate with $\mathrm{R} 134 \mathrm{~A}, \mathrm{~d}=0.267$ ", $\mathrm{R} \_$internal $=0.530 "$ 82

Figure 32: Calculated static pressure drop contribution to the total measured value for Data sets 9-13: Vertical Curvature Ratio Study. 83

Figure 33: Experimental two-phase refrigerant pressure drop and prediction using MS\&H (1986) correlation for Data sets 9-13: Vertical Curvature Ratio Study. 85

Figure 34: Experimental two-phase refrigerant pressure drop and prediction using Grönnerud (1979) correlation for Data sets 9-13: Vertical Curvature Ratio Study. 86

Figure 35: Wojtan flow pattern map for $\mathrm{d}=0.315$ " tested for data set 5 per Table 5 calculated at fluxes of 70,30 and $10 \mathrm{~kg} / \mathrm{m} 2 \mathrm{~s}$ using R134A...

Figure 36: Wojtan flow pattern map for $\mathrm{d}=0.186$ “ tested for data set 7 per Table 5 calculated at fluxes of 70,30 and $10 \mathrm{~kg} / \mathrm{m} 2 \mathrm{~s}$ using R134A.......

Figure 37: Wojtan flow pattern map for $\mathrm{d}=0.315$ " tested for data set 2 per Table 5 calculated at fluxes of 35,15 and $5 \mathrm{~kg} / \mathrm{m} 2 \mathrm{~s}$ using R600A.

Figure 38: Wojtan flow pattern map for $\mathrm{d}=0.186$ " tested for data set 8 per Table 5 calculated at fluxes of 35,15 and $5 \mathrm{~kg} / \mathrm{m} 2 \mathrm{~s}$ using R600A.

Figure 39: Percent breakdown between each flow pattern across evaporator length using Wojtan (2005) map at tested Mass Fluxes for Data sets 14, R134A (Data set 16 has a very similar result). 94

Figure 40: Percent breakdown between each flow pattern across evaporator length using Wojtan (2005) map at tested Mass Fluxes for Data sets 15, R600A (Data set 17 has a very similar result). 95

Figure 41: Frictional pressure gradient across full range of qualities using Silva Lima \& Thome (2012) model at tested Mass Fluxes for Data sets 14, R134A (Data set 16 has a very similar result).

Figure 42: Frictional pressure gradient across full range of qualities using Silva Lima \& Thome (2012) model at tested Mass Fluxes for Data sets 15, R600A (Data set 16 has a very similar result). 
Figure 43: Experimental two-phase refrigerant pressure drop and prediction using Silva Lima \& Thome (2012) correlation for Data sets 14-17: Horizontal orientation study.... 98

Figure 44: Ratio of predicted two-phase refrigerant pressure drop using Silva Lima \& Thome (2012) correlation to experimental data for Data sets 14-17: Horizontal orientation study.

Figure 45: Experimental two-phase refrigerant pressure drop and prediction using Adjusted Silva Lima \& Thome (2012) correlation for Data sets 14-17: Horizontal orientation study

Figure 46: Ratio of predicted two-phase refrigerant pressure drop using Adjusted Silva Lima \& Thome (2012) correlation to experimental data for Data sets 14-17: Horizontal orientation study 101

Figure 47: Overall predictive performance comparison between Grönnerud (1979), adjusted Müller-Steinhagen \& Heck (1986) and adjusted Silva Lima \& Thome (2012) correlations.

Figure 48(A-B): Silva Lima \& Thome (2012) frictional pressure gradient and percent breakdown between flow patterns and locations at tested Mass Fluxes for Data set 1, R134A.

Figure 49(A-B): Silva Lima \& Thome (2012) frictional pressure gradient and percent breakdown between flow patterns and locations at tested Mass Fluxes for Data set 2, R600A. 106

Figure 50(A-B): Silva Lima \& Thome (2012) frictional pressure gradient and percent breakdown between flow patterns and locations at tested Mass Fluxes for Data set 7, R134A.

Figure 51(A-B): Silva Lima \& Thome (2012) frictional pressure gradient and percent breakdown between flow patterns and locations at tested Mass Fluxes for Data set 8, R600A. 108

Figure 52: Experimental two-phase refrigerant pressure drop and prediction using Silva Lima \& Thome (2012) correlation for Data sets 9-13: Vertical Curvature Ratio study. 110 Figure 53: Experimental two-phase refrigerant pressure drop and prediction using Silva Lima \& Thome (2012) correlation for Data sets 1-8:Vertical Orientation study. 111

Figure 54: Experimental two-phase refrigerant pressure drop and prediction using adjusted MS\&H (1986) correlation for Data sets 1 - 8: Vertical Orientation Study...... 112

Figure 55: Experimental two-phase refrigerant pressure drop and prediction using Grönnerud (1979) correlation for Data sets 1 - 8 
Figure 56: Ratio of predicted two-phase refrigerant pressure drop using Silva Lima \& Thome (2012) correlation to experimental data for Data sets 1 - 8: Vertical Orientation Study.

Figure 57: Ratio of predicted two-phase refrigerant pressure drop using adjusted MullerSteinhagen \& Heck (1986) correlation to experimental data for Data sets 1 - 8: Vertical

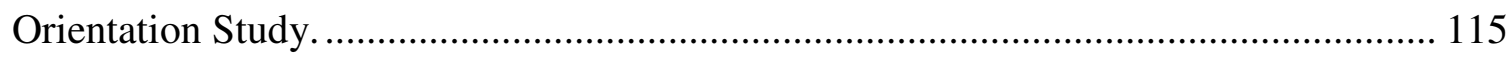

Figure 58: Ratio of predicted two-phase refrigerant pressure drop using Grönnerud (1979) correlation to experimental data for Data sets 1 - 8: Vertical Orientation Study.116

Figure 59: Stratified two-phase flow cross-section .................................................. 129 


\section{INTRODUCTION}

Annual household refrigerator sales in the US are projected to be 12 million by 2017 (statista.com, 2015). And based on the electricity prices for US in 2014 of $\$ 0.10 / \mathrm{kW} \mathrm{hr}$ an American household with one high efficiency refrigerator will spend on average $\$ 80.00$ per year on refrigerator energy usage (Energy.gov, 2015). A $1^{0} \mathrm{~F}$ saturation temperature drop as the result of the pressure drop through the evaporator will reduce the COP of the common compressor by close to $1 \%$ (Embraco, 2015), which increases annual energy usage by approximately $\$ 7.68$ million to run 12 million household refrigerators in the US. Thus, the cost of energy required to run the compressor or keep it running longer to compensate for the pressure loss through the system tubing needs to be studied and understood as it is also a part of the overall performance of the appliance which must be competitive in the market.

Furthermore, evaporator tube geometry is optimized for material and manufacturing cost savings as well as energy and environmental considerations. One of the most common ways to reduce evaporator material cost is diameter and length reduction. Aluminum evaporators are most widely used in modern refrigerators. Their wall thickness decrease is limited to avoid kinking during tube bending into the evaporator shape. Thus, the inner diameter of the tube suffers the result of the material savings, which leads to pressure drop and higher energy usage concerns. Also a constant reduction in space taken by the 
sealed system (evaporator, compressor, condenser and expansion valve) leads to tightening of the bend curvature ratio and experiments with evaporator shape and orientation.

On the other hand, a reduction in internal diameters of the refrigerant system components allows decreasing the amount of refrigerant used, which should be recovered and recycled after the life of the refrigerator in order to decrease greenhouse effect. Deeper understanding of the diameter reduction tradeoffs will allow a common usage of R600A refrigerant in the United States in a near future. This refrigerant provides $60-70 \%$ higher cooling capacity compared to commonly used R134A, but it is being regulated to a maximum charge of $57 \mathrm{~g}$ per refrigerator due to its higher flammability (EPA, 2010).

Although theoretical predictions of pressure drop mechanisms occurring in two-phase vapor-liquid flows are still not robust, a considerable number of correlations for refrigerant pressure drop exist. For conditions outside the range of the original data from which these correlations were derived, the deviations of several $100 \%$ between predicted and measured values may be found (Muller-Steinhagen \& Heck, 1986). Most widely used pressure drop models are designed to work for mass flux ranges of 100 to $500 \mathrm{~kg} / \mathrm{m}^{2} \mathrm{~s}$. In comparison, modern household refrigerator systems experience mass fluxes close to 20 $\mathrm{kg} / \mathrm{m}^{2} \mathrm{~s}$, a value well outside of the range for which most correlations were developed. Many correlations were developed for water-air, oil-air, other non-refrigerant two-phase mixtures and several refrigerants, such as R22 or R11, which are being actively phased out. Household refrigerators today commonly use R134A and are slowly transitioning towards greener refrigerants, such as R600A. Thus, the goal of this study is to possibly 
fill the gap in predicting the pressure drop particularly under conditions that modern household refrigerators operate and for refrigerants typically used. This is done here by applying two popular empirical correlations, Grönnerud, 1979 and Muller-Steinhagen \& Heck, 1986, to experimental data that extends to lower mass fluxes and two additional refrigerants. A comparison using one of the latest phenomenological two-phase pressure drop correlations proposed by Silva Lima \& Thome (Silva Lima \& Thome, Part 2, 2012) is also made. The goal of the work is to possibly extend the range of application or adjust these models to accurately predict pressure drop through the evaporator in a domestic refrigerator. 


\section{BACKGROUND}

Multiple papers and studies were published on the subject of two-phase flow through the tubes and pipes in various industries. In general, they are divided into three categories: empirical, analytical and phenomenological.

\section{Empirical models}

Empirical methods do not require knowledge of the flow pattern characteristics and are based on extensive databases used for their development. These models are normally easy to use and some examples include Lockhart and Martinelli, 1949; Bankoff, 1960; Cicchitti et al., 1960; Thom, 1964; Pierre, 1964; Baroczy, 1965; Chawla, 1967; Chisholm, 1973; Friedel, 1979; Grönnerud, 1979; Müller-Steinhagen \& Heck, 1986. A very important drawback of these models is that their accuracy is only proven within the range of the database they are based on. Nowadays, these models are still being widely used because they provide an acceptable accuracy with relative simplicity (Moreno Quibèn \& Thome, 2007b).

\section{Analytical models}

Analytical models are mathematical correlations developed without the use of empirical data. This fact does not limit their use to a particular dataset. Unfortunately, an important 
downfall of these models is their high complexity and often iterative nature. In addition, an experimental data is still required for validation (Moreno Quibèn \& Thome, 2007b).

\section{Phenomenological models}

Two-phase pressure drop models are considered phenomenological models if they take into account the flow pattern. Some examples of such models include Bandel, 1973; Beattie, 1972; Hashizume et al., 1985; Olujić, 1985; and Hart et al., 1989. These were developed from late 70 s to late 80 s. Unfortunately, phenomenological models do require a certain amount of empirical data, even though they are heavily based on theory underlining each of the flow patterns. Also none of these models are able to predict twophase pressure drop for all flow patterns besides one of the most recent ones, which was originally developed by Moreno Quibèn \& Thome (2007) and improved by Silva Lima \& Thome (2012). A very important factor in accuracy of phenomenological models such as these is a reliable flow pattern map used to predict flow transitions between regimes (Moreno Quibèn \& Thome, 2007b).

In this study two popular empirical and one of the newer phenomenological models will be compared to a brand-new data set for a real world system. 


\subsection{Two-Phase Pressure Drop Components}

The two-phase pressure drop through the tubes and pipes consists of three parts: static, momentum, and frictional pressure drop in the following form:

$$
\Delta P_{\text {measured }}=\Delta P_{\text {static }}+\Delta P_{\text {momentum }}+\Delta P_{\text {frictional }}
$$

The static pressure drop is due to the elevation head and for vertical evaporator orientations is a function of the fluid single-phase densities, tube inner diameter and void fraction. The flow direction is also taken into account as in (2) and (3).

Down-flow:

$$
\begin{gathered}
\Delta P_{\text {static }}=-g d\left(\varepsilon \rho_{V}+(1-\varepsilon) \rho_{L}\right) \\
\Delta P_{\text {static }}=g d\left(\varepsilon \rho_{V}+(1-\varepsilon) \rho_{L}\right)
\end{gathered}
$$

The momentum pressure drop is generated by the acceleration of the flow due to evaporation and/or flashing (Silva Lima \& Thome, 2012a). The momentum pressure drop correlation that reflects these changes in kinetic energy for pressure drop through straight tube is given by (4) below (Ould Didi et al., 2001).

$$
\Delta P_{\text {momentum }}=G^{2}\left\{\left[\frac{(1-x)^{2}}{\rho_{L}(1-\varepsilon)}+\frac{x^{2}}{\rho_{V} \varepsilon}\right]_{o u t}-\left[\frac{(1-x)^{2}}{\rho_{L}(1-\varepsilon)}+\frac{x^{2}}{\rho_{V} \varepsilon}\right]_{\text {in }}\right\}
$$

And, finally, frictional pressure drop is generated by the fluid frictional effects and found using complex models described further.

In this study, in contrary to many other studies, all of the above components play a role in the final prediction of the total pressure drop through the evaporator which is subdivided into straight tube sections and U-bends in multiple orientations. The details of each test case are described under the Scope of Work section. 


\subsection{Two-Phase Frictional Pressure Drop in Straight Tubes}

Two-phase pressure drop through portions of the straight tubes has been studied most extensively over the years by multiple researchers. Their phenomenological findings as well as prediction accuracy are overviewed in this section.

For the straight tubes with increasing quality, refrigerant vapor moves at a higher velocity increasing the pressure drop. Furthermore, pressure drop in the straight tubes increases as

the mass flux increases and as the internal diameter of the tube decreases. Also, as the saturation temperature decreases the viscosity and density ratios between two phases increase, therefore increasing pressure drop. But the effect of the mass flux overcomes that of the saturation temperature (Silva Lima \& Thome, 2012a).

Several researchers compared multiple two-phase pressure drop models to measured data. Their findings for straight tube applications are described further.

In August of 1984 H. Muller-Steinhagen \& K. Heck published a paper (MüllerSteinhagen \& Heck, 1986) in which they reviewed and compared 15 well known empirical two-phase pressure drop correlations (Table 1 includes 14 of them, with Müller-Steinhagen $\&$ Heck being $15^{\text {th }}$ ) based on 9300 measurements for a wide variety of fluids and flow conditions. The majority of the data considered in this paper was taken from Duckler's data bank (Duckler, 1962) and the remainder of the data was put together by the Institut für Thermische Varfahrenstechnik (Institute of Thermal Process Engineering, Germany). The data bank includes correlations for different flow directions, such as horizontal, vertical upward and vertical downwards, but a majority of this 
databank consisted of horizontal tube orientations. $94 \%$ of the data is located outside of the range of tube internal diameters used in refrigerator sealed systems. $96 \%$ excludes testing with refrigerants, and the remainder is focused solely on two-phase flows of R12 and R11. A very small percentage of the data (close to or under 1\%) was taken at flows under $100 \mathrm{~kg} / \mathrm{m}^{2} \mathrm{~s}$ and approximately $50 \%$ of data are under 0.10 quality, which is more applicable to the homogeneous models, while household refrigeration systems are operated at 0.35 to 1.00 quality.

Table 1: Comparison of popular correlations by Müller-Steinhagen \& Heck (1986)

\begin{tabular}{|c|c|c|c|c|c|c|}
\hline No. & Author & $\begin{array}{l}\mathrm{RE} \\
(\%)\end{array}$ & $\begin{array}{l}\mathrm{AE} \\
\left(\mathrm{N} \mathrm{m}^{-3}\right)\end{array}$ & $\begin{array}{l}\mathrm{RE}<10 \% \\
(\%)\end{array}$ & $\begin{array}{l}\mathrm{RE}<20 \% \\
(\%)\end{array}$ & $\begin{array}{l}\mathrm{RE}<30 \% \\
(\%)\end{array}$ \\
\hline 1 & Bandel & 32.6 & 5347.1 & 25.8 & 44.7 & 59.9 \\
\hline 2 & Bankoff & 11525.8 & 139561.5 & 7.5 & 12.6 & 16.4 \\
\hline 3 & Chawla & 8697.6 & 696831.7 & 5.5 & 10.5 & 15.3 \\
\hline 4 & Chawla-Bankoff & 142.3 & 47471.3 & $18 . i$ & 32.6 & 40.9 \\
\hline 5 & Chisholm-Baroczy & 340.0 & 5579.6 & 16.5 & 28.9 & 38.2 \\
\hline 6 & Cicchitti & 65.7 & 4531.7 & 15.8 & 30.0 & 42.0 \\
\hline 7 & Dukler & 37.0 & 4916.6 & 14.7 & 29.0 & 43.9 \\
\hline 8 & Friedel & 111.6 & 5015.0 & $18 . i$ & 32.6 & 44.6 \\
\hline 9 & Gronnerud & 44.6 & 10808.0 & 16.0 & 31.4 & 46.5 \\
\hline 10 & Kesper-Moussalli & 69.9 & 6920.6 & 12.5 & 22.3 & 29.9 \\
\hline 11 & Lockhart-Martinelli & 62.8 & 14244.2 & 21.0 & 38.0 & 52.4 \\
\hline 12 & Lombardi-Pedrocchi & 152.3 & 4910.4 & 14.2 & 22.2 & 29.5 \\
\hline 13 & Reza-Chavez & 35.5 & 5490.5 & 18.1 & 37.4 & 54.6 \\
\hline 14 & Storek-Brauer & 36.5 & 7859.0 & 22.2 & 41.9 & 58.7 \\
\hline
\end{tabular}

Müller-Steinhagen \& Heck discovered that the correlation by Bandel, 1973 gives the best agreement between predicted and measured values with average relative error of $32.6 \%$ (Table 1). Reasonable accuracy was also obtained using Grönnerud, 1979; Reza-Chavez, 1985; and Storek-Brauer, 1980 correlations. Furthermore, these authors suggested their own correlation which is presented in more detail further in this study. Its average relative error is $41.9 \%$, which is higher than several of the models described in Table 1, but its simplicity is a decisive factor for many users. This databank does not cover the 
low flow conditions of interest for this study, thus it is imperative to apply some of these models to the new databank.

Later, in 2002, Ould-Didi et al. used a database including five refrigerants and a wide range of conditions to effectively repeat the comparison of most common two-phase pressure drop models (Moreno Quibèn \& Thome, 2007a). They found that Grönnerud, 1979 and Müller-Steinhagen \& Heck, 1986 were equally best with Friedel, 1979 being the third best.

A discrepancy in the result of the above two major comparative studies could be explained by the fact that Müller-Steinhagen \& Heck used a database consisting of not only refrigerants, but also air-oil, air-water and water-steam fluid combinations.

Grönnerud, 1972; Müller-Steinhagen \& Heck, 1986 and Friedel, 1979 correlations were also compared by Moreno Quibèn \& Thome (Moreno Quibèn \& Thome, 2007b) against their own database (Moreno Quibèn \& Thome, 2007a). The authors concluded that the Friedel, 1979 and Müller-Steinhagen \& Heck, 1986 significantly underpredict their data and do not capture the location of the frictional pressure gradient peak for three refrigerants: R134A, R22 and R410A. However, the Grönnerud, 1979 model worked considerably better at lower flows and qualities under 0.65 , above which it overpredicted the data; it was also able to accurately locate pressure gradient peak (Moreno Quibèn \& Thome, 2007b). Moreno Quibèn \& Thome, 2007 suggested their own correlation for straight tube pressure drop, which is based on the Wojtan, 2005 flow pattern map. 
Thus out of three comparative studies discussed here, Müller-Steinhagen \& Heck, 1986 and Grönnerud, 1979 were found to be best performing empirical correlations more than once and for that reason they are going to be applied in this study. Silva Lima \& Thome, 2012 correlation, an improved version of Moreno Quibèn \& Thome, 2007 phenomenological model, is also applied in this study. All of these are reviewed in more detail in the following sections.

\subsubsection{Müller-Steinhagen \& Heck Empirical Model}

In the paper by Müller-Steinhagen \& Heck (1986), the authors presented a correlation for two-phase frictional pressure drop in straight pipes. They noticed that due to the increased interaction between the gas and liquid phases, the frictional pressure drop is directly proportional to mixture quality. It is maximized at quality of 0.85 and falls under single-phase gas flow for quality of 1.00. Furthermore, their colleague, W. Bonn observed that for nitrogen measurements two-phase pressure drop at qualities of 0.50 is very similar to that of gas at qualities of 1.00. Thus, Müller-Stenhagen \& Heck used single-phase flow correlations (5) and (6):

$$
\begin{aligned}
& \left(\frac{d P}{d L}\right)_{f, L}=\xi_{L} \frac{G^{2}}{2 \rho_{L} d}=B 1 \\
& \left(\frac{d P}{d L}\right)_{f, V}=z_{V} \frac{G^{2}}{2 \rho_{V} d}=B 2
\end{aligned}
$$

with friction factors defined as by equations (7) and (8): 
$\varkappa_{l}=\frac{64}{R e_{V}}, \quad z_{g}=\frac{64}{R e_{V}} \quad$ for $\quad R e_{L}, R e_{V} \leq 1187$
and $\quad z_{l}=\frac{0.3164}{R e_{L}{ }^{0.25}}, \quad z_{g}=\frac{0.3164}{R e_{V}{ }^{0.25}} \quad$ for $\quad R e_{L}, R e_{V}>1187$

With Reynolds numbers defined using classic correlations (9):

$$
R e_{L}=\frac{G d}{\mu_{L}} \text { and } R e_{V}=\frac{G d}{\mu_{V}}
$$

Observing that measured pressure drop increases nearly linear for qualities under 0.70 Müller-Steinhagen \& Heck used superposition principles and wrote equations (10) and (11):

$$
\begin{gathered}
K=B 1+2(B 2-B 1) x \\
\left(\frac{d P}{d L}\right)_{f}=K(1-x)^{1 / C}+B 2 x^{C}
\end{gathered}
$$

$\mathrm{C}=3$ in (11) and was found by curve fitting measured data.

This equation is not only simple but can also be easily integrated to cover the cases when the flow quality increases along the tube due to heating with the constant heat flux (12):

$$
\begin{aligned}
\int_{0}^{L}\left(\frac{d P}{d L}\right)_{f} d L= & \left\{-\frac{3}{4}(1-x)^{\frac{4}{3}}[B 1+2(B 2-B 1) x]+\frac{1}{4} B 2 x^{4}-\frac{9}{14}(B 2\right. \\
& \left.-B 1)(1-x)^{7 / 3}\right\}_{x_{\text {in }}}^{x_{\text {out }}}
\end{aligned}
$$

Some of the restrictions applicable to the Müller-Steinhagen \& Heck equation are:

- $R e_{L}>100$

- $\quad B 2>B 1$ or gas flow frictional pressure drop is higher than that of liquid flow 
- Not sufficient for lower mass velocities and viscous liquids, since the frictional pressure drop for $x=0.50$ may differ considerably from $x=1.00$, which was the original assumption behind this correlation (this insufficiency will be understood using low mass flux data collected during this study).

- Only valid for prediction of frictional pressure drop in horizontal tubes; static pressure drop must be added for non-horizontal flows and momentum pressure drop should be added if evaporation occurs.

\subsubsection{Grönnerud Empirical Model}

Grönnerud, 1979 frictional pressure drop model for flow in straight tubes is a multiplication of the liquid pressure drop, $\Delta P_{L}$, found using equations (14), (15) and (9a) and a Grönnerud multiplier , $\phi_{g d}$, found with (16) - (19).

$$
\begin{gathered}
\Delta P_{\text {frictional }}=\phi_{g d} \Delta P_{L} \\
\Delta P_{L}=4 f_{L}(L / d) G^{2}\left(1 / 2 \rho_{L}\right) \\
f_{L}=\frac{0.079}{R e_{L}^{0.25}} \\
\Phi_{g d}=1+f_{\text {Froude }}\left[x+4\left(x^{1.8}-x^{10} f_{\text {Froude }}^{0.5}\right)\right]\left[\frac{\left(\frac{\rho_{L}}{\rho_{V}}\right)}{\left(\frac{\mu_{L}}{\mu_{V}}\right)^{0.25}}-1\right]
\end{gathered}
$$

where

$$
f_{\text {Froude }}=1.0 \text { if } F r_{L} \geq 1.0
$$

and

$$
f_{\text {Froude }}=F r_{L}^{0.3}+0.0055\left(\ln \frac{1}{F r_{L}}\right)^{2} \text { if } F r_{L}<1.0
$$


with

$$
F r_{L}=\frac{G^{2}}{g d \rho_{L}^{2}}
$$

This correlation is applicable for the entire range of qualities: $0 \leq x<1$.

\subsubsection{Silva Lima \& Thome Phenomenological Model}

Moreno Quibèn \& Thome (Moreno Quibèn \& Thome, 2007b) developed a general phenomenological model for frictional pressure drop in straight tubes by recognizing that all of the available correlations had important deficiencies such as:

- Not accounting for flow pattern effects particularly important at lower flows (important within the scope of this research with average mass flux at approximately $20 \mathrm{~kg} / \mathrm{m}^{2} \mathrm{~s}$ )

- Not accounting for the influence of the interfacial waves or upper dry perimeter of stratified flows

- Often no regard for the actual velocity of the individual phases by introducing local void fraction correlations

- Often unable to cover the whole range of the flow quality, from 0.00 to 1.00.

Furthermore, Moreno Quibèn \& Thome (2007) flow pattern based correlations were updated by Silva Lima \& Thome using their own database (Silva Lima \& Thome, 2012a) described in Appendix A. The authors used a flow pattern map developed by Wojtan et al. 


\section{Wojtan Two-Phase Flow Pattern Map}

Wojtan et al.(2005a) two-phase flow pattern map was developed using Kattan et al.(1998) flow pattern map as a basis, which in turn used data from dynamic void fraction measurements and observations of the cross-sectional locus of the liquid-vapor interface during stratified-types of flow. Wojtan, Ursenbacher and Thome acquired data for mass fluxes from 70 to $700 \mathrm{~kg} / \mathrm{m}^{2} \mathrm{~s}$ and heat fluxes from 2.0 to $57.5 \mathrm{~kW} / \mathrm{m}^{2}$ for refrigerants R22 and R410A (Appendix A). This extensive study amounted to 1250 data points. The authors extended the original Thome-El Hajal version of the Kattan-Thome-Favrat flow pattern map by defining new transition curves for annular (A) -dryout (D) and dryout mist (M) flow transitions. Further, they subdivided the stratified-wavy region into slug (Slug), slug/stratified-wavy (Slug+SW) and stratified-wavy (SW). Furthermore, new flow pattern map adjusted the transition curve between stratified (S) and stratified wavy (SW) flow for vapor qualities above $\mathrm{x}_{\mathrm{IA}}$, vapor quality at transition from intermittent (I) to annular flow (A). See Figure 1 for example of Wojtan flow pattern map.

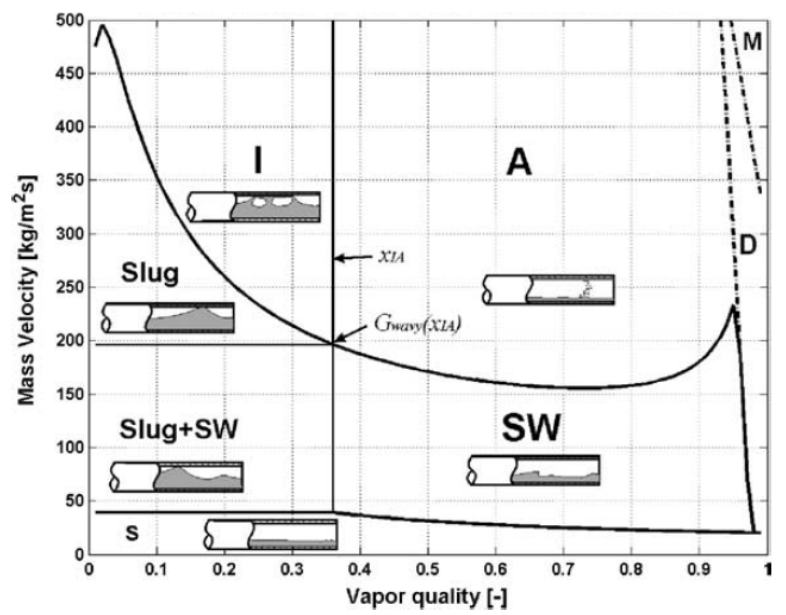

Figure 1: Example of Wojtan flow pattern map as a function of vapor quality and in terms of mass velocity (mass flux) 
Due to its length and complexity a full implementation procedure of the Wojtan et al., 2005 two-phase flow pattern map is provided in Appendix B.

\section{Silva Lima \& Thome Model}

"The frictional pressure gradient model of the flow patterns adjacent to the annular flow pattern are directly influenced by the annular flow “, claims Silva Lima \& Thome in (Silva Lima \& Thome, 2012b). All of the frictional coefficients for Wojtan et al., 2005 flow regimes are based on annular flow frictional coefficient for straight tubes, $f_{\text {straight-annular flow }}$ Silva Lima \& Thome developed their own improved version of $f_{\text {straight-annular flow }}$ as in equation (20).

$$
\begin{aligned}
& f_{\text {straight-annular flow }} \\
& =0.215 \underbrace{\left[\frac{\delta}{d-2 \delta}\right]^{0.515}}_{\Pi_{1}} \underbrace{\left[\frac{\left(\rho_{L}-\rho_{V}\right) g d^{2}}{\sigma}\right]^{-0.298}}_{\Pi_{2}} \underbrace{\left[\frac{\mu_{L}}{\mu_{V}}\right]^{0.285}}_{\Pi_{3}} \underbrace{\left[\frac{\rho_{L} u_{L}{ }^{2}}{\rho_{V} u_{V}^{2}}\right]^{-0.044}}_{\Pi_{4}}
\end{aligned}
$$

where $u_{L}$ and $u_{V}$ are liquid and vapor phase velocities respectively and are defined as (21) and (22).

$$
\begin{gathered}
u_{L}=\frac{\dot{V}_{L}}{\varepsilon A}=\frac{\dot{m}}{\rho_{L} A} \frac{(1-x)}{(1-\varepsilon)}=\frac{G}{\rho_{L}} \frac{(1-x)}{(1-\varepsilon)} \\
u_{V}=\frac{\dot{V}_{V}}{\varepsilon A}=\frac{\dot{m}}{\rho_{V} A} \frac{x}{\varepsilon}=\frac{G}{\rho_{V}} \frac{x}{\varepsilon}
\end{gathered}
$$

In the equation (20) above the dimensionless values hold the following geometrical, physical and flow properties: $\Pi_{1}$ stands for the film thickness effect with respect to vapor 
core diameter; $\Pi_{2}$ is used to account for formation of the interfacial waves; $\Pi_{3}$ is a ratio of the viscous forces of two phases; and $\Pi_{4}$ is ratio of the inertial forces of two phases (Silva Lima \& Thome, 2012b).

Film thickness $\delta$ is calculated using Wojtan et al. correlation (Wojtan et al, 2005b):

$$
\delta=\frac{d}{2}-\sqrt{\left(\frac{d}{2}\right)^{2}-\frac{2 A_{L}}{2 \pi-\theta_{d r y}}}
$$

According to Wojtan et al. (Wojtan et al, 2005b) and Quibèn \& Thome (Moreno Quibèn $\&$ Thome, 2007b) if the liquid occupies over half of the tube, the film thickness results in value above half of the internal diameter, a geometrically impossible result, thus it was suggested that in this case, the value of the film thickness is set equal to half the internal diameter of the tube.

Liquid cross-sectional area $A_{L}$ is found using void fraction $\varepsilon$, and is calculated using equation (24).

$$
A_{L}=A(1-\varepsilon)
$$

The angle $\theta_{d r y}$ was originally introduced by Wojtan (Wojtan et. al, 2005a) in his new flow pattern map and used in the original two phase frictional pressure drop for straight tubes by Moreno Quibèn \& Thome (Moreno Quibèn \& Thome, 2007b). $\theta_{d r y}$ is calculated separately for each flow regime.

The remainder of the variables in this new model are defined in the same manner as in the original frictional pressure drop model of Moreno Quibèn \& Thome (Moreno Quibèn \& Thome, 2007b) using three refrigerants R134A, R22 and R410A. The authors 
determined that while fluid type, diameter and mass flux have a significant effect over the entire range of vapor quality, heat flux had an effect only near and after the dryout (D) region of the Wojtan et al. two-phase flow pattern map (Wojtan et al, 2005a), which for most refrigerants is above 0.8 for some and above 0.9 for most of the tested configurations. See Appendix A depicting the Moreno Quibèn's \& Thome's 2543 point databank.

Quibèn \& Thome segregated their data described in (Moreno Quibèn \& Thome, 2007a) of the publication based on the flow pattern across the whole length of the straight tube test section (Table 2). Notice that stratified (S) region is not covered by their data, but much of the data developed and presented in this thesis falls into this region.

Table 2: Segregated experimental values by flow regime using Wojtan et al. flow pattern map (Moreno Quibèn \& Thome, Part 1, 2007)

\begin{tabular}{|c|c|c|c|c|c|c|c|c|c|}
\hline Fluid & $D(\mathrm{~mm})$ & Slug + SW & SW & Slug & I & A & $\mathrm{D}$ & M & S \\
\hline R134a & 13.8 & 6 & 3 & 5 & 2 & 13 & 0 & 0 & 0 \\
\hline $\mathrm{R} 22$ & 8 & 28 & 20 & 18 & 12 & 75 & 21 & 17 & 0 \\
\hline $\mathrm{R} 22$ & 13.8 & 18 & 54 & 15 & 37 & 162 & 44 & 47 & 0 \\
\hline R410A & 8 & 26 & 19 & 24 & 55 & 167 & 121 & 110 & 0 \\
\hline R410A & 13.8 & 78 & 115 & 17 & 77 & 166 & 104 & 69 & 0 \\
\hline Total & & 156 & 211 & 79 & 183 & 583 & 290 & 243 & 0 \\
\hline
\end{tabular}

Interesting algebraic observation was made by the authors that the mass flux does not affect the void fraction calculation for mass velocities above $50 \mathrm{~kg} / \mathrm{m}^{2} / \mathrm{s}$ (Moreno Quibèn \& Thome, 2007b).

A full list of pressure drop correlations developed using this databank and used in pattern-dependent model of Silva Lima \& Thome is provided in Appendix C.

Thus, by editing the annular flow correlation for straight tube originally proposed by Moreno Quibèn \& Thome (Moreno Quibèn \& Thome, 2007b), Silva Lima \& Thome 
(Silva Lima \& `Thome, 2012b) were able to show the mean error of only $1 \%$ and the standard deviation of $15 \%$ for their test conditions (see Appendix A for description). Almost their entire database for two-phase flow in straight tubes was captured within \pm $30 \%$ error window by the correlation (Silva Lima \& Thome, 2012b).

\subsection{Two-Phase Frictional Pressure Drop in U-bends}

A common approach in studying the two-phase pressure drop uses a serpentine tube with multiple U-bends along its length. The flow is assumed to be adiabatic and is achieved by insulating the tubes and maintaining a constant quality. Frictional pressure drop in the straight tubes is calculated based on the measurement along the first straight section of the serpentine. Then the remaining pressure drop value is divided by the number of the U-bends. Unfortunately, this approach overestimates the pressure drop in the U-bends themselves, because of the effects of perturbations on the straight sections up- and downstream of the U-bend, the effects of increase in the vapor quality due to flashing from the large pressure drops in the U-bends, and the influence of the saturation temperature on fluid properties (Silva Lima \& Thome, 2012a).

Furthermore, perturbations in serpentine test samples with straight tube length under twelve internal diameters between two U-bends may propagate throughout consecutive bends of the serpentine leading to further variation between the bends in the same test sample. Thus, serpentine data reduction method allows as much as $130 \%$ error in U-bend

pressure gradient, which, in turn, effects the predictions of the local pressure saturation 
temperature and heat transfer coefficients, (Silva Lima \& Thome, 2012a). U-bends, as a very common geometrical characteristic of the compact sealed systems, are split into horizontal, vertical up-flow and vertical down-flow orientations and are considered separately in this study.

\subsubsection{Horizontal U-bends}

A horizontal U-bend is a complex singularity in the flow that leads to flow perturbation and an additional force - centrifugal force due to curvature. In the single phase flows a centrifugal force is directed towards the outer wall of the U-bend. Along with the boundary layer at the wall centrifugal force creates a secondary flow organized into two symmetrical vortices. The fluid at the core moves outward and at the wall inward (Silva Lima \& Thome, 2010). The two vertices in addition to the main flow along the centerline of the tube create a very complex flow even further complicated by the two-phase flow. A heavier density phase tends to group along the walls creating a perturbation up- and downstream of the horizontal U-bend. Figure 2 is an example of peripheral and axial relative pressure distribution in pipeline section containing a U-bend with water flow. 


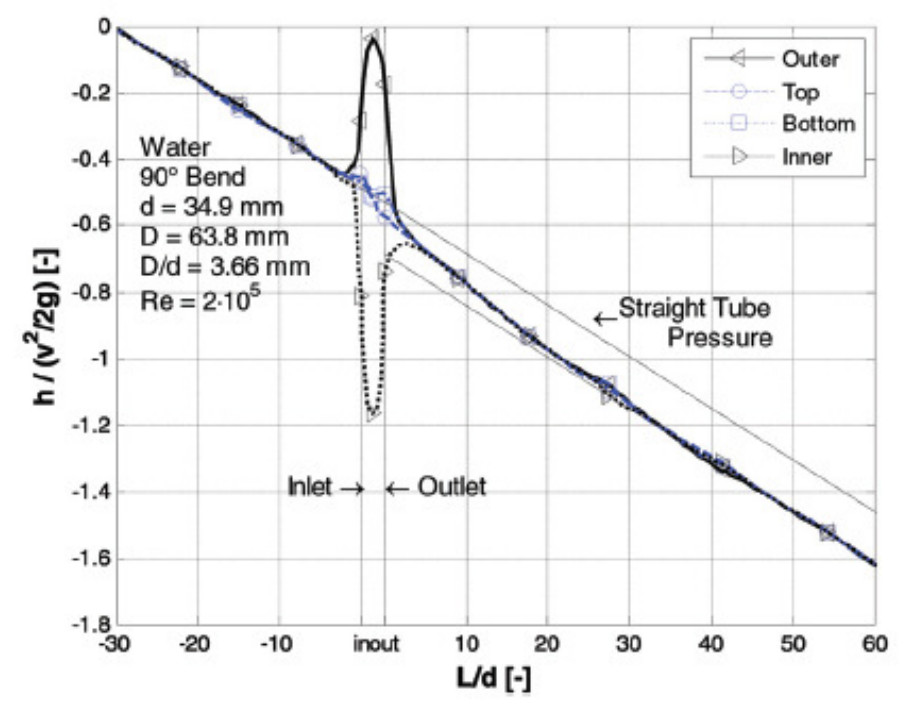

Figure 2: Peripheral and axial relative pressure distribution along the pipeline containing a horizontal U-bend (Ito, 1960)

Due to the lack of the available information around the evolution of the pressure drop along and up- and down-stream of the smooth horizontal U-bends for two-phase refrigerants Silva Lima \& Thome, 2010 set their objectives to measure the pressure drop in straight portions leading to a U-bend, a U-bend itself and the peripheral pressure difference between the inner and outer sides of the straight tubes contiguous to the Ubend.

An interesting finding Silva Lima \& Thome, 2010 reported is that the peripheral pressure differences, even as close at four internal diameters to the bend, are negligible. They also found experimentally that frictional pressure drop across the horizontal U-bend is approximately twice that of the straight tube. Additionally, for even medium velocities the perturbation caused by the U-bend propagates under six internal diameters upstream of the horizontal U-bend. 
The authors made the following assumptions. 1) The static pressure drop can be ignored due to no flow elevations. 2) Momentum pressure drop generated by the acceleration of the flow due to evaporation is negligible, even though a pressure drop across the test section does lead to the small changes in quality. Thus the measured pressure drop across the horizontal U-bend is assumed to be fully due to frictional losses.

The U-bend effect on the total pressure drop increases with the increase of mass flux and decrease with curvature ratio of the U-bend (a ratio of the bend diameter to the diameter of the tube), but also decreases with the decrease of the internal diameter of the tube as curvature ratio increases (see Figure 3.c). These unexpected results suggest that a small increase in the curvature ratio resulted from keeping the U-bend radii the same but decreasing the tube internal diameter had enough impact to increase U-bend effect on the total pressure drop even for smaller tube internal diameters, Figure 3. 


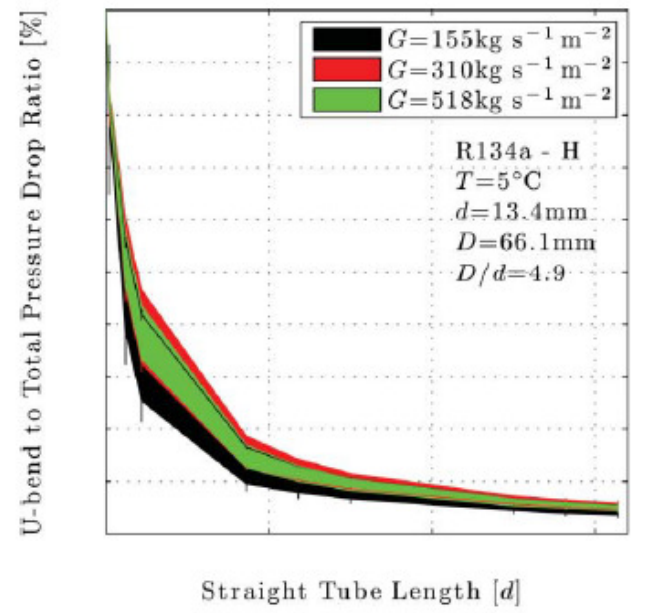

(a)

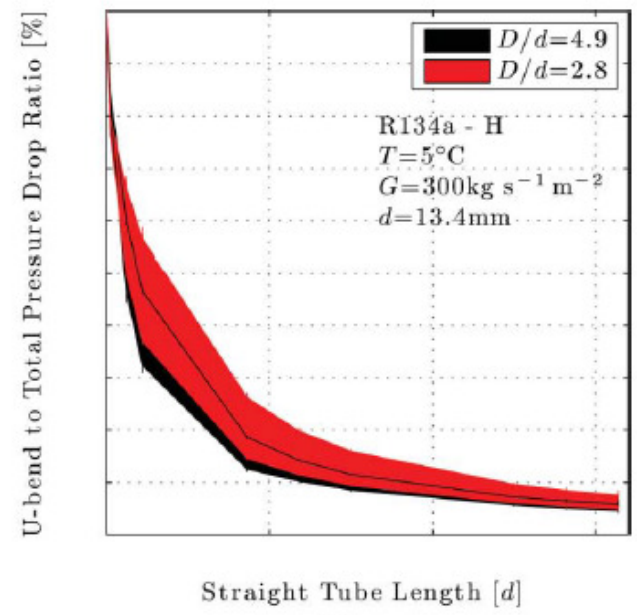

(b)

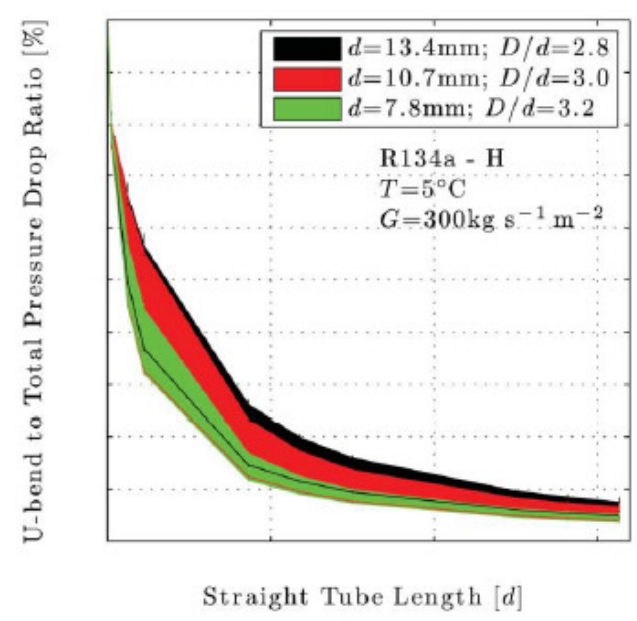

(c)

Figure 3: Impact of the U-bend frictional pressure drop on the total frictional pressure drop for R134a at $41^{\circ} \mathrm{F}$ flowing at $300 \mathrm{~kg} / \mathrm{m}^{2} \mathrm{~s}$ in different test sections based on (a) mass flux $\mathrm{G}$, (b) curvature ratio D/d, and (c) tube internal diameter d (Silva Lima \& Thome, Part 1, 2012)

Another very important finding made by Silva Lima \& Thome (Silva Lima \& Thome, 2012a) is the fact that the pressure gradient ratio for the measurements taken at the beginning of the straight tube and across the horizontal U-bend is fairly constant for higher mass fluxes but does scatter at lower ones (the authors tested only $155 \mathrm{~kg} / \mathrm{m}^{2} \mathrm{~s}$ at the lowest mass flux). The straight tube to U-bend pressure gradient ratio decreases with 
increased curvature ratio and trends are similar for samples with similar curvature ratios,

Figure 4(a).

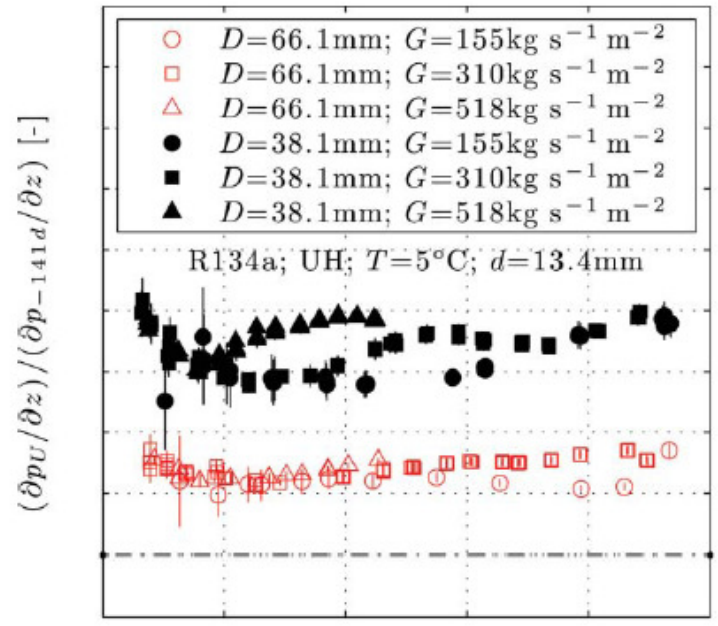

Vapor Quality [-]

(a)

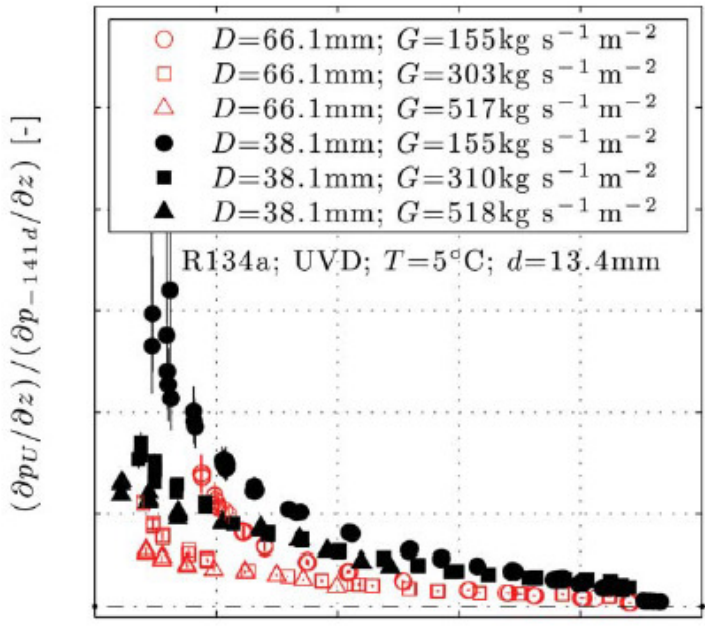

Vapor Quality [-]

(b)

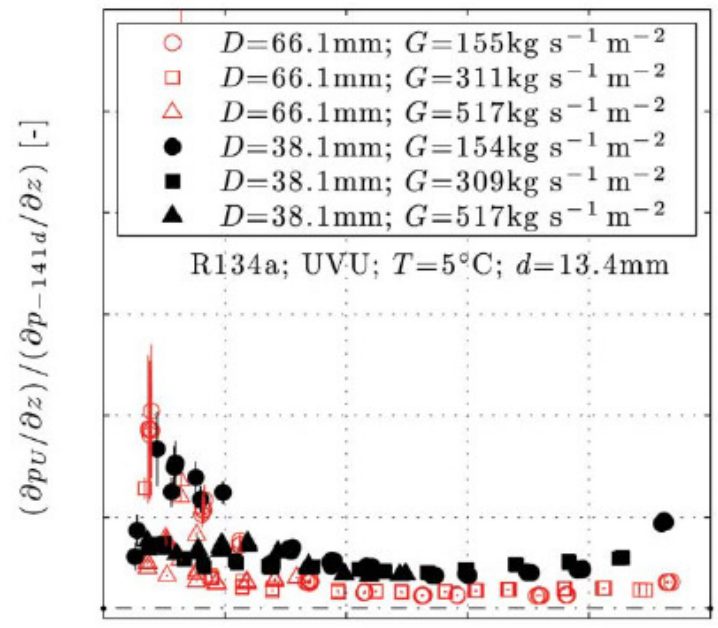

Vapor Quality [-]

(c)

Figure 4: Ratio between U-bend frictional pressure gradient and that at the inlet of the straight tube (-141d) for $R 134 \mathrm{~A}$ at $41^{\circ} \mathrm{F}$ with tube $\mathrm{ID}=0.527 \mathrm{in}, \mathrm{U}$-bend $R=1.5$ in for different orientations: (a) horizontal, (b) vertical downflow, and (c) vertical upflow (Silva Lima \& Thome, 2012b ) 


\subsubsection{Vertical U-bends}

Further efforts in studying pressure drops cross U-bends by Silva Lima \& Thome (Silva Lima \& Thome, 2012a) included two refrigerants, two saturation temperatures, three tube diameters bent into five U-bend sizes (see Appendix A for the description of the database). The authors have also considered vertical U-bend configuration in this study for both flow directions as shown.
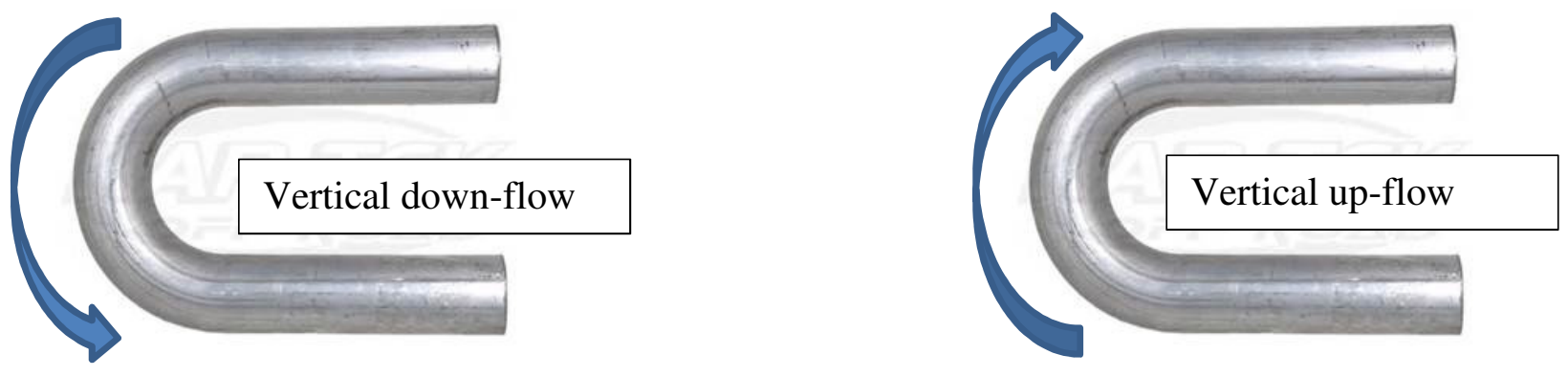

U-bend pressure drops in any orientation follow similar dependencies from experimental parameters like vapor quality, mass flux, saturation temperature and internal diameter of the tubes as described in Section 2.3 for straight horizontal tubes. U-bend pressure drop also has an inverse relationship with the U-bend curvature ratio.

Measurement of frictional pressure drop across vertical U-bends is done by subtraction or addition of the gravitational pressure drop from the total measured pressure drop in case of the downward or upward flows respectively. The gravitational effect was found to be higher for lower qualities due to increased refrigerant densities at lower vapor quality. Logically this makes sense, since with higher quality the void fraction increases and vapor density becomes more dominant resulting in decrease of the gravitational effect. Another very important observation made by Silva Lima \& Thome (Silva Lima \& 
Thome, 2012a) is that the gravitational effects diminish at higher mass fluxes because the dependence of the total pressure drop from the mass flux is much higher than from the gravitational effects. This fact was also observed by the author of this paper and will be described and analyzed further.

\section{Vertical down-flow configuration}

Vertical down-flow configuration also showed similarities to horizontal U-bends for similar curvature ratios, Figure 4(b). Here though, the quality dependence of the U-bend to straight section frictional pressure gradient ratios is more evident. It decreases significantly with increased vapor quality and approaches values close 1 . As for the horizontal configuration the U-bend to straight section pressure gradients ratio is higher for smaller bend radii and lower mass fluxes. At qualities below 0.2 the ratios become extremely high and Silva Lima \& Thome explanation that gravitational pressure drop becomes the dominant effect at lower qualities.

\section{Vertical up-flow configuration}

A very interesting dependence on quality is found for the vertical upflow configuration, Figure 4(c). At lower qualities and flows a ratio of U-bend to straight portion pressure gradients is as high as 20 for lower mass fluxes. Further this ratio finds a local minimum for the majority of the mid-quality range and at the higher qualities the ratio increases 
again to reach value as high as 10 for lower fluxes and smaller U-bend radii. Silva Lima \& Thome (Silva Lima \& Thome, 2012a) suggest that an increase in ratios at high qualities could be due to the localized liquid hold up that is not accounted in the void fraction calculations.

\subsubsection{Two-Phase Pressure Drop Models for U-bends}

Most of the available publications on the two-phase refrigerant pressure drops across the U-bends are focusing on the horizontal bend orientation. These correlations include Geary (1975), Chen et al. (2004b), Domanski and Hermes (2006) and Paliwoda (1992) (Silva Lima \& Thome, 2012b).

Geary's model (Geary, 1975) was based on experimental results of R22 in a serpentine tube. He proposed a Darcy friction factor correlation as a function of the vapor-phase Reynolds number which is based on the vapor-phase superficial velocity. Geary's model did not predict pressure gradients for qualities above 0.8 . He suggested the use of a single-phase correlation by Ito (1959) (Ito, 1959) for vapor higher qualities assuming pure-vapor pressure gradients.

Chen et al. (2004b) used his own database and added the data of Geary (Ito, 1959). They suggested a similar correlation to Geary model, but suggested different empirical factors, added the effects of the Weber number and used mixture Reynolds number, rather than vapor-phase Reynolds number as in original Geary correlation. 
Domanski and Hermes (2006) used databases made by Geary and Chen. They adjusted the Müller-Steinhagen and Heck correlation for straight tubes described earlier in this paper and applied it to the U-bend pressure gradient data. These authors suggested a multiplier, $\mathrm{K}$ to the original Müller-Stainhagen and Heck correlation, which is based on the geometry of the U-bend, flow conditions and fluid properties, (25)-(26).

$$
\begin{gathered}
\frac{d P}{d L}=K \frac{d P_{\text {Muller Stainhagen and Heck }}}{d L} \\
K=a_{0}\left(\frac{G x d}{\mu_{V}}\right)^{a_{1}}\left(\frac{1}{x}-1\right)^{a_{2}}\left(\frac{\rho_{L}}{\rho_{V}}\right)^{a_{3}}\left(\frac{D}{d}\right)^{a_{4}}
\end{gathered}
$$

Domanski and Hermes found two sets of $a_{n}$ coefficients. One for the combined database of Geary and Chen at al. and one which only included Geary database with the goal to remove data taken with the shortest straight portion length in the U-bend serpentine. The coefficients these authors determined are provided in Table 3.

Table 3: Domanski and Hermes (2006) coefficients used to calculate multiplier $\mathrm{K}$ for original Müller-Steinhagen \& Heck model.

\begin{tabular}{|l|l|l|l|l|l|}
\hline Domaski and Hermes coefficients & $\mathbf{a}_{\mathbf{0}}$ & $\mathbf{a}_{1}$ & $\mathbf{a}_{2}$ & $\mathbf{a}_{3}$ & $\mathbf{a}_{4}$ \\
\hline Based on Geary and Chen database & 0.0052 & 0.59 & 0.22 & 0.27 & -0.69 \\
\hline Based only on Geary database & 0.0065 & 0.54 & 0.21 & 0.34 & -0.67 \\
\hline
\end{tabular}

Paliwoda (1992) used his own extensive database for two-phase flows in different pipe components and suggested the correlation for the U-bends in particular, which is based on the friction factor $f$ and two coefficients $\beta$ and $\vartheta,(27)$ : 


$$
\Delta p=f \frac{G^{2}}{2 \rho_{V}} \beta
$$

Paliwoda found the friction coefficient values separately based on the curvature ratio of the U-bend. These coefficients are presented in the Table 4.

Table 4: Paliwoda (1992)friction factor coefficients based on the curvature ratio, D/d.

\begin{tabular}{|c|c|c|c|c|c|c|c|c|}
\hline$D / d$ & 2.0 & 2.5 & 3.0 & 3.5 & 4.0 & 5.0 & 6.0 & 8.0 \\
\hline$f$ & 0.280 & 0.210 & 0.190 & 0.175 & 0.160 & 0.140 & 0.130 & 0.120 \\
\hline
\end{tabular}

Coefficient $\beta$ and $\vartheta$ are found using equations (28) and (29):

$$
\begin{gathered}
\beta=[\vartheta+C(1-\vartheta) x](1-x)^{0.333}+x^{2.276} \\
\vartheta=\frac{\Delta p_{L}}{\Delta p_{V}}=\frac{\rho_{V}}{\rho_{L}}\left(\frac{\mu_{L}}{\mu_{V}}\right)^{0.25}
\end{gathered}
$$

Here coefficient $\mathrm{C}$ is an empirical term determined to be 3 for $\mathrm{U}$-bends.

A comparison of the modern U-bend pressure gradients made by Silva Lima \& Thome (Silva Lima \& Thome, 2012b) showed that most of them overpredict pressure drop gradients in the U-bend itself (Figure 5). Geary, Chen, Domaski and Hermes correlations used all or parts of the same database and thus they all show similar accuracy ranging from 44 to $65 \%$ mean error. Chen's correlation predicts $43 \%$ of data and Domanski and Hermes' correlation predicts $28 \%$ of data within $\pm 30 \%$ error band. Paliwoda's model, however, even though it underpredicts the data, showed the best accuracy with $67 \%$ of data predicted within the $\pm 30 \%$ error band. 


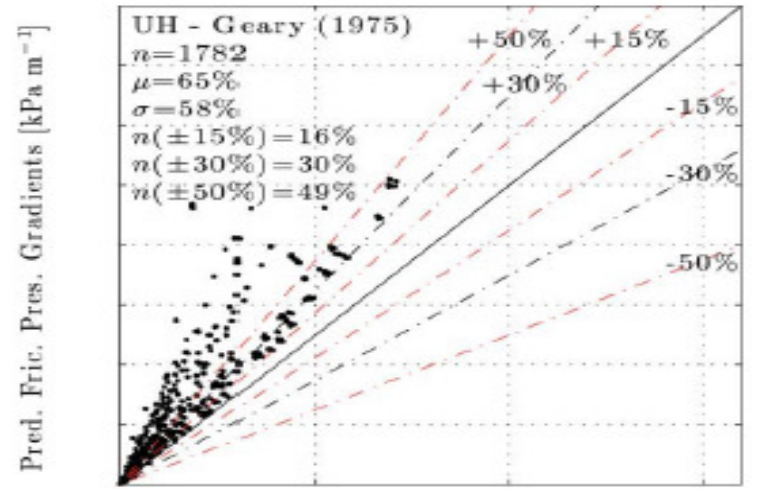

Exp. Fric. Pres. Gradients [kPa m-1]

(a)

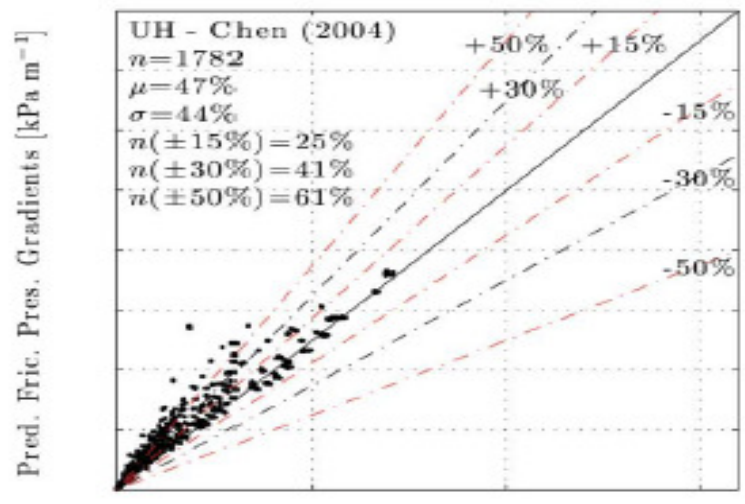

Exp. Fric. Pres. Gradients [kPa m-1]

(c)

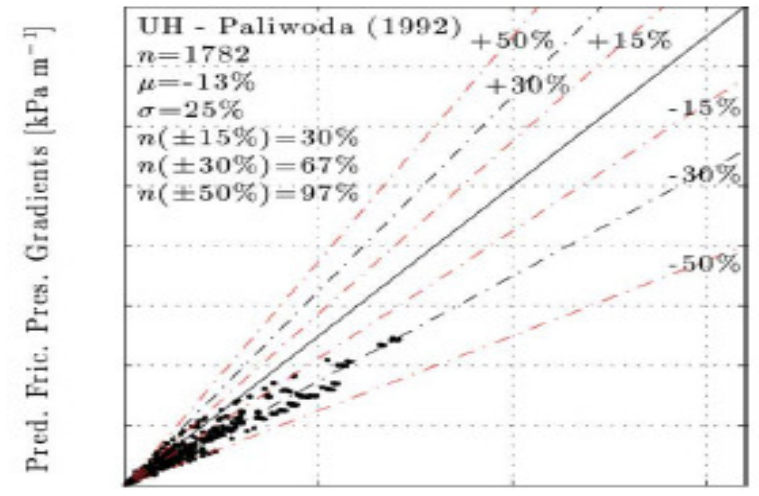

Exp. Fric. Pres. Gradients [kPa m-1]

(b)

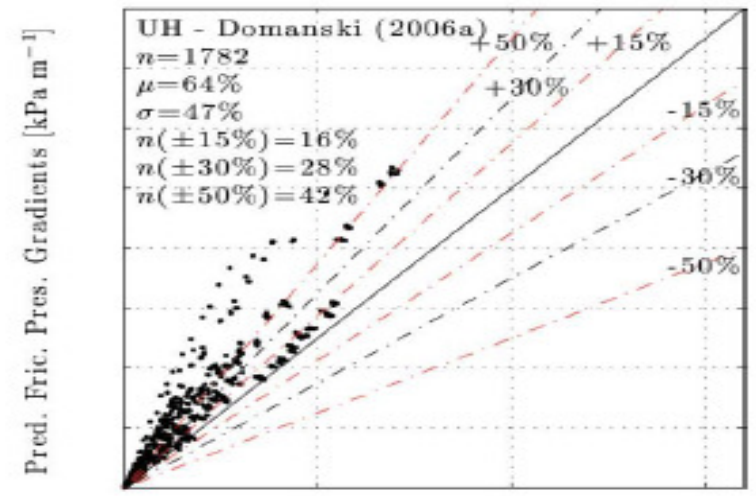

Exp. Fric. Pres. Gradients [kPa m-1]

(d)

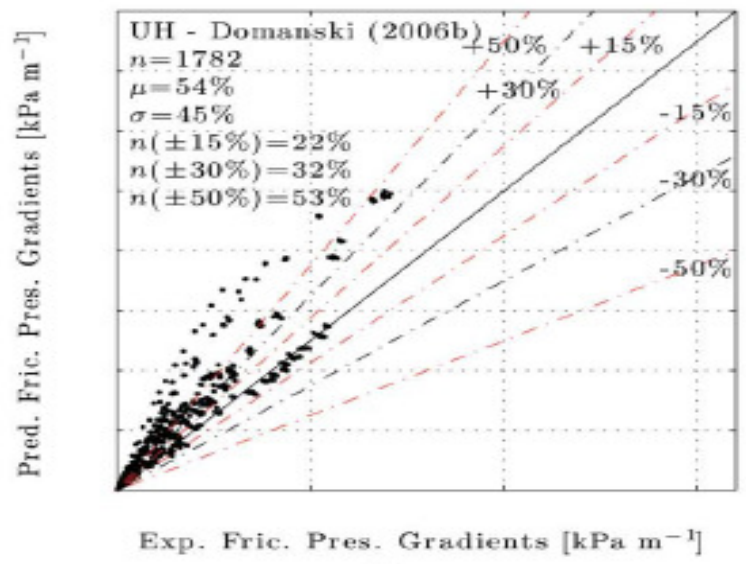

(e)

Figure 5: Comparison between the experimental data and prediction from existing models for horizontal flow based on Silva Lima \& Thome study (Silva Lima \& Thome,Part 2, 2012), including models of: (a) Geary, (b) Paliwoda, (c) Chen, (d) Domanski and Hermes a, and (e) Domanski and Hermes b. 
Thus, if any of the over predictive models are used, the saturation temperature and pressure of the evaporator would be higher than expected, which could lead to under sizing of the compressors and pumps as well as decrease in the performance of the system.

Furthermore real sealed systems consist of not only horizontal, but also vertical up- and down-flow U-bends which, in general, are more common in practice for household refrigerators. The only recent literature found on the two-phase pressure drop through the vertically oriented U-bends is the work by Silva Lima \& Thome (Silva Lima \& Thome, 2012b) .

New U-bend two-phase pressure drop prediction model suggested by Silva Lima \& Thome is unique in its basis on the simplified interfacial two-phase flow structure. The authors used their own U-bend flow structure study and determined that for most of the tested conditions the flow structure through the U-bends remains the same as at the inlet of the straight tube. However, their results also showed that in special cases, such as for stratified flow through the vertical U-bends the interfacial flow structure may change all along the bend. To avoid over complication of their model, Silva Lima \& Thome assumed that the flow conditions through the U-bend do not differ from that in the inlet of the adjacent straight tube. A large portion of the databank collected in this study includes stratified flows through the vertical U-bends; thus, a comparison of the Silva Lima \& Thome model with experimental results in this study will be used to check this simplifying assumption made by Silva Lima \& Thome. 


\subsubsection{Silva Lima \& Thome Model for U-bends}

In the second part of their paper Silva Lima \& Thome (Silva Lima \& Thome, 2012b) published an update to the straight tube two-phase frictional pressure drop model of Moreno Quibèn \& Thome described in section 2.3.3 of this paper, as well as a new flow pattern based multi-orientation model for U-bends.

In their frictional pressure drop model for U-bends in different orientations Silva Lima \& Thome (Silva Lima \& Thome, 2012b) showed that up- and downstream effects of the Ubends on the pressure gradient in the straight section of the tubes can be ignored until further studies of these effects. Nevertheless, when they applied updated Moreno Quibèn \& Thome correlation for straight tubes integrated with a new model for U-bends, the results showed that for 5393 experimental data points the mean error does not exceed $6 \%$ and standard deviation is under $26 \%$; $92 \%$ of data is inside a $\pm 30 \%$ error window (Silva Lima \& Thome, 2012b). The accuracy of these two models integrated together is very good and for this reason it will be applied to the brand-new databank collected for this study.

Even though integration of updated Moreno Quibèn \& Thome model for straight tubes and Silva Lima \& Thome model for U-bends showed a very high predictive accuracy (Silva Lima \& Thome, 2012b), the experimental data used for this comparison was solely based on a single straight tube and U-bend pair under adiabatic conditions. Thus, there was effectively no heat transfer into the refrigerant and no change in vapor quality along 
the test section. The authors admit that the question about the performance of these models in the real, complete system still remained.

When checking their models using diabatic data for a single pair of straight tube and a Ubend, authors integrated over the whole length of the samples using steps of $1 \mathrm{~d}$ and updating the vapor quality and local saturation conditions for each step (Silva Lima \& Thome, 2012b).

The results showed that once again out of 5393 diabatic experimental data points the comparison yields only $3 \%$ mean and maximum of $19 \%$ standard deviation errors with $90 \%$ of all database predicted with less than $\pm 30 \%$ error.

Full list of equations used by Silva Lima $\&$ Thome, similar to those for straight tubes, are presented in Appendix D. 


\section{SCOPE OF WORK}

Silva Lima \& Thome have created an integration of two frictional pressure drop models for straight tubes and U-bends and can predict pressure drop with the highest accuracy within their tested databank among any other two-phase frictional pressure drop models available. Their models can cover most major elements of the modern refrigeration systems, such as U-bends in multiple orientations. But unfortunately, the databank used by these authors did not fully cover the lower flow regions, which mostly fall under Stratified flow patterns. Low flows are very common for smaller sealed systems which are found in household refrigerators.

Müller-Steinhagen \& Heck, 1986 and Grönnerud, 1979 models are much older, but simpler to use when compared to the Silva Lima \& Thome. They are often referred to during design of small refrigeration appliances for ease of implementation and reasonable accuracy. But once again, they were not developed for low flows which are considered in this study. Furthermore, none of the aforementioned models have considered the use of R600A refrigerant, which is receiving more and more national attention due to its cooling and environmental properties.

The databank developed for this study is based on a full size evaporator with multiple Ubends in various orientations. The quality variation along the evaporator is achieved with the flexible heater wrapped around the length of the tube and providing constant heat flux 
at steady state conditions. The inlet and outlet properties are controlled to reflect actual saturation properties commonly found in the modern bottom freezer refrigerator. Four internal diameters, four curvature ratios, two evaporator orientations and two refrigerants, R134A and R600A, were tested. The total length of the evaporators was kept same or similar between all the samples. A detailed description of test samples is available in Table 5.

Most of the data was taken for vertical orientation of the evaporator as it is the most common installation method in household refrigerators. This largest set of data only varied the tube internal diameter for both refrigerants (Data sets 1-8 in Table 5). Further, a few samples were remade with different U-bend sizes and retested vertically once again to capture the effects of the U-bend curvature ratio on the total pressure drop (Data sets 913). Next, some configurations were tested horizontally to understand the static pressure drop effect and to eliminate the vertical U-bends from the system (Data sets 14 and 15). And lastly, a double horizontal U-bend configuration was tested, where the same length of the evaporator with the potential to be packed in the smaller space by doubling the number of horizontal U-bends was tested in horizontal position (Data sets 16 and 17). Note that the total length L of the evaporator tube varies from approximately 385 to 406 inches for different samples. This is due to intentional equality of the straight tubes lengths between adjacent U-bends of 24.65 inches for all samples: while this dimension was kept same, the U-bend length differed based on its radius. Another contribution to length difference was due to the length of the inlet/outlet ports of the evaporator. These ports were also participating in the heat exchange and total pressure drop through the 
evaporator and local pressure drop through these was calculated using appropriate correlations.

Thus, this databank was created to understand most of the geometrical options considered during the design of the evaporator in a common refrigerator with the final goal to establish a correlation that could be used to predict refrigerant pressure drops in a wide range of evaporator geometries.

Table 5: Databank description

\begin{tabular}{|c|c|c|c|c|c|c|c|}
\hline $\begin{array}{c}\text { Data set } \\
\text { reference } \\
\text { number }\end{array}$ & $\begin{array}{l}\text { Sample } \\
\text { number }\end{array}$ & $\begin{array}{c}\text { Refrigerant } \\
\text { type }\end{array}$ & $\begin{array}{c}\text { Tube } \\
\text { internal } \\
\text { diameter } \mathrm{d}, \\
\text { in }\end{array}$ & $\begin{array}{l}\text { Tube } U \text {-bend } \\
\text { internal } \\
\text { radius } R_{\text {internal }} \text {, } \\
\text { in }\end{array}$ & $\begin{array}{c}\text { Total } \\
\text { evaporator } \\
\text { length } \mathrm{L} \text {, in }\end{array}$ & $\begin{array}{c}\text { Evaporator } \\
\text { orientation }\end{array}$ & $\begin{array}{c}\text { Total } \\
\text { number of } \\
\text { U-bends }\end{array}$ \\
\hline \multicolumn{8}{|c|}{ Vertical orientation study } \\
\hline 1 & 1 & $\mathrm{R} 134 \mathrm{~A}$ & 0.315 & 0.575 & 397.53 & Vertical & $12 \mathrm{~V}, 1 \mathrm{H}$ \\
\hline 2 & 1 & R600A & 0.315 & 0.575 & 397.53 & Vertical & $12 \mathrm{~V}, 1 \mathrm{H}$ \\
\hline 3 & 2 & $\mathrm{R} 134 \mathrm{~A}$ & 0.267 & 0.530 & 396.10 & Vertical & $12 \mathrm{~V}, 1 \mathrm{H}$ \\
\hline 4 & 2 & R600A & 0.267 & 0.530 & 396.10 & Vertical & $12 \mathrm{~V}, 1 \mathrm{H}$ \\
\hline 5 & 3 & $\mathrm{R} 134 \mathrm{~A}$ & 0.243 & 0.530 & 394.00 & Vertical & $12 \mathrm{~V}, 1 \mathrm{H}$ \\
\hline 6 & 3 & R600A & 0.243 & 0.530 & 394.00 & Vertical & $12 \mathrm{~V}, 1 \mathrm{H}$ \\
\hline 7 & 4 & R134A & 0.186 & 0.530 & 391.90 & Vertical & $12 \mathrm{~V}, 1 \mathrm{H}$ \\
\hline 8 & 4 & R600A & 0.186 & 0.530 & 391.90 & Vertical & $12 \mathrm{~V}, 1 \mathrm{H}$ \\
\hline \multicolumn{8}{|c|}{ Vertical curvature ratio study } \\
\hline 9 & 5 & $\mathrm{R} 134 \mathrm{~A}$ & 0.315 & 0.750 & 405.78 & Vertical & $12 \mathrm{~V}, 1 \mathrm{H}$ \\
\hline 10 & 1 & $\mathrm{R} 134 \mathrm{~A}$ & 0.315 & 0.575 & 397.53 & Vertical & $12 \mathrm{~V}, 1 \mathrm{H}$ \\
\hline 11 & 6 & $\mathrm{R} 134 \mathrm{~A}$ & 0.267 & 0.750 & 404.41 & Vertical & $12 \mathrm{~V}, 1 \mathrm{H}$ \\
\hline 12 & 2 & $\mathrm{R} 134 \mathrm{~A}$ & 0.267 & 0.530 & 396.10 & Vertical & $12 \mathrm{~V}, 1 \mathrm{H}$ \\
\hline 13 & 7 & $\mathrm{R} 134 \mathrm{~A}$ & 0.267 & 0.342 & 385.16 & Vertical & $12 \mathrm{~V}, 1 \mathrm{H}$ \\
\hline \multicolumn{8}{|c|}{ Horizontal orientation study } \\
\hline 14 & 2 & $\mathrm{R} 134 \mathrm{~A}$ & 0.267 & 0.530 & 396.10 & Horizontal & $13 \mathrm{H}$ \\
\hline 15 & 2 & R600A & 0.267 & 0.530 & 396.10 & Horizontal & $13 \mathrm{H}$ \\
\hline \multicolumn{8}{|c|}{ Double horizontal U-bend study } \\
\hline 16 & 8 & $\mathrm{R} 134 \mathrm{~A}$ & 0.267 & 0.530 & 384.20 & Horizontal & $26 \mathrm{H}$ \\
\hline 17 & 8 & R600A & 0.267 & 0.530 & 384.20 & Horizontal & $26 \mathrm{H}$ \\
\hline
\end{tabular}

Furthermore, appropriate parts of experimental data collected with samples described above were compared with Müller-Steinhagen \& Heck, Grönnerud and Silva Lima \& Thome correlations to understand their performance for a low flow conditions and geometries frequently found in the household refrigerators. This will allow for more energy efficient and cost effective designs of the refrigerator sealed systems. 


\section{TEST FIXTURE AND EXPERIMENTAL CONDITIONS}

The test fixture diagram is shown in Figure 8. It consists of a complete sealed system using the components of a household refrigerator. The system was located on the mobile cart that allows easy transportation and service.

\subsection{Test Fixture Description}

Figure 6 below shows the schematic of the test fixture used in this study.

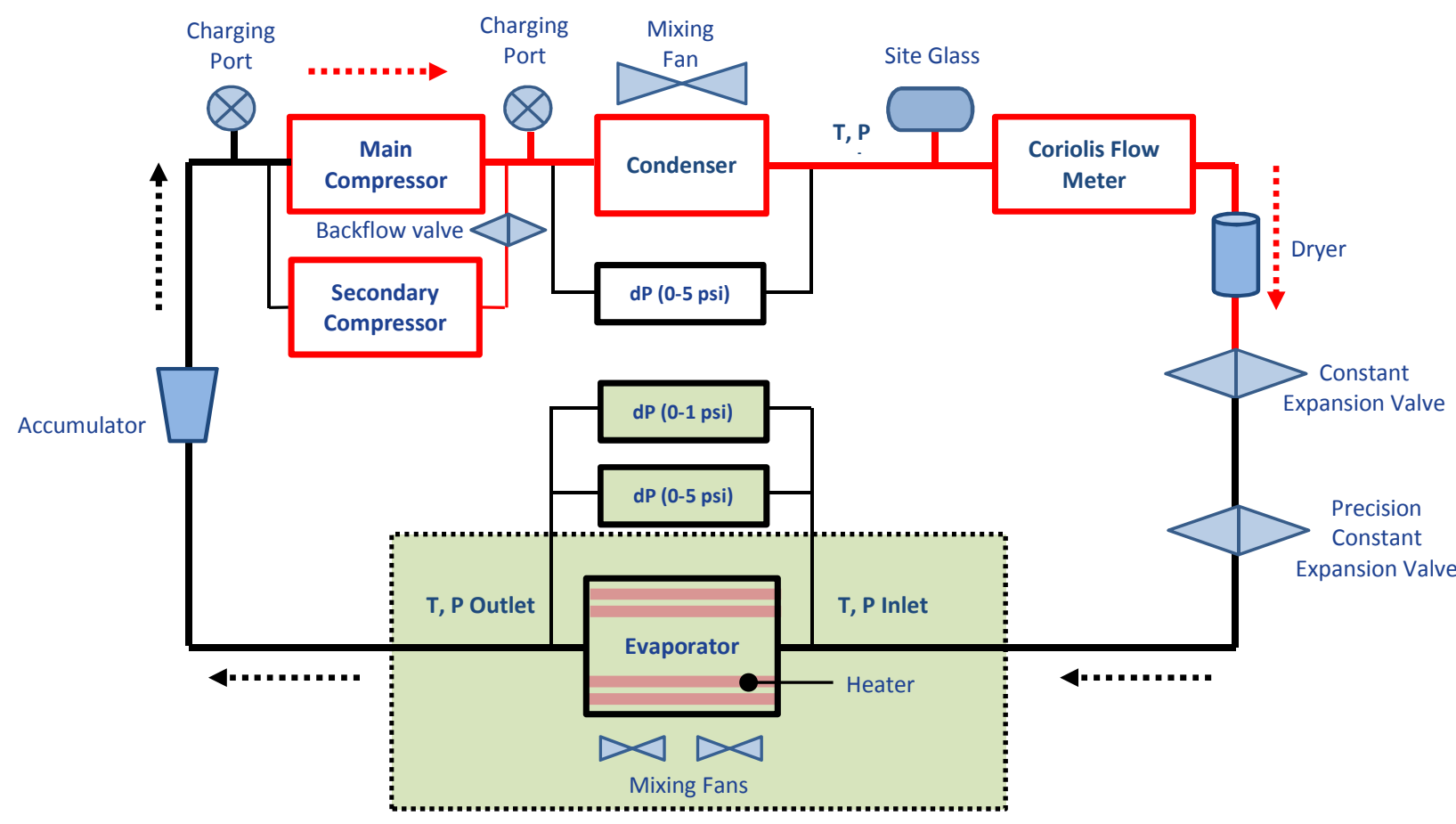

Figure 6: Experimental Fixture Diagram 
For all tests the fixture was located in the temperature controlled chamber maintained at $90^{\circ} \mathrm{F}$. Temperature control is used to avoid small fluctuations in the heat flux and helped increase the effectiveness of the heater control. $90^{\circ} \mathrm{F}$ ambient temperature provides an additional heat load used to compensate for door openings in the actual refrigerator. An evaporator under test was located in the insulated enclosure built with thick foam panels covered with fiberglass sheets and vacuum panels The enclosure is schematically shown with green rectangle. The insulation was needed for the control of constant heat transfer into the evaporator achieved by evenly wrapping a flexible heater around the full length of the evaporator. The heater was firmly taped to the tube using aluminum tape.

Two constant speed fans were installed inside of the insulation box to help mix the air for even heat flux distribution from the heater. The inlet and outlet refrigerant conditions are measured using Omega 4-wire RTDs and Setra absolute pressure gauges with 0-100 psia ratings. Two Setra differential pressure gauges are installed in parallel to measure the pressure drop over the length of the evaporator. The operation ranges of these gauges, 0-1 psid and 0-5 psid, were selected to maximize the accuracy of the measurements for the range of tested samples.

Upstream of the compressor an accumulator is used to prevent the liquid refrigerant entering the intake tube of the compressor. Two compressors in parallel were used to increase the flow range of the system. Low and high pressure charging ports are located on both sides of the main compressor to assist with servicing of the fixture. A secondary compressor is used in addition to the main one during testing with R600A. A backflow prevention valve is installed on the outlet of the secondary compressor to avoid 
potentially damaging backflow occurring during operation of the main compressor alone. Another Setra 0-5 psid differential pressure gauge is installed across the condenser and a mixing fan is used to enhance the heat rejection from the condenser. Upstream of the condenser is a site glass used for visual control of the refrigerant subcooling. Another set of Omega 4-wire RTD and Setra absolute pressure gauge (0-300 psia) are located downstream from the condenser for quantification of subcooled refrigerant properties. A Coriolis flow meter is located further down the system for measurement of the all-liquid mass flow. A filter dryer is a part of the system downstream of the flowmeter and helps with the removal of the moisture from the system during operation.

Most main components of the testing fixture are also shown on Figures 7-10 below. 


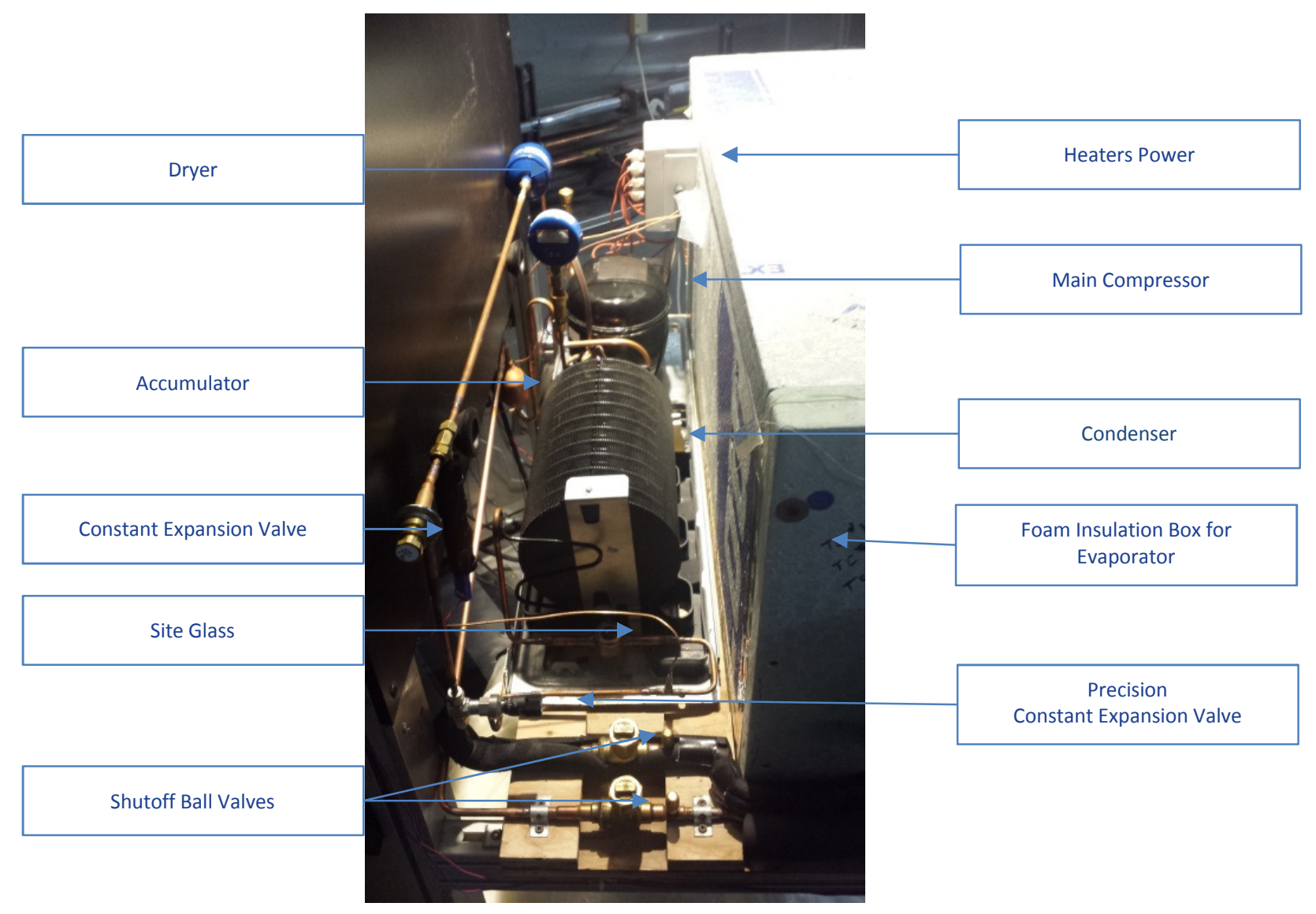

Figure 7: Experimental Fixture Photo (left-side view)

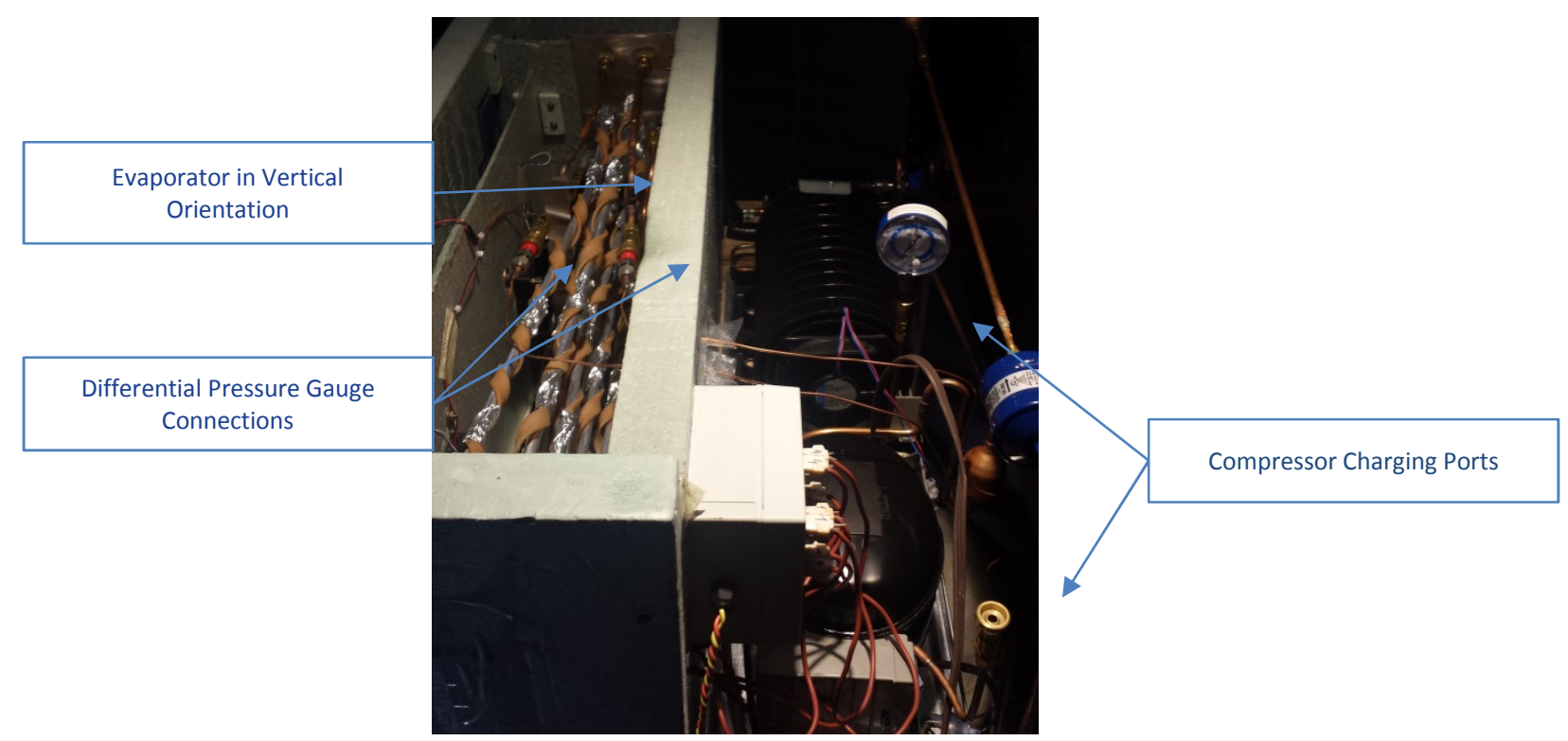

Figure 8: Experimental Fixture Photo (right-side view) 


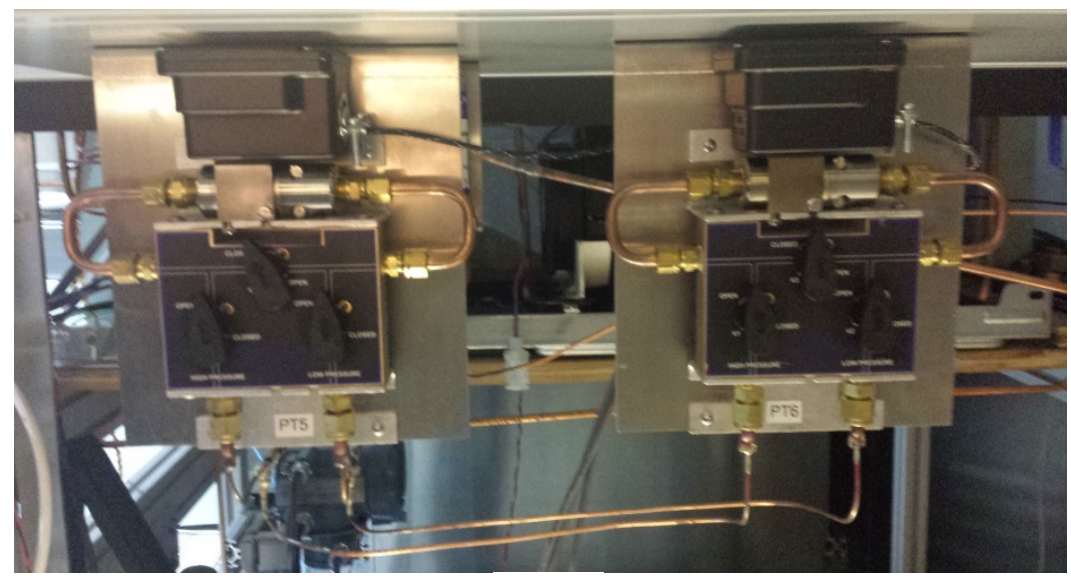

(a)

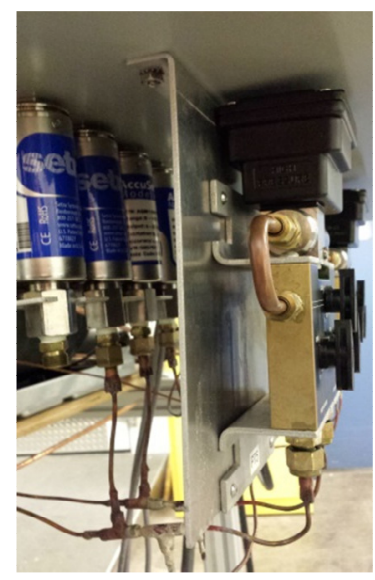

(b)

Figure 9: Pressure Sensors: (a) Differential pressure transducers in parallel across evaporator, (b) Absolute pressure transducers

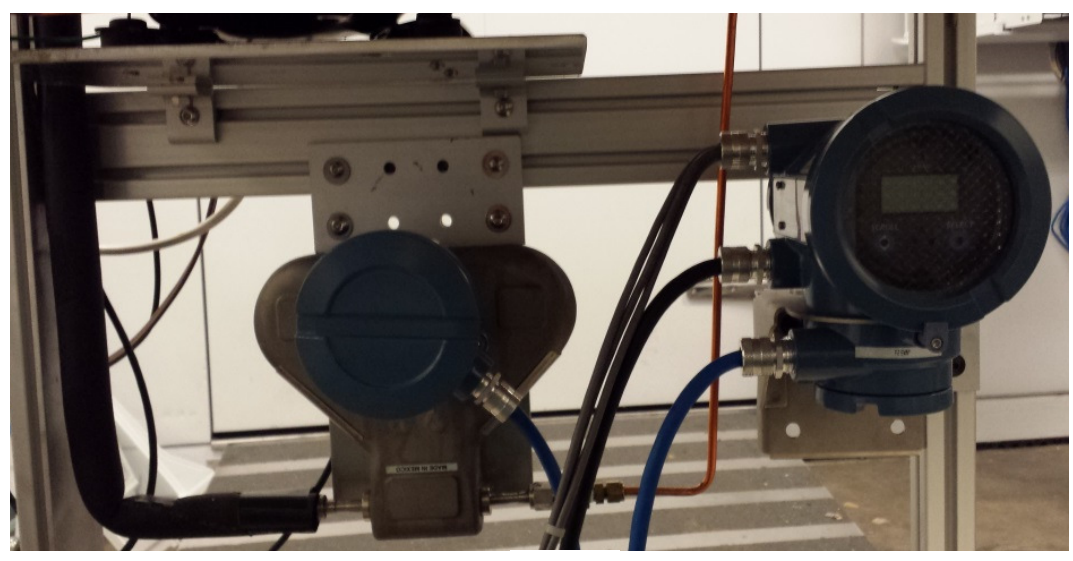

(a)

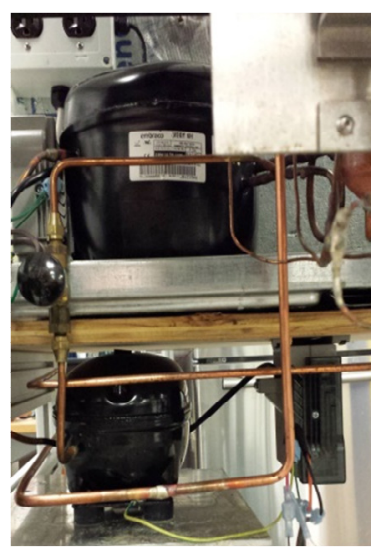

(b)

Figure 10: (a) Coriolis flowmeter and transducer, (b) Main (top) and secondary (bottom) compressors. 


\subsection{Test Configurations}

Three test configurations are shown on Figures $11-13$ further.

Figure 11 shows a sample of vertically tested evaporator with 12 vertical U-bends and a single horizontal U-bend. The direction of the flow was set up for mostly liquid to climb up one side of the evaporator through 6 vertical U-bends and 7 straight passes, cross over the horizontal U-bend at the top and flow down through 6 vertical U-bends and 7 straight passes to all vapor quality at the exit. This direction of the flow allowed higher differential pressure drops and improved accuracy of pressure drop measurements because the system operated closer to the midrange of the pressure transducersAll Ubends in a single evaporator were made with the same bend radius configured per Table 5. All straight passes of evaporators were oriented horizontally; portion of vertical straight tubes at the inlet and outlet of the evaporators were accounted for in calculations using corresponding straight tube pressure drop correlations including static pressure losses.
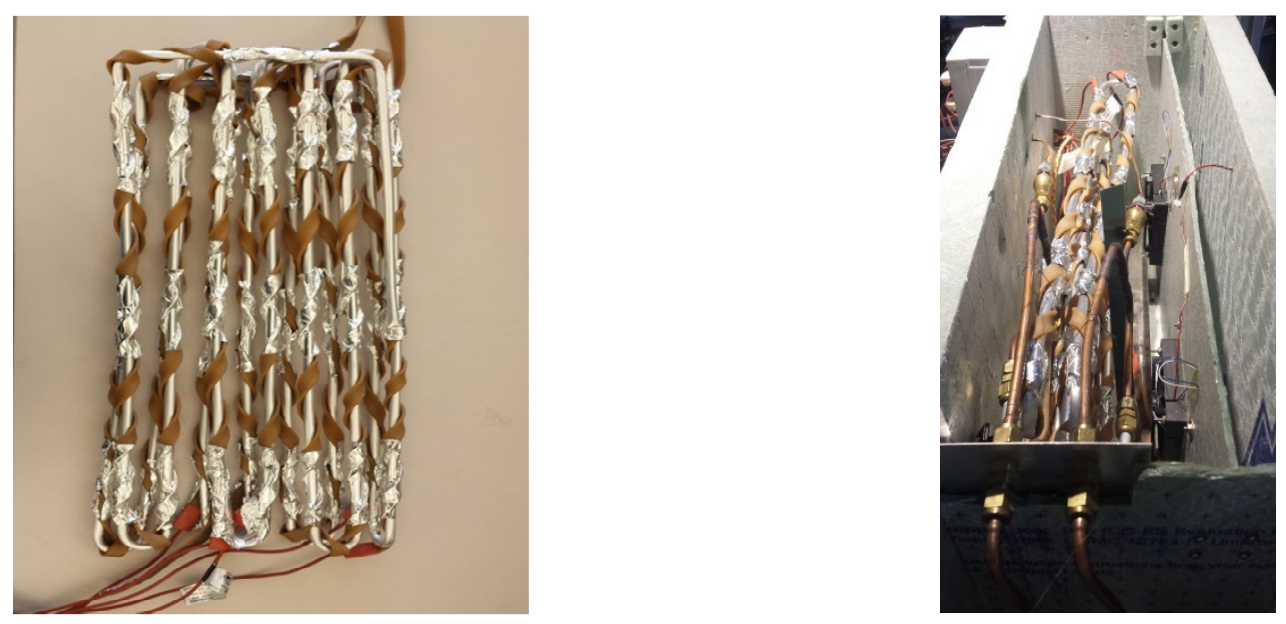

Figure 11: Twelve vertical and one horizontal U-bends in vertical evaporator orientation (samples 17 in Table 5) 
Figure 12 represents all horizontal evaporator configurations with 13 horizontal U-bends. The horizontality and flatness of the evaporator set up was ensured with C-clamps and levels. As for vertical configuration, the whole length of the evaporator tube between two differential pressure taps was accounted for in calculations.
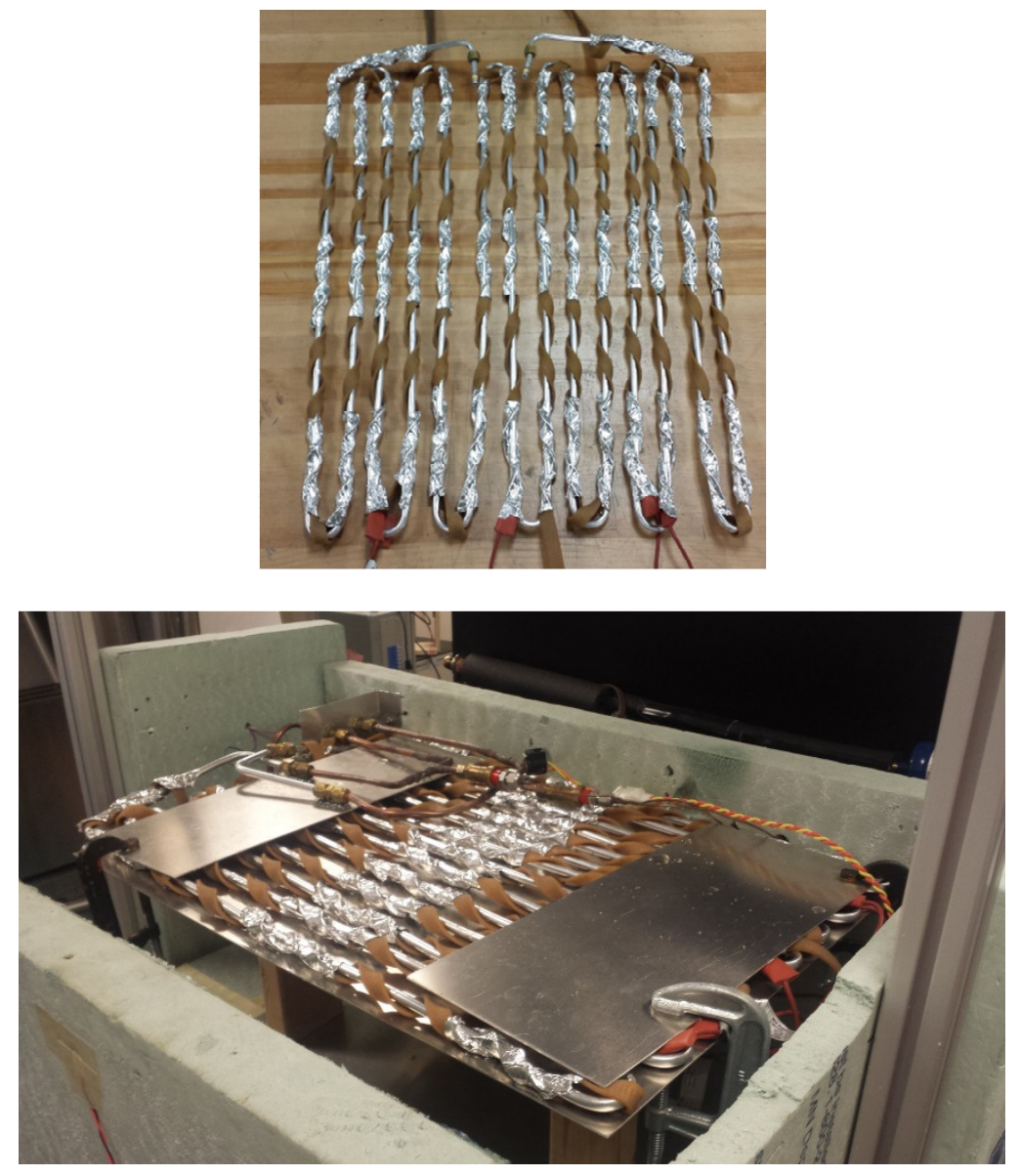

Figure 12: 13 horizontal U-bends in horizontal evaporator orientation (sample 8 in Table 5)

Finally, Figure 13 represents the double, 26, U-bend horizontal configuration. This configuration complicated the design of insulating box due to its increased size in one direction. Thus, it was decided to fold this evaporator in two resulting in approximately 
1.5 inches increase in elevation between the bottom and top layer of the 26 U-bends. This increase in elevation was assumed to be negligible.
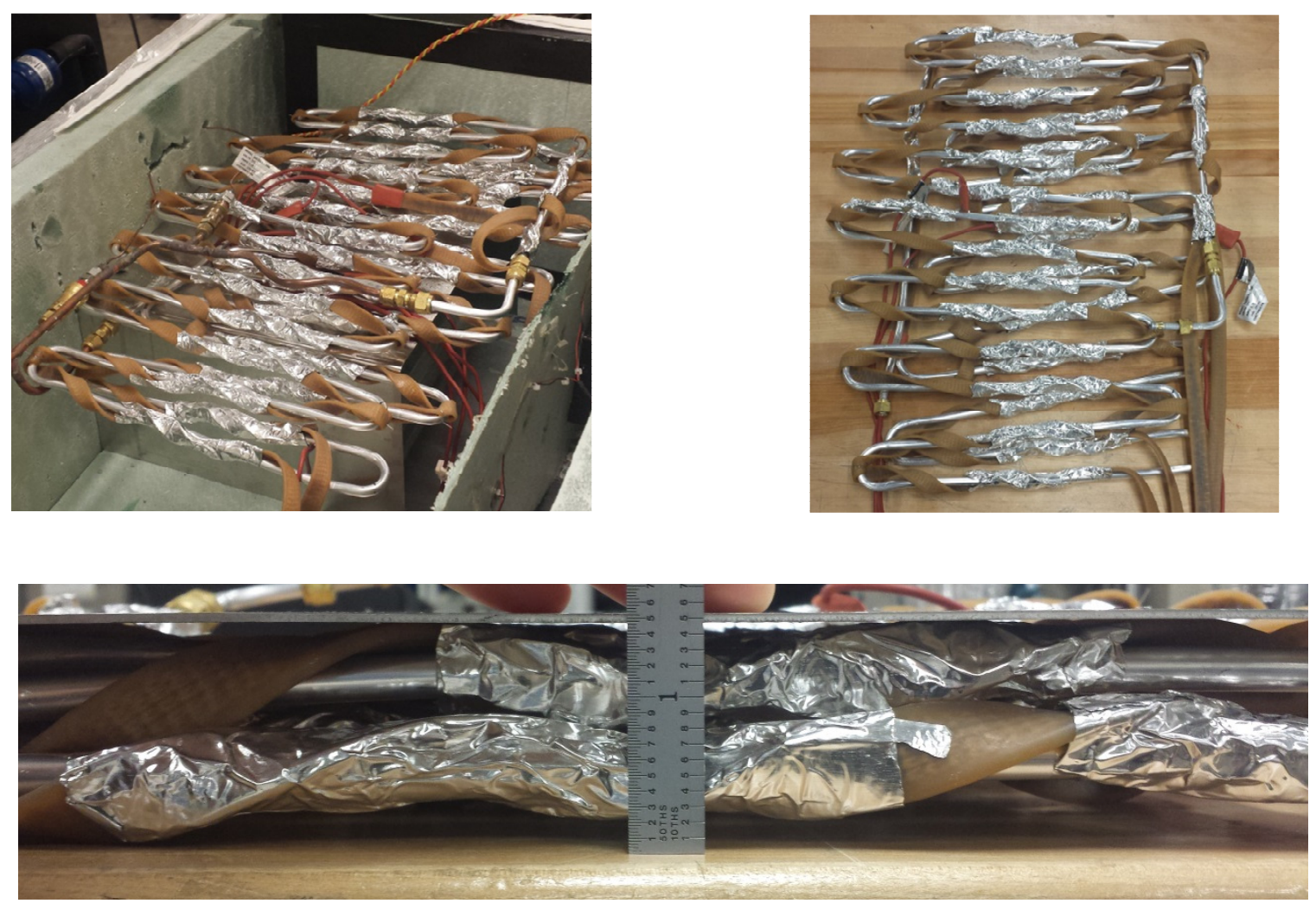

Figure 13: 26 horizontal U-bends in horizontal evaporator orientation (sample 9 in Table 5)

As for the 13 horizontal U-bend configuration, this set up was also clamped and leveled (not shown in Figure 13) 


\subsection{Experimental Conditions and Control}

At the beginning of each test set for each evaporator, system flow was adjusted to the needed value first, followed by regulation of the evaporator inlet saturation temperature and the PID controller was engaged to provide the required heat flux over the evaporator. The data from all available sensors was collected continuously, but only data points at steady state outlet conditions were used in this study.

\subsubsection{Mass Flow}

The mass flow of the system was controlled using frequency generators connected to compressor actuators. Frequency range for both compressors was 53 - $150 \mathrm{~Hz}$. During operation of both compressors on the same time, the available mass flows ranged as $4-$ 9.5 lb/hr for R134A and $2.5-7 \mathrm{lb} / \mathrm{hr}$ for R600A. The main compressor, rated for R134A was not capable to provide enough speed to achieve a needed flow range for R600A, which normally requires larger compressors. Thus, a secondary, larger compressor was engaged during tests with R600A. To overcome the back pressure during the start-up of both compressors, they were started at low speeds on the same time and adjusted to needed test conditions. Backflow needle valve was all the way closed when secondary compressor was not in use. The order of the mass flows tested per sample was chosen randomly, i.e. the compressors' speed(s) were adjusted to higher or lower mass flows randomly through the course of the testing set for each evaporator. 


\subsubsection{Inlet Saturation Temperature}

The refrigerant inlet and outlet conditions for the evaporator were controlled using manual adjustments as well as PI controller for the heater. The saturation temperature at the inlet of the evaporator was adjusted to be near $-11^{\circ} \mathrm{F}$, which corresponds to inlet pressures of 16 psia for R134A and 9 psia for R600A. By keeping similar inlet saturation temperatures between all samples, the performance comparison was simplified. Furthermore, the saturation temperature of $-11^{\circ} \mathrm{F}$ closely resembles the operation of this system in a household refrigerator. Two constant expansion valves, which serve as a replacement for the traditional capillary tubes in series were used (Figure 7) to adjust inlet pressures for each test point and to reach value of $P_{\text {inlet }} \pm 0.2$ psia.

\subsubsection{Heat Flux PI Control}

The goal was to create evaporator system conditions closely resembling that of an actual household refrigerator. An electric heater was evenly wrapped around the evaporator and Proportional and Integral gains were used to control the current to the heater. The control variable used was superheat temperature at the exit of the evaporator. A value of $5^{\circ} \mathrm{F}$ was used, which is slightly higher than found in operation but was a more easily achievable setting. Stable conditions were assumed to be achieved at $T_{S H} \pm 0.2^{\circ} \mathrm{F}$. Considering an average length of the evaporator commonly used in the bottom freezer refrigerators of over 33 feet, total of four 261 Watt 1/2" x 10' long heating tapes (4.3

W/in ${ }^{2}$ ) were used. Heaters, manufactured by Omega (SRT051-100), provide uniform heat distribution and are moisture resistant. Their wiring was strategically completed in order 
to control them as a union capable to supply $0-261$ Watt when $0-4 \mathrm{~mA}$ of current are added through data acquisition system using SCR control. SCR is a Silicon Control Rectifier which supplies partial sine wave AC voltage to the heater based on the phase angle.The proportional and integral control gain settings were found using careful tuning technique in order to minimize the overshoot of superheat value and achieve the desired value in a shortest period of time.

\subsection{Instrumentation and Data Acquisition}

Data acquisition was accomplished using National Instruments CompactRIO Platform with remote control and data collection using Chamber Data Acquisition System designed for various testing with multiple test fixtures in the temperature controlled chambers. All sensors used during testing were calibrated prior using industry standard calibration equipment.

\subsubsection{Sensors and Calibration}

All sensors, including RTDs, pressure gauges and a flow meter where calibrated before collecting data. 


\section{Temperature (RTDs)}

All RTDs used for testing were Omega 100 Ohm 1/3 DIN Platinum standard closed end sensors for immersion applications. The accuracy class $1 / 3 \mathrm{DIN}= \pm 1 / 3(0.3+0.005|\mathrm{t}|)^{\circ}$ C From -50 to $250^{\circ} \mathrm{C}$, or approximately $\pm 1 / 3(0.21+0.003|\mathrm{t}|)^{\circ} \mathrm{F}$ from $-58^{\circ} \mathrm{F}$ to $482^{\circ} \mathrm{F}$.

All three RTDs were calibrated using temperature controlled water-glycol bath with reference thermometer. 50 data points were taken for a temperature range of $-20^{\circ} \mathrm{F}$ to $130^{\circ} \mathrm{F}$ within the range of temperatures of the calibration equipment. This range covered the temperatures seen by RTDs during operation, which are near $-11^{0} \mathrm{~F}$ for evaporator RTDs and approximately $102^{\circ} \mathrm{F}$ for condenser RTDs.

Figure 14 below shows a normal probability density distribution for the calibration error based on the full calibration scale of $150^{\circ} \mathrm{F}$. Condenser measurements are used to determine the state of the refrigerant entering the flow meter and to calculate the quality of the vapor entering the evaporator. An accurate flow measurement can only be made for a single-phase flow. The normal probability graphs were found using MiniTab normal probability function using 50 data points found during calibration of RTDs. Mean and standard deviation values for each RTD (as well as other sensors further) are shown to the left of each normal probability graph. 
$\underline{\text { Evaporator inlet temperature }}$

Evaporator outlet temperature

Sample N, FCS 50

Mean, FCS $\quad-0.018$

St.Dev, FCS 0.135

Sample N, FCS 50

Mean, FCS

St.De, FCS

50
0.061
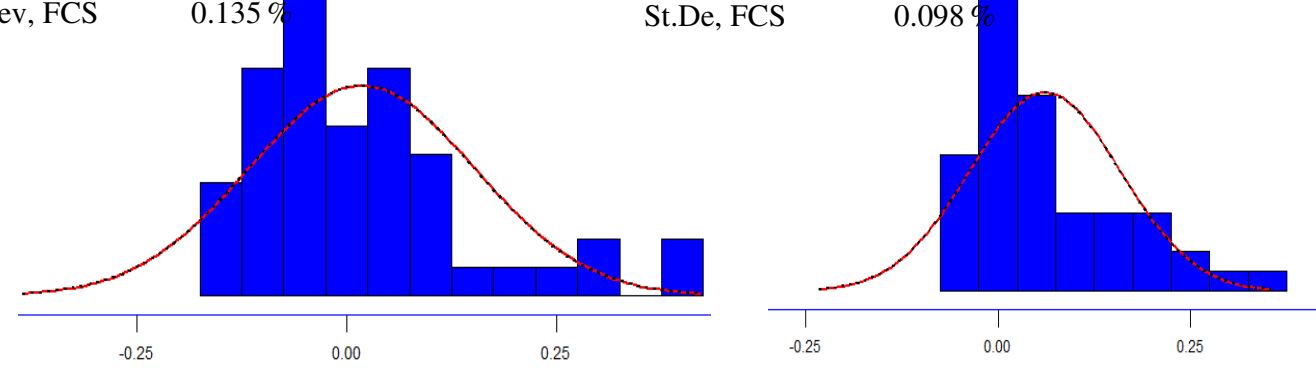

Condenser outlet temperature

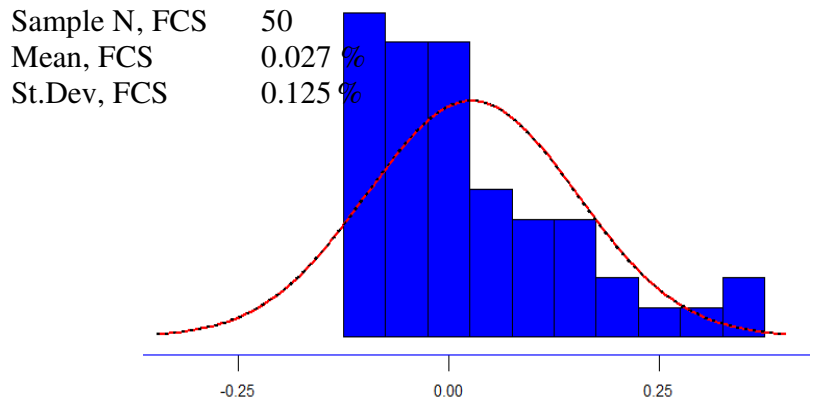

Figure 14: RTD error probability density versus calibration error (FS): (a) Evaporator Inlet RTD, (b) Evaporator Outlet RTD, (c) Condenser Outlet RTD. (FCS -full calibration scale of $150^{\circ}$ F)

The uncertainty for the temperature measurements was set to be equal to the sum of mean error and twice the standard deviation plus the error of the reference calibration thermometer. Table 6 below shows the uncertainty values for all RTDs.

Table 6: Temperature Measurements Uncertainty

\begin{tabular}{|l|l|}
\hline \multicolumn{1}{|c|}{ RTD Name } & Uncertainty $\left({ }^{\mathbf{0}}\right.$ F $)$ \\
\hline Evaporator inlet $R T D$ & \pm 0.378 \\
\hline Evaporator outlet $R T D$ & \pm 0.386 \\
\hline Condenser outlet $R T D$ & \pm 0.416 \\
\hline
\end{tabular}




\section{Mass Flow (Flow Meter)}

The accuracy of Coriolis flow meters is cited by the manufacturer as $0.15 \%$ of the measured value. Thus, the accuracy of the highest measured value in this study is $9.5 \pm$ $0.014 \mathrm{lb} / \mathrm{hr}$.

\section{Absolute Pressures}

Refrigerant pressures at the inlet an outlet of the evaporator and at the outlet of the condenser were measured with Setra Accusense pressure transducers with manufacturer reported accuracy of $\pm 0.05 \%$ FS. The inlet and outlet evaporator transfuses rated for 0 100 psia (accuracy of \pm 0.05 psia), while condenser transducer had a range of $0-300$ psia (accuracy of \pm 0.15 psia). Figure 15 shows the statistical summary of the calibration performed in - house using Fluke calibration system.

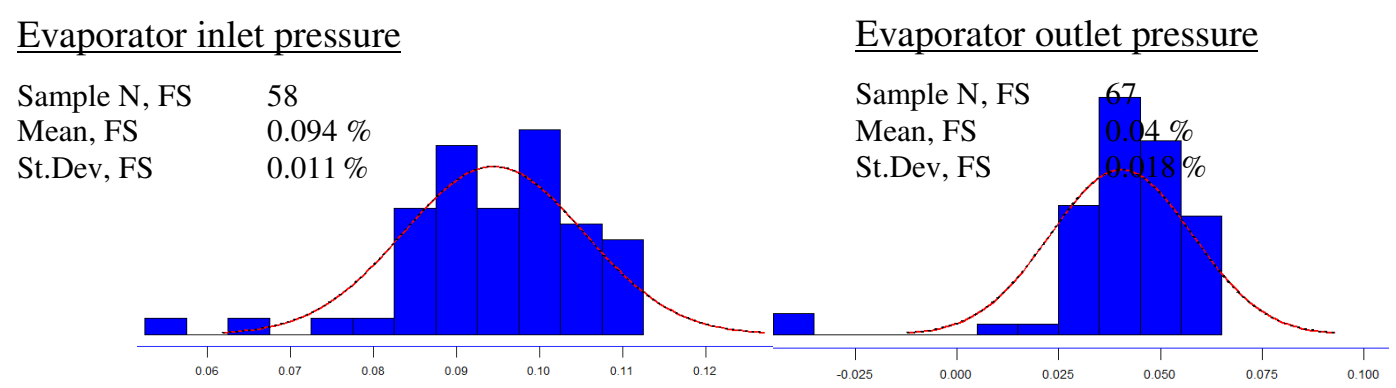

Condenser outlet pressure

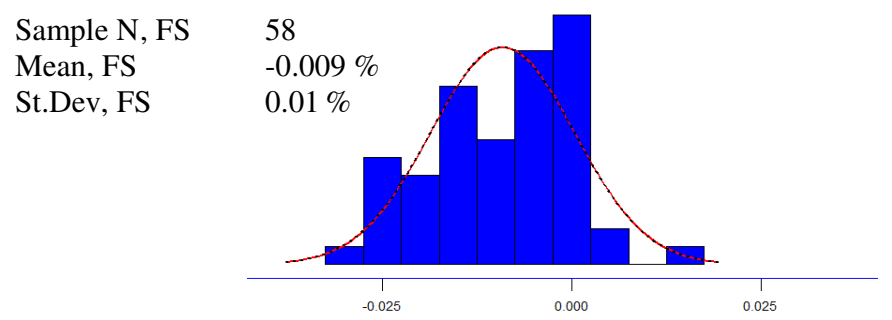

Figure 15: Pressure transducers error probability density versus calibration error (FS): (a) Evaporator inlet pressure, (b) Evaporator outlet pressure, (c) Condenser outlet pressure. (FS -full scale) 
Fluke calibration equipment consisted of a pressure box with 300 psig maximum pressure which included a hand air pump and two ports for a reference pressure gauge (Fluke $2700 \mathrm{G}$ series with $-12-300$ psig range) and a transducer under test. The accuracy of the reference gauge was $\pm 0.02 \%$ FS per manufacturer documentation.

In order to take conservative values for transducer uncertainties, they were set equal to the sum of mean error and twice the standard deviation plus the error of the reference calibration thermometer. Table 7 below shows the uncertainty values summary.

Table 7: Absolute Pressure Measurements Uncertainty

\begin{tabular}{|l|l|}
\hline Pressure Transducer Name & Uncertainty, psia \\
\hline Evaporator inlet pressure $(0-100$ psia $)$ & \pm 0.176 \\
\hline Evaporator outlet pressure $(0-100$ psia $)$ & \pm 0.136 \\
\hline Condenser outlet pressure $(0-300$ psia $)$ & \pm 0.093 ( \pm 0.15 is used $)$ \\
\hline
\end{tabular}

Calibration uncertainty results for condenser outlet pressure gauge show uncertainty below the manufacturer accuracy of $\pm 0.15 \mathrm{psia}$, thus for further calculations an uncertainty of \pm 0.15 will be used as more conservative.

\section{Differential Pressures}

The pressure drops occurring in the evaporator under test and the condenser were measured with Setra Model 230 differential pressure transducer compatible with any gas or liquid as long as it meets compatibility requirements with the materials or its components. In order to use R600A with these transducers, the original Viton "O"-rings on the bleed screws were replaced with the Buna N "O"-rings prior to starting the tests. 
Two differential transducers across the evaporator were installed in parallel. Transducer with the range of 0-1 psig was used to measure pressure drop for most samples; however, 0-5 psid transducer readings were utilized for the smallest internal diameter sample. Another 0-5 psid differential pressure transducer was installed to measure a condenser pressure drop for some samples. The accuracy of differential pressure transducers is reported by the manufacturer as $\pm 0.25 \% \mathrm{FS}$ with the zero shift of $\pm 0.004 \% \mathrm{FS} / \mathrm{psig}$ line pressure. Thus, $0-5$ psid and $0-1$ psig transducers promise accuracy of \pm 0.0125 psid and \pm 0.0025 psid, respectively. See Table 8 below for summary of uncertainties of differential pressure gauges for both refrigerants (the breakdown between refrigerants is needed to encompass the differences in the line pressure for zero shift calculation). A total uncertainty for differential pressure transducers is a sum of accuracy and zero shift values (Table 8).

Table 8: Differential Pressure Measurements Uncertainty

\begin{tabular}{|c|l|l|l|}
\hline \multicolumn{3}{|c|}{ R134A } \\
\hline $\begin{array}{c}\text { Differential Pressure } \\
\text { Transducer Name }\end{array}$ & \multicolumn{1}{|c|}{ Accuracy, psid } & Zero Shift, psid & \multicolumn{1}{c|}{$\begin{array}{c}\text { Uncertainty, } \\
\text { psid }\end{array}$} \\
\hline Evaporator $(0-1$ psid $)$ & \pm 0.0025 & \pm 0.00006 & \pm 0.0026 \\
\hline Evaporator $(0-5$ psid $)$ & \pm 0.0125 & \pm 0.0003 & \pm 0.013 \\
\hline Condenser $(0-5$ sid $)$ & \pm 0.0125 & \pm 0.032 & \pm 0.044 \\
\hline \multicolumn{3}{|c|}{ R600A } \\
\hline $\begin{array}{c}\text { Differential Pressure } \\
\text { Transducer Name }\end{array}$ & Accuracy, psid & Zero Shift, psid & $\begin{array}{c}\text { Uncertainty, } \\
\text { psid }\end{array}$ \\
\hline Evaporator $(0-1$ psid $)$ & \pm 0.0025 & \pm 0.00022 & \pm 0.0027 \\
\hline Evaporator $(0-5$ psid $)$ & \pm 0.0125 & \pm 0.0011 & \pm 0.013 \\
\hline Condenser $(0-5$ sid $)$ & \pm 0.0125 & \pm 0.018 & \pm 0.05 \\
\hline
\end{tabular}

Manufacturer recommendation for utilizing these pressure transducers is to correct for any zero and/or span offsets by software adjustment or control system, whenever 
possible. This step was completed before testing each configuration listed in Table 5 using the manufacturer recommended procedure.

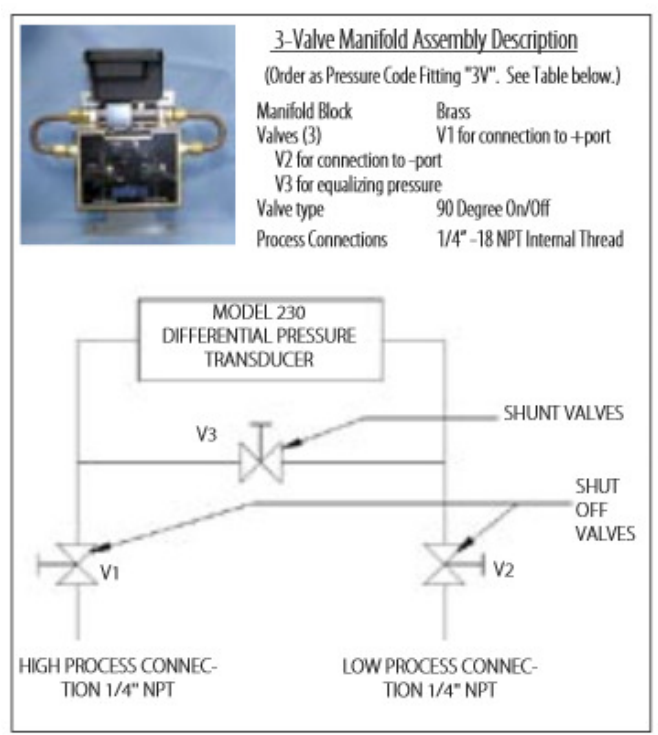

Figure 16: Differential Pressure Transducer 3-Valve Manifold Assembly

Prior to charging the system with refrigerant, three valves in the manifold (Figure 16) were set to: High and Low pressure valves (V1 and V2) - closed; Shunt valve (V3) open. This protected them during charging process and the set up. The shunt valve equalizes the pressure across the high and low ports relieving the pressure off of the transducer diaphragm. After the system was charged and while the internal pressure is still above atmospheric (approximately 14.5 psi locally), the bleed screws were opened for 1-2 seconds until only bubble-free liquid flows out. Bleed screws on high pressure side were bleed first, following by two low pressure side bleed screws. Next, valves V1 and V2 were opened slowly to avoid hammering, starting with V2. And lastly, the shunt valve, V3, was closed to start transducer operation. 
After the testing was completed and a next evaporator configuration needed to be installed, the shunt valve, V3, was opened and pressure port valves, V1 and V2, were closed to remove the transducers from operation.

\subsubsection{Data Acquisition and Processing}

Data acquisition using Chamber Data Acquisition system was performed every 10 seconds until enough data was collected at steady state conditions to meet accuracy requirements to be with standard deviations under $1 \%$ of measured value for mass flow and under $5 \%$ of measured value for differential pressure measurements. Steady state conditions were believed to be achieved when two control variables, evaporator inlet pressure and outlet superheat, achieved the values $P_{\text {inlet }} \pm 0.2$ psia and $T_{S H} \pm 0.2{ }^{\circ} \mathrm{F}$, respectively.

After experimental data collection, MatLab was used to process readings from all transducers and reduce each data set to a single data point combining flow physical information at steady state conditions, differential pressure measurements, and accuracy information,. Results of the data reduction are presented in Experimental Results section further in this paper.

\subsection{R134A and R600A Physical and Chemical Properties Comparison}

R134A, a HydroFluorCarbon (HFC) refrigerant, is very common in the US as well as around the world. Its chemical name is Tetrafluoroethane and formula $\mathrm{CH}_{2} \mathrm{FCF}_{3}$. R134A 
has similar thermodynamic properties as R-12 (dichlorodifluoromethane), but with less ozone depletion potential (engineeringtoolbox.com).

Table 9 below shows how physical properties for R134A and R600A compare at Tsat = $11^{\circ} \mathrm{F}$ (found using REFPROP software) as well as other information:

Table 9: R134A and $\mathrm{R600A}$ physical (at $\left.-11^{\circ} \mathrm{F}\right)$, ecological and safety properties

\begin{tabular}{|c|c|c|}
\hline Property & R134A & R600A \\
\hline Vapor density, $\mathrm{kg} / \mathrm{m}^{3}$ & 5.6 & 1.8 \\
\hline Liquid density, $\mathrm{kg} / \mathrm{m}^{3}$ & 1372.2 & 606.6 \\
\hline Vapor dynamic viscosity, $\mathrm{Ns} / \mathrm{m}^{2}$ & $9.8 \mathrm{E}-6$ & 6.3E-06 \\
\hline Liquid dynamic viscosity, $N s / m^{2}$ & $370.7 \mathrm{E}-6$ & $\begin{array}{c}263.0 \mathrm{E}- \\
6\end{array}$ \\
\hline Molar mass, $\mathrm{g} \mathrm{mol}^{-1}(1)$ & 102.0 & 58.1 \\
\hline Ozone depletion potential $(O D P)^{(2)}$ & 0 & 0 \\
\hline $\begin{array}{l}\text { Global warming potential, GWP }(100 \text { year } \\
{\text { integration })^{(3)}}^{(3)} \text { Ge }\end{array}$ & 1300 & 8 \\
\hline Standard 34 Safety Group ${ }^{(2)}$ & A1 & A3 \\
\hline
\end{tabular}

(1) (Domaski and Yashar, 2006)

(2) (Calm and Hourahan, 2001)

(3) (Maclaine-cross and Leonardi, 1996)

Thus, R600A has a negligible global worming potential in comparison to that of R134A, which is why it is being heavily introduced in household refrigeration. However, it has a higher flammability rank, which is addressed by reduction of charge in the system, which is possible due to R600A's higher COP and lower molar mass. 
In 1996 Maclaine-Cross and Leonardi did a performance comparison between several refrigerants including R134A, R12 and R600A affecting the measured energy consumption of domestic refrigerators for an idealized Rankine cycle operating between $15^{\circ} \mathrm{C}\left(5^{\circ} \mathrm{F}\right)$ and $30^{\circ} \mathrm{C}\left(86^{\circ} \mathrm{F}\right)$ saturation temperatures. They have summarized the following important advantages to using R600A:

1) Since R600A is a lower pressure refrigerant, the low pressure side of the sealed system (evaporator side) does not suffer high pressure increase during storage of the refrigerator, when pressures equalize across the system. This impacts capital cost since tubing wall thicknesses are reduced, and consequently increases COP through reduced heat transfer resistance.

2) Lower compressor discharge temperature allows a cheaper and more efficient electric motor.

3) Large effective displacement of R600A implies a larger compressor, but since condenser gauge pressures are approximately half that of R134A (112 psi for R134A and 59 psi for R600A in Maclaine-cross and Leonardi study) the compressor wall thickness can be halved as well.

4) R600A has about half the COP loss due to pressure drop through the condenser when compared to other refrigerants.

5) Heat transfer by forced convection in the condenser and evaporator of small unit occurs mainly by conduction through the thin liquid film at the tube wall. The usual correlations for heat transfer (ASHRAE, 1993) depend mainly on the ratio of the thermal conductivity of the liquid to its dynamic viscosity, $k / \mu$. At $5^{0} \mathrm{~F}$ saturation temperature, this ratio equals to $0.293 \mathrm{~kJ} / \mathrm{kg} \mathrm{K}$ for $\mathrm{R} 134 \mathrm{~A}$ and 0.496 
$\mathrm{kJ} / \mathrm{kg} \mathrm{K}$ for R600A. Thus heat transfer conductance is higher for R600A, which leads to smaller COP losses due to the thermal resistances.

6) Having larger molecule size R600A is expected to have lower diffusion loss through the sealing compounds of refrigerant system.

One disadvantage mentioned by Maclaine-Cross and Leonardi, 1996 is R600A's below atmospheric evaporator pressure may ingress the air through the seals reducing reliability. But this issue occurred when open-drive compressors were used, which are not in use any longer. Thus, Maclaine-Cross and Leonardi, 1996 concluded that R600A refrigerators show the energy savings of up to $20 \%$ compared to R134A and R12. It also has half the leakage, pressure loss and condenser pressure, as well as double the heat transfer coefficient of the other two refrigerants. A comparative summary table created by the authors is provided in Appendix E. 


\section{EXPERIMENTAL RESULTS}

The experimental results will be presented based on the orientations of the separate studies outlined in Table 5. For all graphical presentations of the data the plots created using R134A refrigerant will be shows in solid lines and round markers, while plots created using R600A refrigerant will be presented by dashed lines and diamond markers. Further, the data taken from the same evaporator will be color coded the same for better visual analysis of the results. All pressure drop plots have an additional point added at $d P$ $=0$ psid and $\dot{m}=0 \mathrm{lb}_{\mathrm{m}} / \mathrm{hr}$ assuming no pressure drop at no flow conditions (psid here stands for differential pressure in pounds per square inch). This point allows an addition of the cubic trendline to each set of data which showed to have the best graphical fit to the experimental data and is used purely for easier visualization of the results.

\section{Vertical orientation study}

Figure 17 shows measured two-phase pressure drop values through vertical evaporators with twelve vertical and one horizontal U-bend (data sets 1-8 in Table 5). This is the most complex part of the overall study conducted in this research and will be analyzed last after some simplifications are made based on the remainder of the data. 
Overall, this data set possesses some similarities between two-phase pressure drop tendencies of R134A and R600A. Both refrigerants have minimal changes of the pressure drops for lower flows and larger tube internal diameters. However as the flow increases pressure drop starts to climb and its gradient increases with decreasing internal tube diameter.

For both sets of data, for R134A and R600A, maximum tested flow is limited to a certain value for several reasons. For R600A samples maximum mass flow rate is governed by the abilities of the two parallel compressors to run with lower density refrigerant: density of R600A vapor is approximately $30 \%$ of the R134A vapor density. For R134A, the maximum tested mass flow is determined by the range of the differential pressure transducers (larger one has a high limit of 5 psid) and the goal to test with flows commonly used in the household refrigerators (normally $6-8 \mathrm{lb}_{\mathrm{m}} / \mathrm{hr}$ ). 


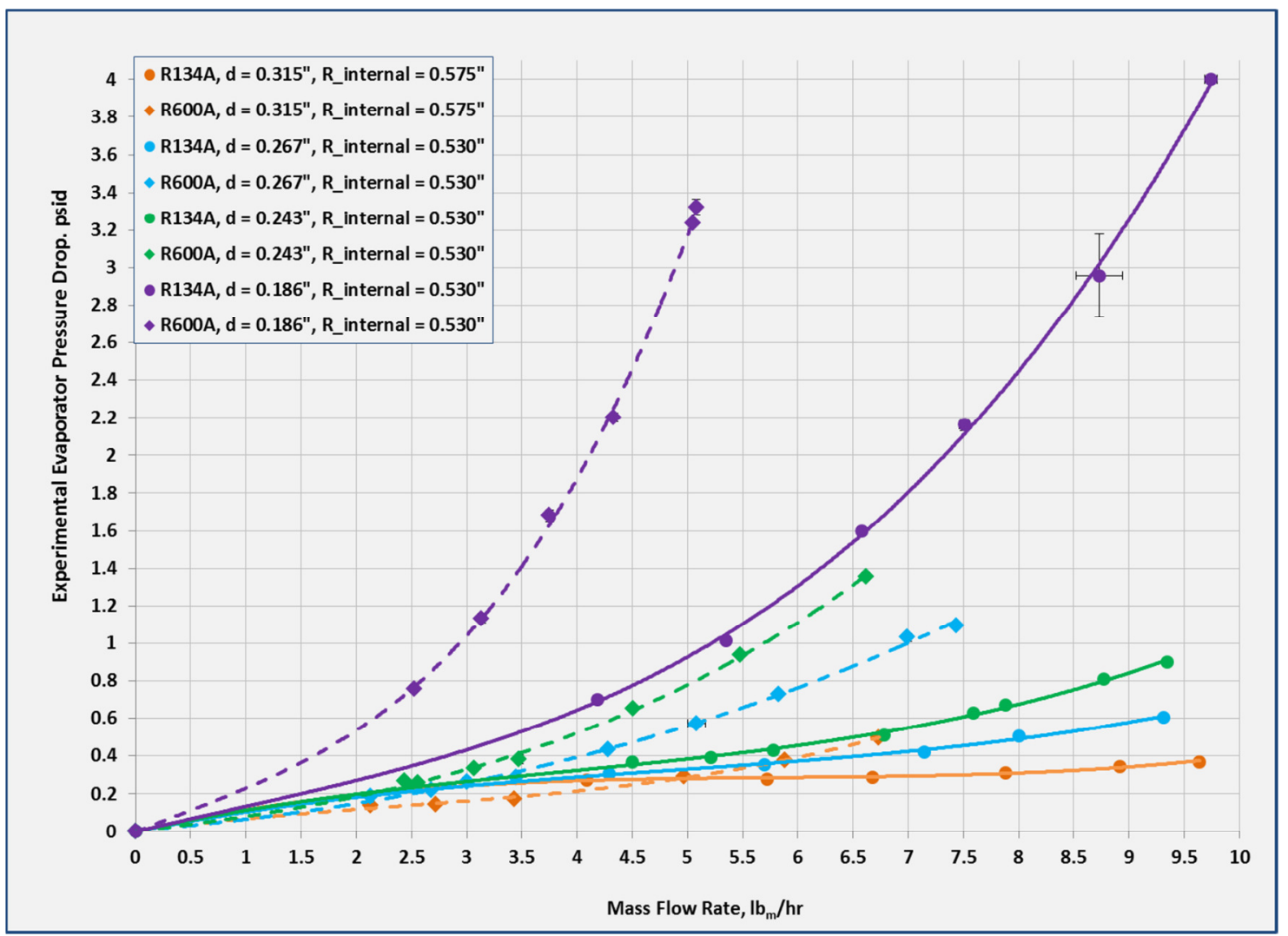

Figure 17: Vertical evaporator orientation study with 12 Vertical and 1 Horizontal U-bends per data sets 1-12 from Table 5 (see Figure 11 for photos of installation)

\section{Vertical curvature ratio study}

Based on data sets 9-13 in Table 5, Figure 18 shows the results for several curvature ratios of the vertical evaporator configuration for R134A using tube internal diameters of 0.315 and 0.267 inches. Four U-bend internal radii was used in this testing: 0.750, 0.575, 0.530 and 0.342 inches. The curvature ratio, D/d was calculated using equation (30). Example for the first data set with $\mathrm{R} 134 \mathrm{~A}, \mathrm{~d}=0.315 ", \mathrm{R}_{\text {internal }}=0.750$ ” is also shown below: 


$$
\frac{D}{d}=\frac{2 \cdot R_{\text {internal }}+2 \cdot t+d}{d}=\frac{2 \cdot 0.750^{\prime \prime}+2 \cdot 0.030^{\prime \prime}+0.315^{\prime \prime}}{0.315^{\prime \prime}}=5.95^{\prime \prime}
$$

( $\mathrm{t}$ stands for tube wall thickness)

Thus, a curvature ratio for this data set equals 5.95”.

Here the pressure drop data points for same tube sizes located in a very near proximity to each other seemingly independent from the curvature ratio of the samples. Thus for clarity of the plot only one trendline is plotted for each of the tube sizes of 0.315 and 0.267 inches internal diameter, since trendlines for other curvature ratios would locate themselves in a close proximity.

It is evident from the U-bend curvature ratio study that there is no clear defined relationship between the total two-phase pressure drop through the evaporator in the household refrigerator and the curvature ratio of the samples. However, a much stronger relationship is apparent for data sets with the same internal diameter of the tubes. This relationship was also evident from Figure 17 for data sets 1-12. 


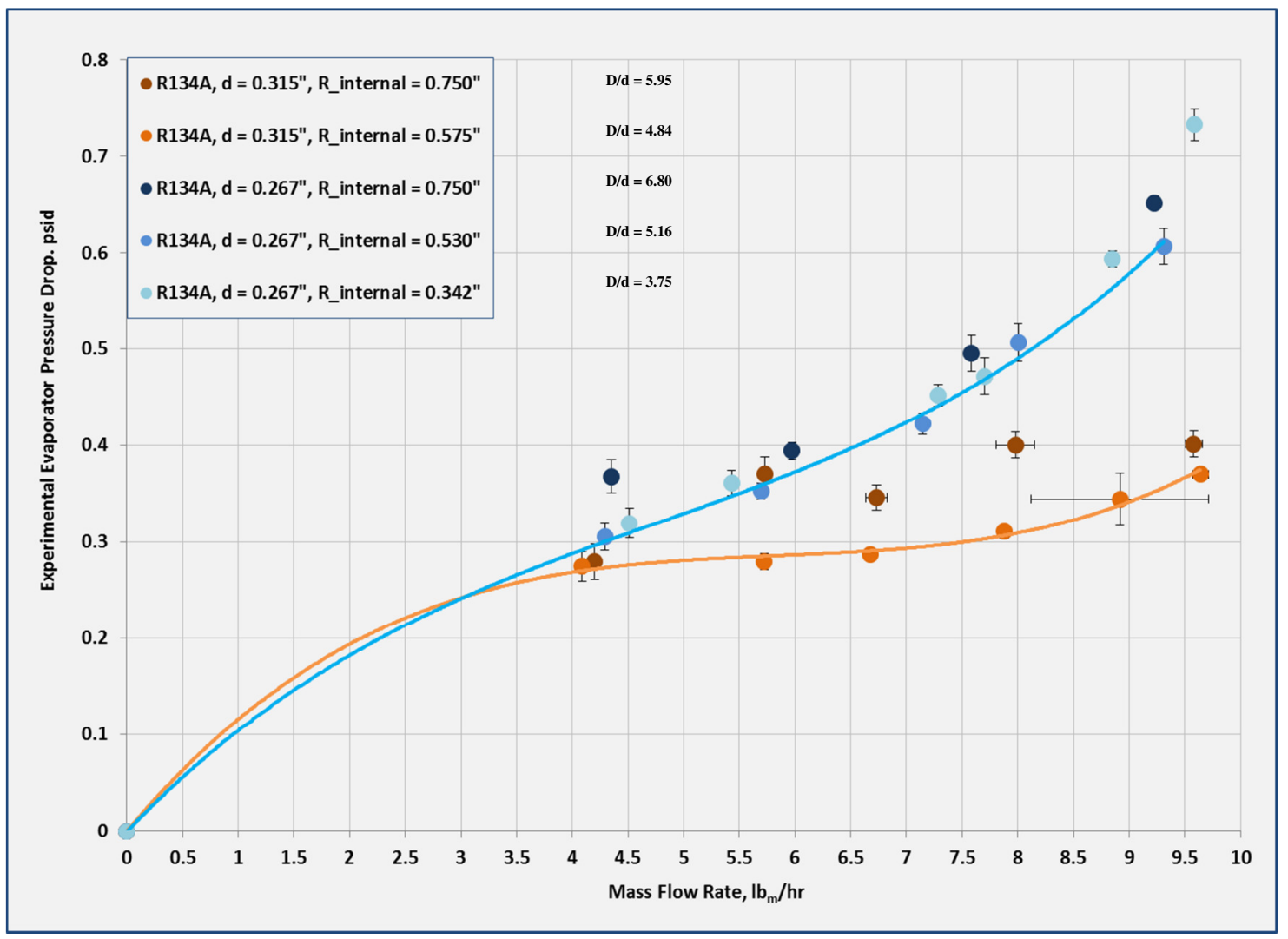

Figure 18: Vertical evaporator orientation study with 12 Vertical and 1 Horizontal U-bends per data sets 9-13 from Table 5 (see Figure 11 for photos of installation)

\section{Horizontal orientation and double $U$-bends study}

Figure 19 represents the data for horizontal orientation of the evaporators in the $13 \mathrm{U}$ bend and 26 U-bend configurations. The data corresponds to data sets 14 to 17 in Table 5 .

In the horizontal orientation of the U-bends the total pressure drop appears to be only slightly dependent on the number of the U-bends: the trendlines of the data points for 13 and 26 horizontal U-bends for the evaporators of very similar length are almost coincident. It appears that at low flows under $9.5 \mathrm{lb}_{\mathrm{m}} / \mathrm{hr}$ for $\mathrm{R} 134 \mathrm{~A}$ and $7 \mathrm{lb} / \mathrm{hr}$ for R600A horizontal evaporators with U-bend radii at least as low as 0.5 inches have two- 
phase pressure drop that is independent of the number of the U-bends and could be treated as straight continuous horizontal tubes. For that reason all three correlations, including simple Müller-Steinhagen \& Heck (1986) and Grönnerud (1979), can easily be compared to this data without violating the applicability of these correlations.

Furthermore, the close overlay of the two curves, the one with 13 U-bends and the one with 26 U-bends, for each of the refrigerants is evidence of the repeatability of the test process adopted for this research. Two different evaporators were used to collect this data and their manufacturing and installation, as well as test conditions had a high accuracy and repeatability based on these results.

Thus, out of three components of the two-phase total pressure drop discussed in Section 2.2, the static portion $\Delta P_{\text {static }}$ (equations (2) - (3)), is zero, momentum portion $\Delta P_{\text {momentum }}$ (equation (4)), can be simplified to equation (30) below, since vapor quality $x$, at the outlet is one or very close to one.

$$
\Delta P_{\text {momentum }}=G^{2}\left\{\left[\frac{1}{\rho_{V} \varepsilon}\right]_{\text {out }}-\left[\frac{(1-x)^{2}}{\rho_{L}(1-\varepsilon)}+\frac{x^{2}}{\rho_{V} \varepsilon}\right]_{\text {in }}\right\}
$$




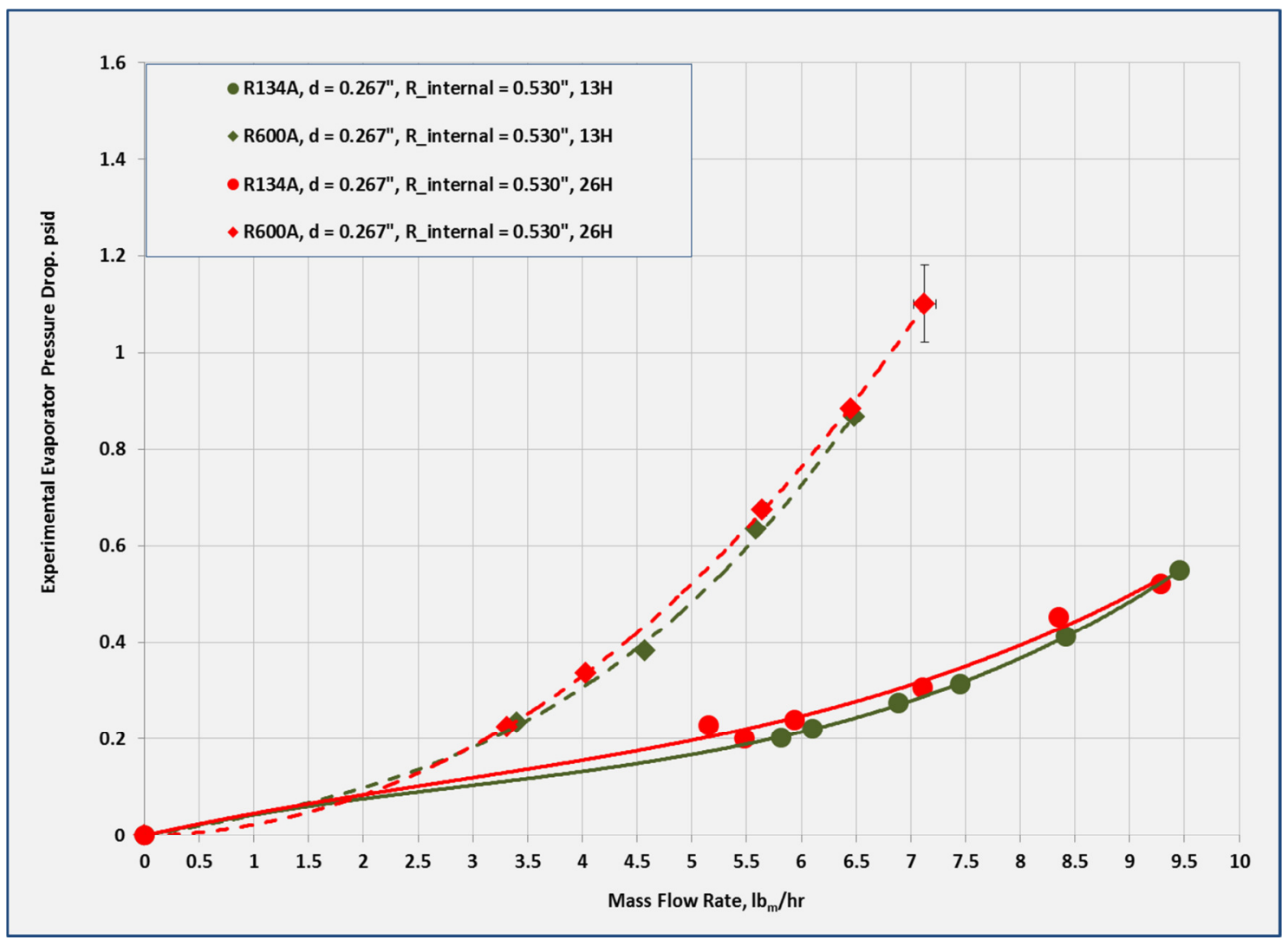

Figure 19: Horizontal evaporator orientation study with 13 Horizontal U-bends per data sets 14-15 and Double U-bend horizontal evaporator study with 26 Horizontal U-bends per data sets 16-17 in Table 5 (See Figure 12 and 13 for photos of installation)

Since this data set can be simplified to just a straight horizontal evaporator, the total pressure drop will be calculated based only on the state of inlet and outlet points of the samples without piecewise approach used for more complex geometries of data sets 1-13 from Table 5 .

Another simplifying assumption that is made based on this data is that a single horizontal U-bend present in the geometry of the vertical evaporators at low flows can be treated as a part of the straight horizontal tube. 


\section{ANALYSIS}

For all implemented models in this analysis section the range of operational quality was divided into $10^{-4}$-size steps. The assumption has been made that quality along the length of the evaporator changes linearly. At each step the properties of the single-phases, such as viscosity and density, where calculated based on the predicted new pressure in the evaporator found by continuous subtraction of the calculated pressure drop value from the initial measured inlet pressure. Since the evaporator outlet refrigerant properties where controlled using superheat value of $5^{\circ} \mathrm{F}$ due to fixture limitations (actual household refrigerator normally operated at evaporator superheat of nearly zero), another assumption was made that the quality becomes equal to one ten inches before the end of the evaporator; after that the vapor becomes superheated and single-phase vapor pressure drop equations apply.

\subsection{Horizontal orientation and double U-bends study (Data sets 14-17)}

Since Müller-Steinhagen \& Heck (1986, MS\&H further), and Grönnerud (1979), can be compared to data collected in horizontal orientations without violating the applicability of these correlations, data shown in Figure 19 will be analyzed first. As was mentioned 
before, 13 horizontal U-bend study and 26 horizontal U-bend study depicted in Figure 19 show very similar results for respective refrigerants, and the conclusion has been made that at low flows under $7 \mathrm{lb} / \mathrm{hr}$ for R600A and under $9.5 \mathrm{lb} / \mathrm{hr}$ for R134A, the evaporator behaves similarly to horizontal straight evaporator of equivalent length.

Furthermore, since horizontal orientation evaporator study (data sets 14-17) is the simplest to analyze due to absence of vertical flow, it will also be used to understand the contributions of momentum pressure drop and refrigerant property changes during the drop in pressure along the tube to the total predicted value.

For this data set total two-phase pressure drop is a function of momentum and frictional components; static pressure drop is equal to zero since all samples are oriented in horizontal plane (eq. 32).

$$
\Delta P_{\text {measured }}=\Delta P_{\text {momentum }}+\Delta P_{\text {frictional }}
$$

Figures 20 and 21 show calculated values of momentum pressure drop, $\Delta P_{\text {momentum }}$, portion of the total predicted value calculated using both, MS\&H (1986) and Grönnerud (1979) correlations.

From Figures 20 and 21, momentum pressure drop due to change in kinetic energy during evaporation and/or flashing is a small part of the total predicted pressure drop, which, however, can lead to under-predicting by as much as $3.4 \%$ using MS\&H (1986) correlation and $4.4 \%$ using Grönnerud (1979) for these flows if not included as a part of calculations. 
This possible under-prediction was calculated using equation (33):

$$
E_{\text {momentum }}=\frac{-\Delta P_{\text {momentum }}}{\Delta P_{\text {total_frictional }}+\Delta P_{\text {momentum }}} 100 \%
$$

The negative sign is used to show that the total predicted pressure drop is decreased by calculated percentage of total value if momentum pressure drop is not accounted for.

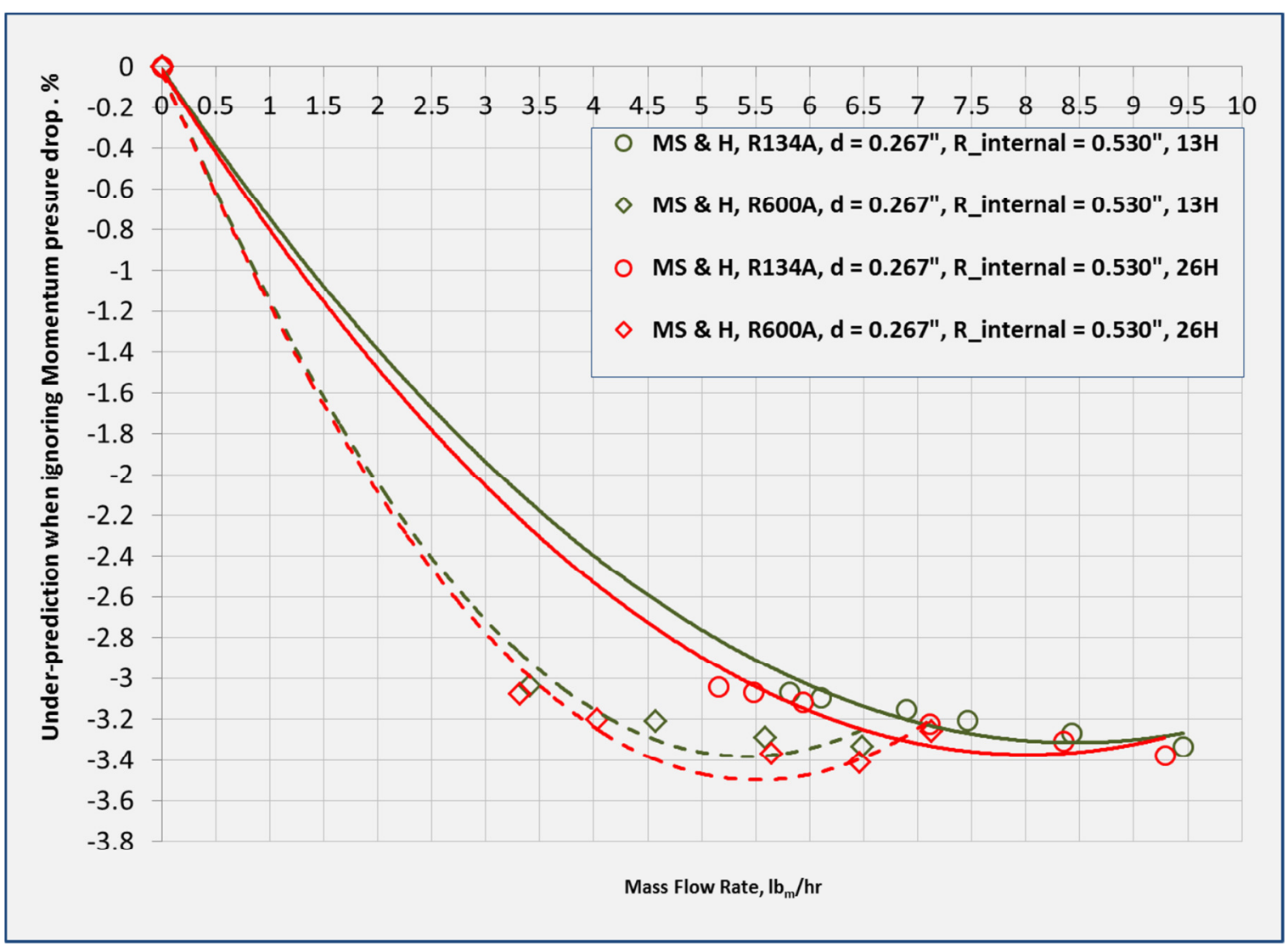

Figure 20: Under-prediction of the total pressure drop as the result of ignoring momentum pressure drop contribution while using MS\&H correlation for Data sets 14-17: Horizontal orientation study. 


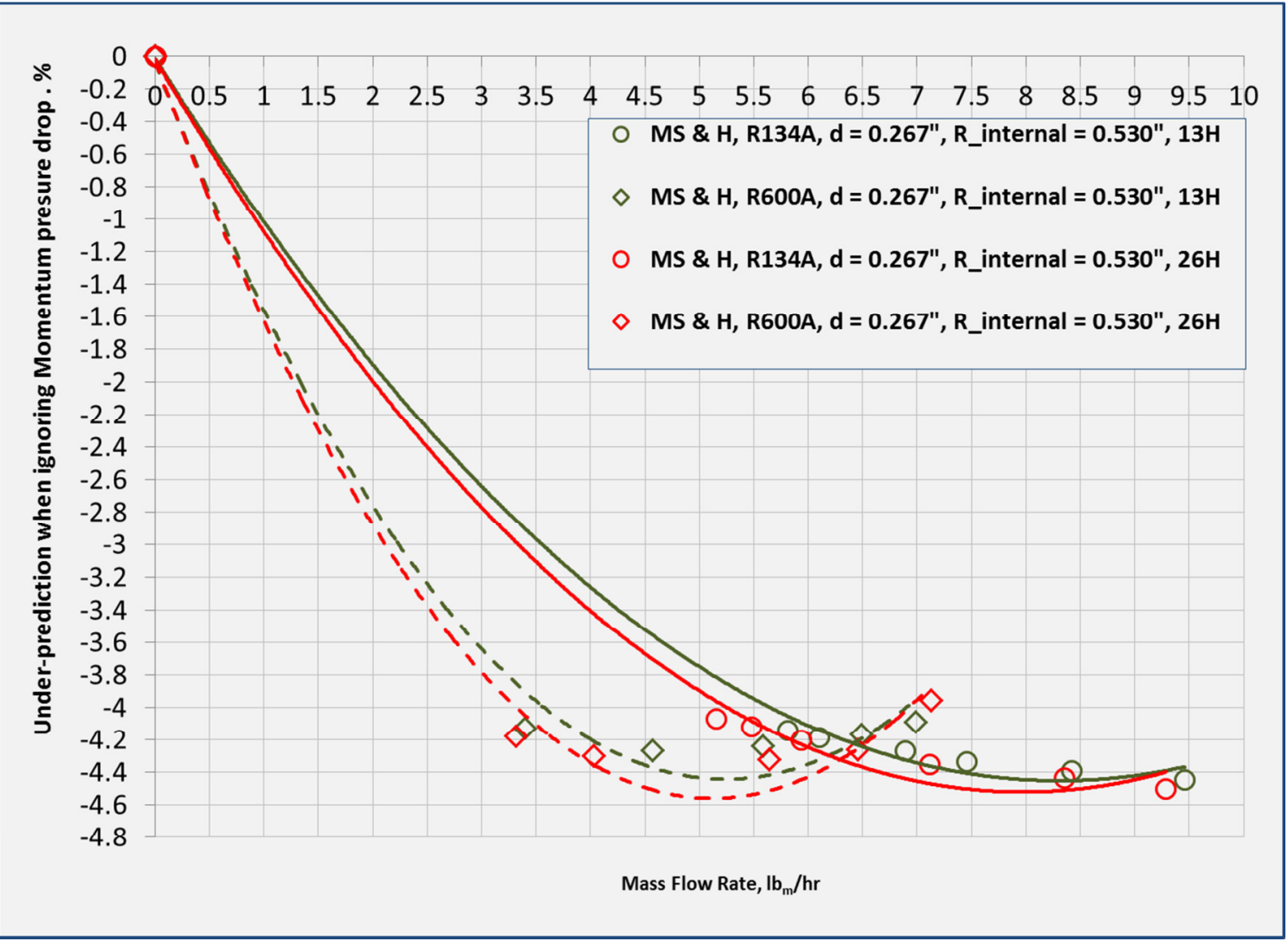

Figure 21:Under-prediction of the total pressure drop as the result of ignoring momentum pressure drop contribution while using Grönnerud correlation for Data sets 14-17: Horizontal orientation study.

From Figures 20 and 21 it is important to note, that momentum pressure drop contribution is similar for data collected using the same refrigerants and slightly increases with increasing mass flux of the refrigerant flow.

Figures 22 and 23 represent possible under-predicting of the total two-phase pressure drop when changes in refrigerant properties are not accounted for with decreasing pressure through the evaporator tube. Several research studies were previously conducted on refrigerant two-phase pressure drop in evaporators that did not include the fact that the properties of singe-phase liquid and vapor change along the length of the evaporator due to a decrease in pressure and related increase in temperature. Thus, if total pressure drop 
was calculated based on properties at the inlet of the evaporator, a possible underprediction could reach $6 \%$ for these low flows and is expected to increase further at higher flows (see Figure 21).

This possible under-prediction was calculated using equation (34):

$$
E_{\text {momentum }}=\frac{\Delta P_{\text {total_frictional_NIPC }}-\Delta P_{\text {total_frictional_IPC }}}{\Delta P_{\text {total_frictional_IPC }}} 100 \%
$$

(Where NIPC stands for Not Including Property Changes and IPC stand for Including Property Changes)

Thus, if single phase property changes along the tube are accounted for in prediction of two-phase pressure drop using MS\&H (1986), the total predicted value will be higher by as much as $6 \%$ for R600A and $2 \%$ for R134A (Figure 22) with MS\&H (1986) correlation and as much as $4.75 \%$ for R600A and $1.5 \%$ for R134A (Figure 23) with Grönnerud (1979) correlation. 


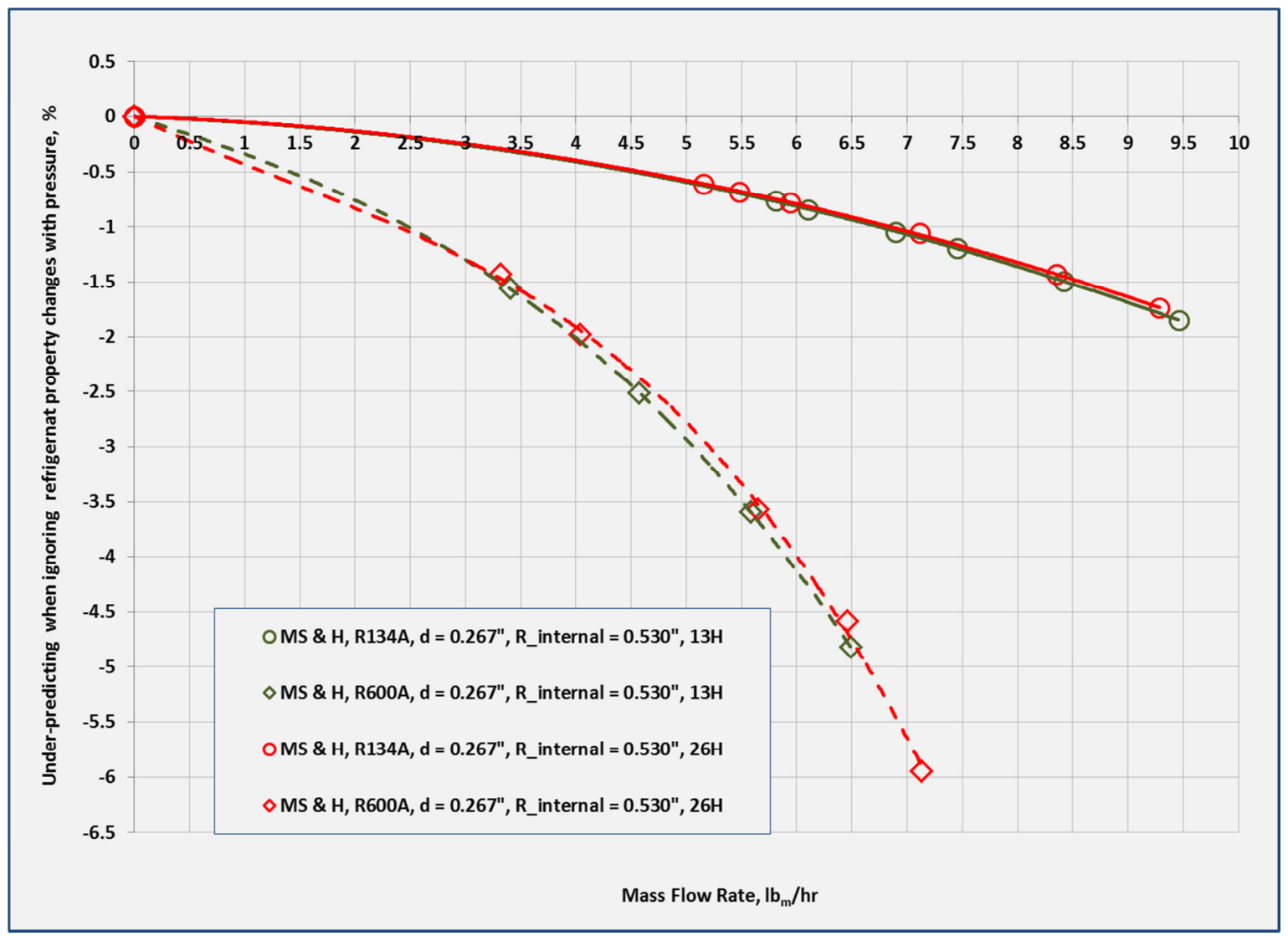

Figure 22: Under-prediction of the total pressure drop as the result of ignoring refrigerant property changes with decrease of pressure along the tube while using MS\&H correlation for Data sets 14-17: Horizontal orientation study. 


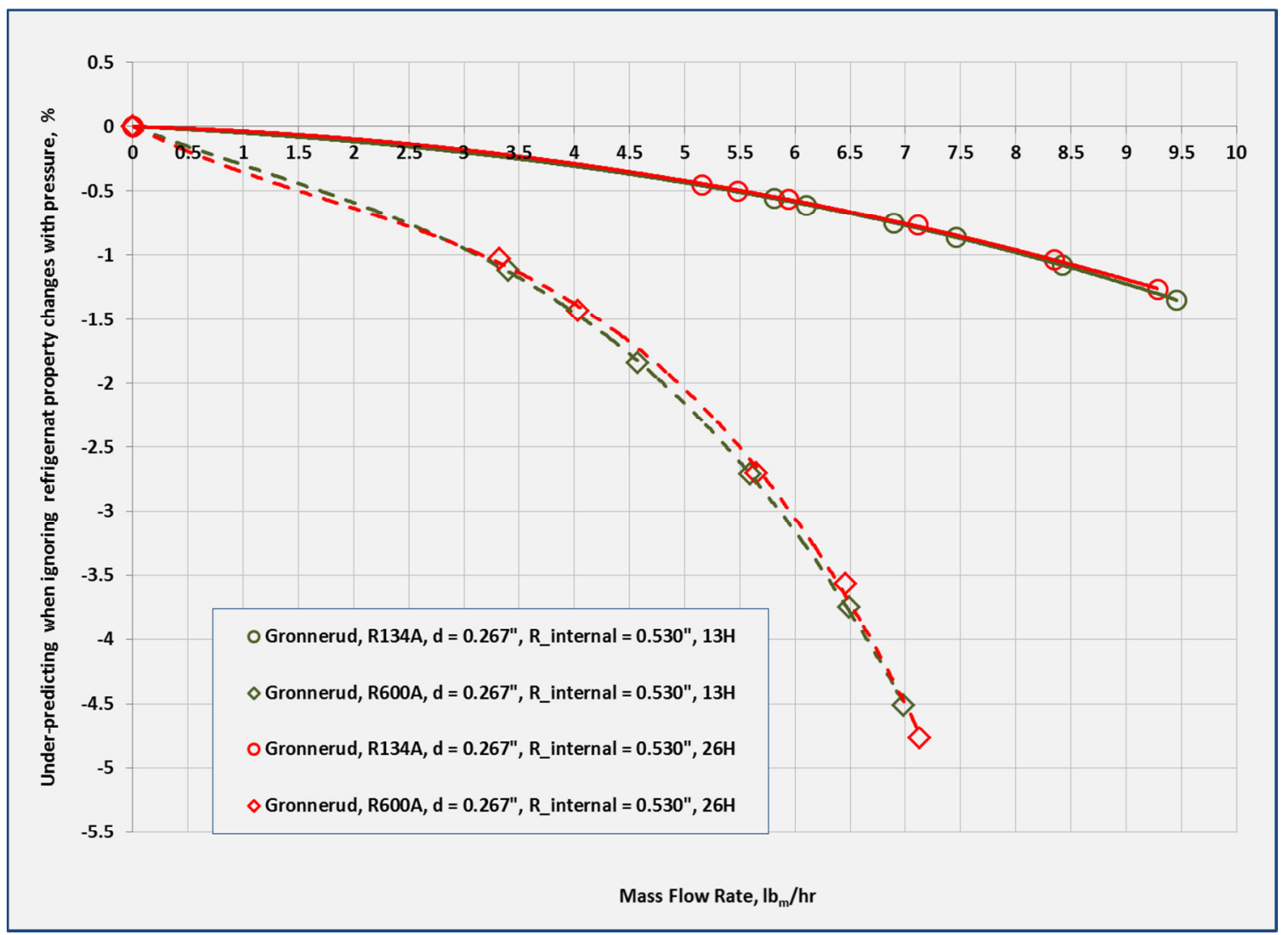

Figure 23:Under-prediction of the total pressure drop as the result of ignoring refrigerant property changes with decrease of pressure along the tube while using Grönnerud (1979) correlation for Data sets 14-17: Horizontal orientation study.

It is also important to note, that property change contribution to total pressure drop prediction for R600A and R134A are similar for both evaporator samples (data sets 14-15 with 13 horizontal U-bends and data sets 16-17 with 26 horizontal U-bends from Table 5). However, for R600A the contribution of refrigerant properties is much larger. This effect was investigated by calculating the changes in four properties for both refrigerants: vapor and liquid density and vapor and liquid viscosity. The total frictional pressure drops predicted using MS\&H (1986) and Grönnerud (1979) are functions of all of these properties and their gradients in the particular range of pressures have a direct effect on the total prediction by the correlation. Table 10 below shows how the property gradients 
differ between the pressures of 14.8 and 16 psi that occur in the evaporator along its length.

Table 10: Property gradients in operating pressure range (16 to 14.8 psi) along evaporator

\begin{tabular}{|l|l|l|}
\hline Property gradient $=$ Property $(\mathrm{P}=16 \mathrm{psi}) /$ Property $(\mathrm{P}=14.8 \mathrm{psi})$ & $\mathrm{R} 134 \mathrm{~A}$ & $\mathrm{R} 600 \mathrm{~A}$ \\
\hline Vapor Density & 1.0763 & 1.0755 \\
\hline Liquid Density & 0.9962 & 0.9962 \\
\hline Vapor Viscosity & 1.0064 & 1.0074 \\
\hline Liquid Viscosity & 0.9757 & 0.9763 \\
\hline
\end{tabular}

\section{Total Müller-Steinhagen \& Heck (1986) pressure drop}

A total pressure drop prediction using MS\&H (1986) model is shown using Figures 24 and 25. Figure 25 represents the ratio of predicted to measured total two-phase pressure drop using this simple correlation.

The slope of the pressure drop increase with increased mass flow rate is predicted well, but over-predicted by 10-40\% for both refrigerants (Figure 25). 


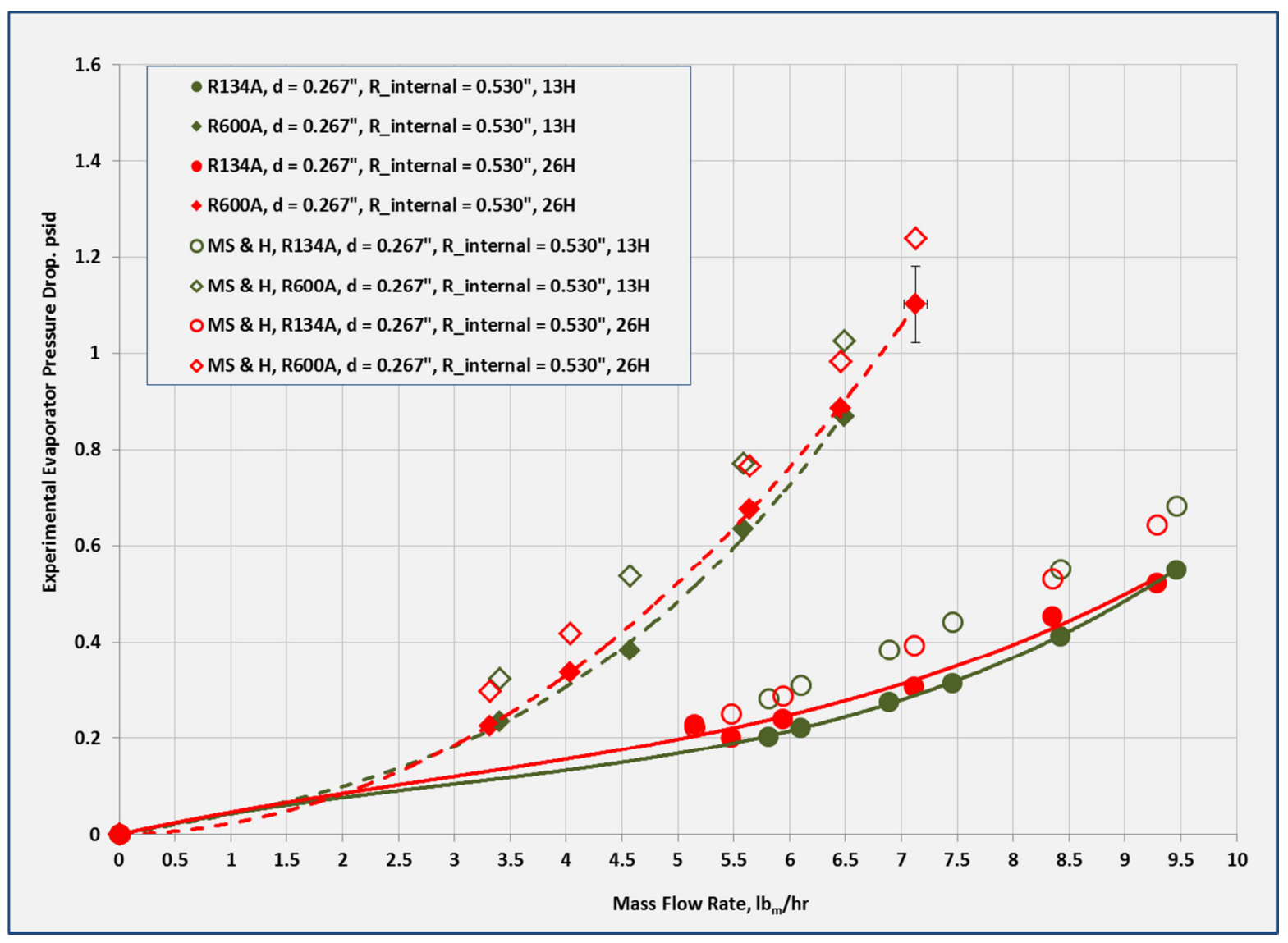

Figure 24: Experimental two-phase refrigerant pressure drop and prediction using MS\&H (1986) correlation for Data sets 14-17: Horizontal orientation study. 


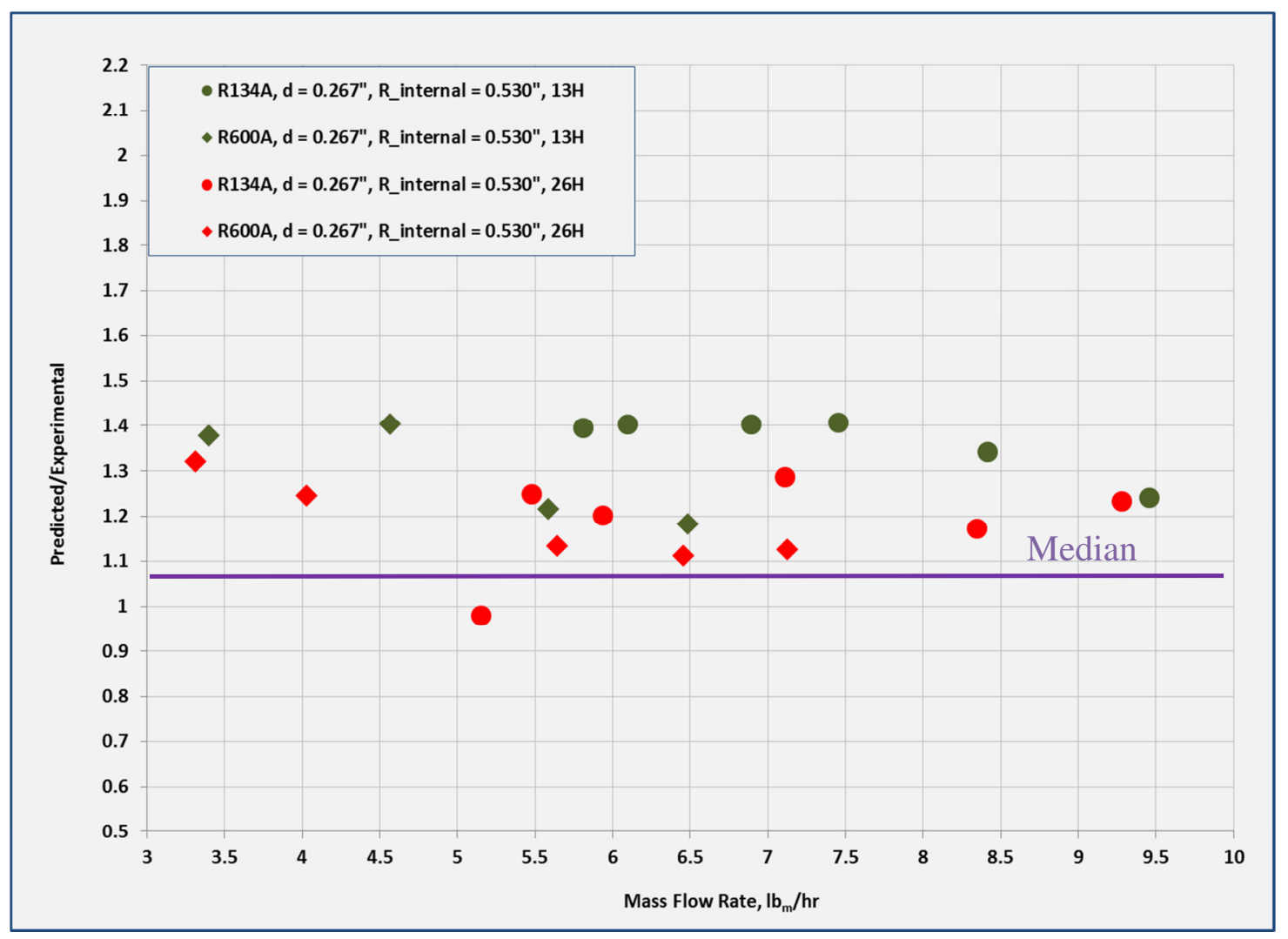

Figure 25: Ratio of predicted two-phase refrigerant pressure drop using MS\&H (1986) correlation to experimental data for Data sets 14-17: Horizontal orientation study.

MS\&H (1986) correlation could easily be adjusted for prediction of two-phase frictional pressure drop in this range of low flows and its performance can be improved significantly and independently of the type of refrigerant (R134A or R600A) since the total error for both refrigerants is similar. Since the error for all data points in this set appears to be independent of the mass flow rate, an addition of a multiplier to the MS\&H frictional pressure drop, $\Delta P_{\text {frictional }}$, will reduce the error by approximately half.

However, it is important to note, that the following update to MS\&H (1986) correlation should be applied only to the evaporator configurations in horizontal orientations and with flows ranging from 3 to $9.5 \mathrm{lb} / \mathrm{hr}$ and inlet saturation temperatures close to $-11^{\circ} \mathrm{F}$. 
Considering that data sets 16 and 17 showed the insignificance of the horizontal U-bend number in the design, all horizontal configurations of evaporators with similar geometries could potentially use equation (35):

$$
\left(\frac{d P}{d L}\right)_{f}=0.867 \cdot\left(K(1-x)^{\frac{1}{C}}+B 2 x^{C}\right)
$$

Equation (35) can be used instead of original equation (11) provided in Section 2.3.1.

It improves average error from $26 \%$ down to $11 \%$ with standard deviation of the error lowered from 11.3 to $9.8 \%$. See Figures 26 and 27 for comparison with 24 and 25 above.

Thus, Müller-Steinhagen \& Heck (1986) correlation can perform with reasonable accuracy for two-phase flows of R134A and R600A when it is slightly adjusted using a multiplier of 0.867 . 


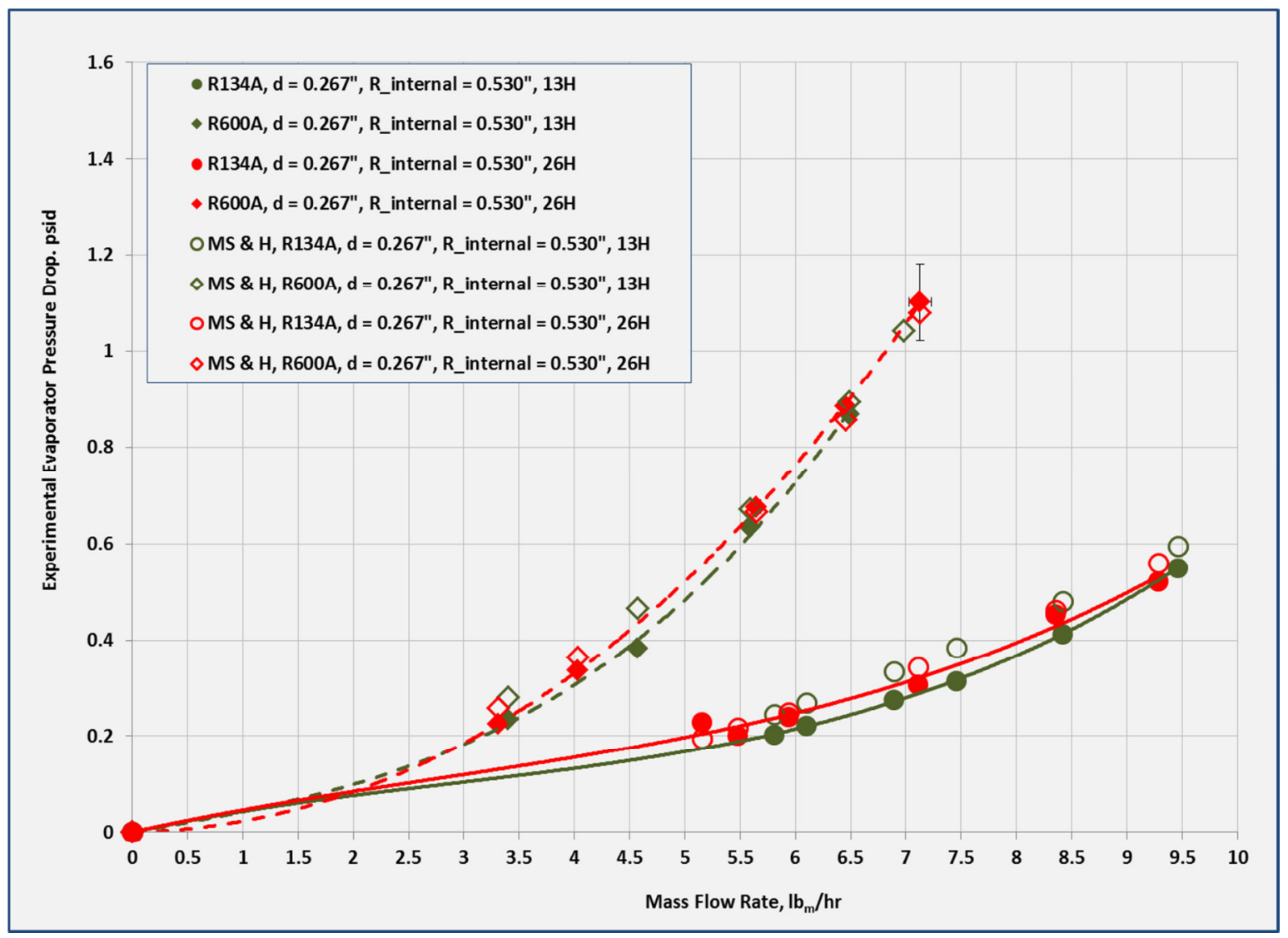

Figure 26: Experimental two-phase refrigerant pressure drop and prediction using Adjusted MS\&H (1986) correlation for Data sets 14-17: Horizontal orientation study. 


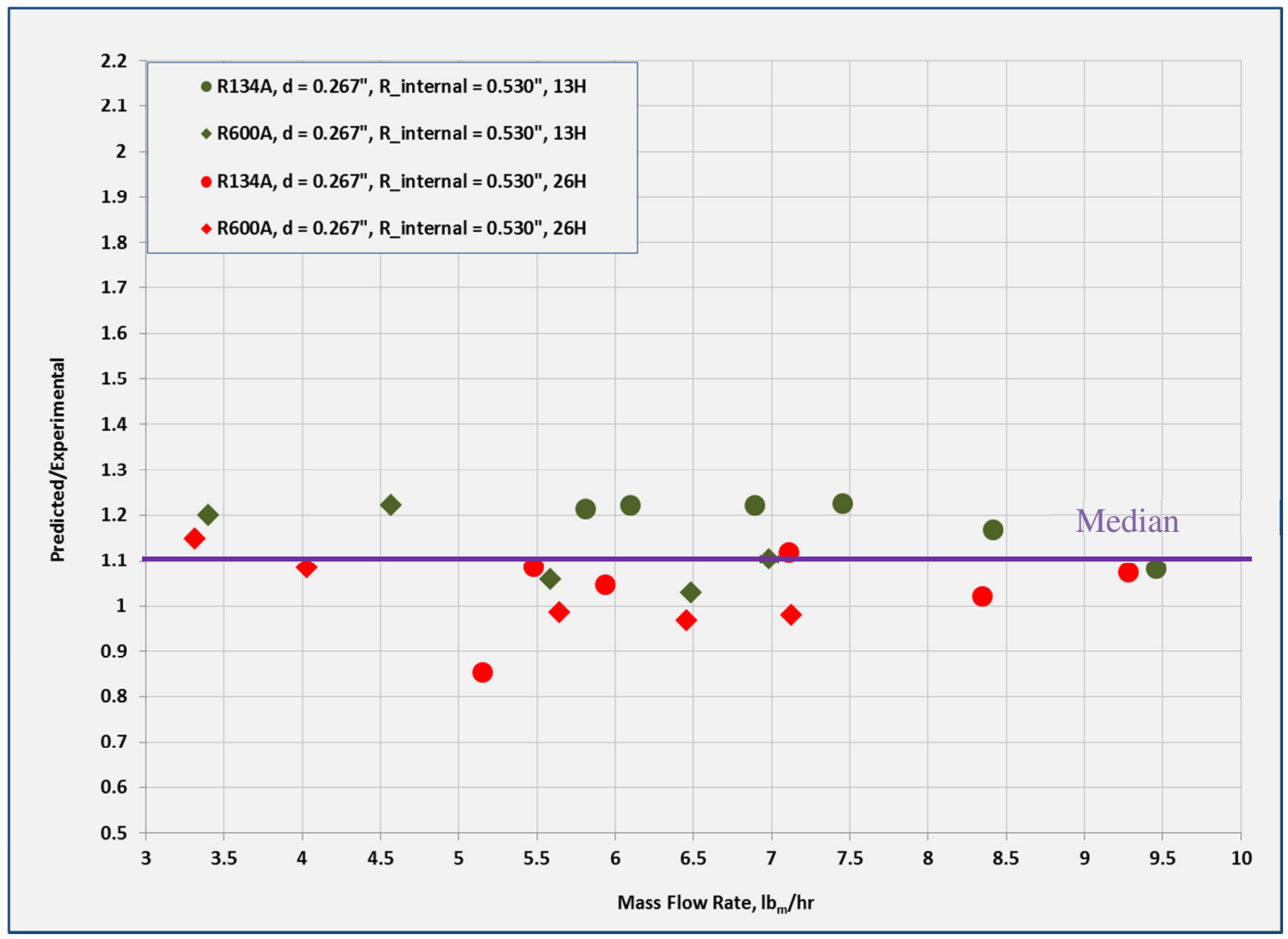

Figure 27: Ratio of predicted two-phase refrigerant pressure drop using Adjusted MS\&H (1986) correlation to experimental data for Data sets 14-17: Horizontal orientation study. 


\section{Total Grönnerud (1979) pressure drop}

A total pressure drop prediction using Grönnerud (1979) model is shown using Figures 28 and 29. It is evident that the original Grönnerud correlation performs rather well with average error of only $-4.4 \%$ and standard deviation of the error of $7.6 \%$. This correlation also appears to perform slightly less successfully with R600A refrigerant and has a higher dependence on the mass flow rate in comparison with MS\&H, (1986).

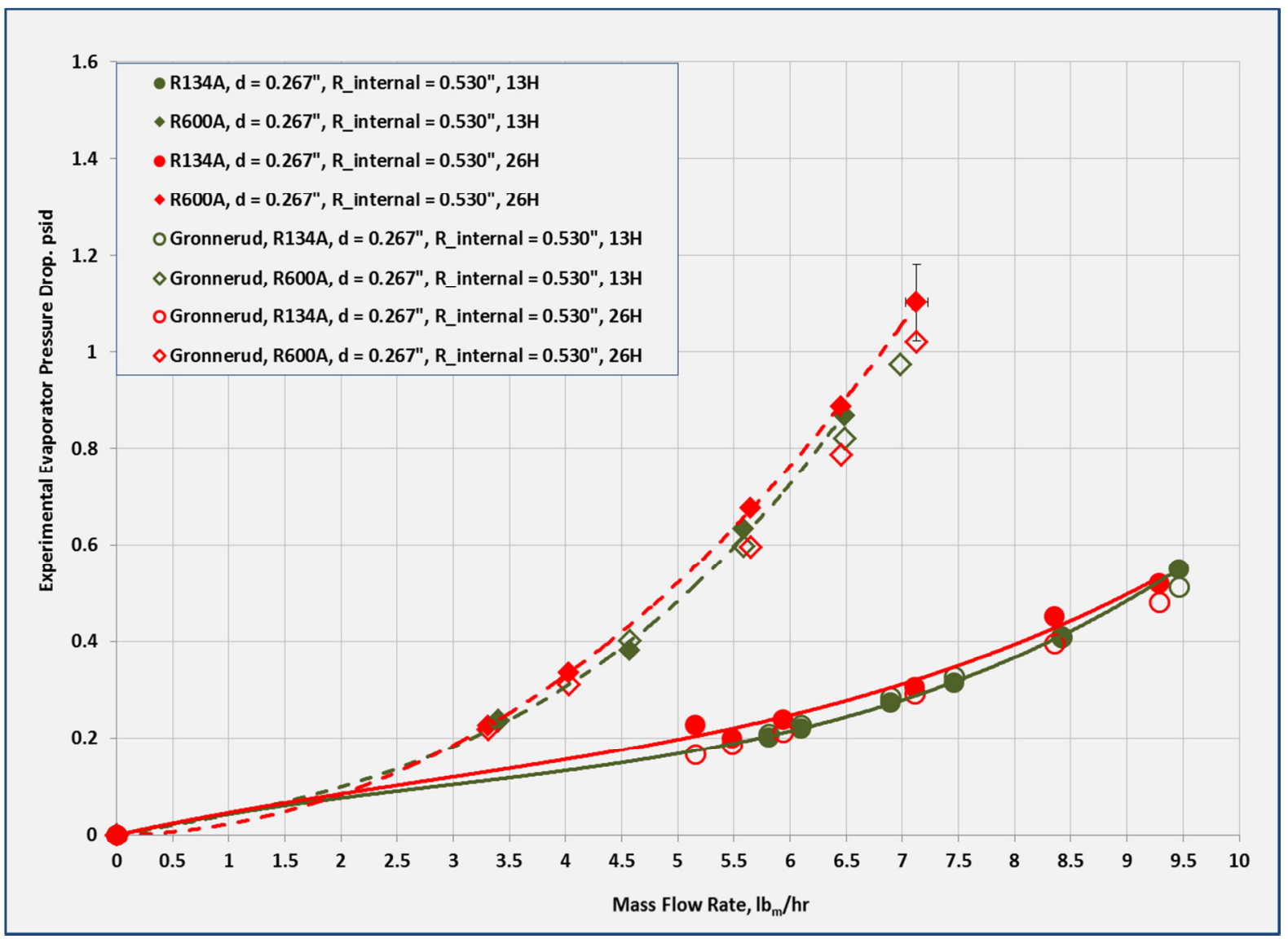

Figure 28: Experimental two-phase refrigerant pressure drop and prediction using Grönnerud (1979) correlation for Data sets 14-17: Horizontal orientation study. 


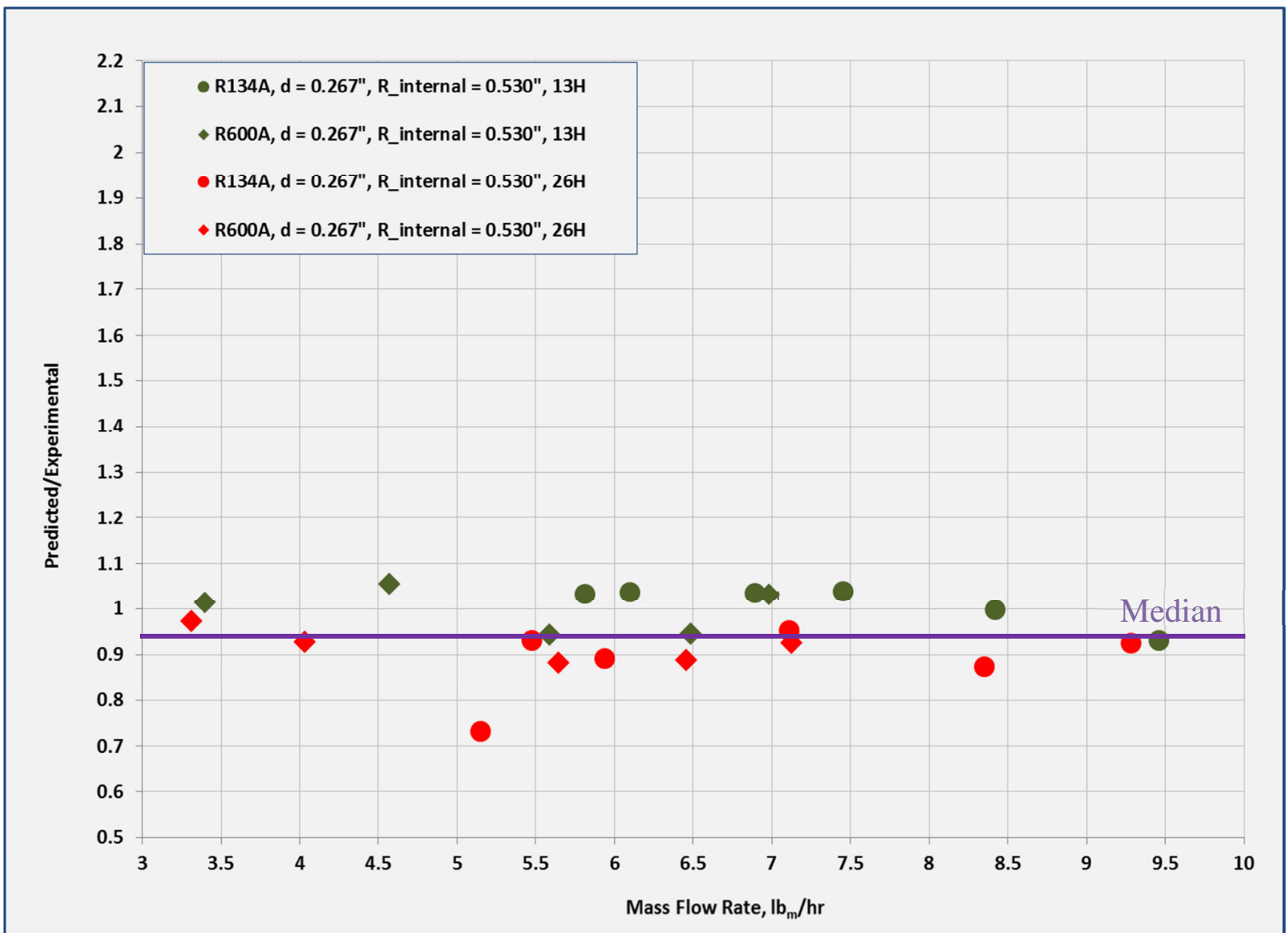

Figure 29: Ratio of predicted two-phase refrigerant pressure drop using Grönnerud (1979) correlation to experimental data for Data sets 14-17: Horizontal orientation study.

Since this correlation already works quite well, it does not need to be adjusted. 


\subsection{Vertical curvature ratio study (Data sets 9-13)}

Data sets 9-13 (Figure 18) add new complicating components to the total two-phase pressure drop prediction in comparison to previously discussed horizontal 13 and $26 \mathrm{U}$ bend orientation (data sets 14-17). Here, flow perturbation due to vertical U-bends and static pressure drop due to elevation equal to vertical U-bend diameter are expected to create additional pressure drop.

Experimental findings described by Silva Lima \& Thome (Silva Lima \& Thome, Part 1, 2012) suggested that there is an inverse relationship between the curvature ratio and pressure drop in vertically oriented U-bends. Their lowest measured mass flows, however, were three times higher than those tested for this study.

Thus, measured data shown in Figure 18 does not show a strong relationship between Ubend diameters, $\mathrm{D}$ (shown in terms of U-bend internal radius), or in terms of the curvature ratio, D/d, for three curvature ratios with $0.267^{\text {“ }}$ internal diameter tube. However, other two curves presented on Figure 18, for 0.315 " tube, did not show this same similarity between them; and, in contrary to Silva Lima \& Thome's findings, have a direct relationship with curvature ratio. This result is not only counterintuitive, but also does not follow physical trends studies previously by Silva Lima \& Thome (2012) and others, where the smaller U-bends diameters lead to higher pressure drop effects due to increased flow perturbation phenomenon. Thus, the data for 0.315 " internal diameter tube will be considered with extra care for any further correlation development or adjustments made in this paper. 
However, for 0.267 " internal tube diameter a lack of differentiation between the data with different curvature ratios leads to the conclusion that the effect of the flow perturbation due to vertical U-bends and the effect of static pressure drop with elevation changes do not have measurable sensitivity to curvature ratio as much as to internal tube diameter itself.

A total predicted pressure drop for vertical orientation with multiple vertical U-bends is calculated based on the equation (36).

$$
\begin{aligned}
\Delta P_{\text {measured }}= & \Delta P_{\text {static }}+\Delta P_{\text {momentum }} \\
& +\Delta P_{\text {frictional }(U-\text { bend and straight tube separately })}
\end{aligned}
$$

A frictional pressure drop, $\Delta P_{\text {frictional }}$, cannot be calculated only based on the straight tube correlations, such as MS\&H and Grönnerud even though previous section, horizontal orientation and double U-bends study (Data sets 14-17), showed that there is no significant dependence of total two-phase pressure drop on the horizontal U-bends for extremely low flows. However, it used to be a common practice in evaporator design to assume that the U-bend contribution is fully accounted for by the static pressure drop component alone and only recently, when two phase flow through U-bends began to be more studied and understood, it became more evident how important it is to include accurate pressure drop correlations across U-bends and not use straight tube correlations for the remainder of the evaporator geometry.

As a part of this chapter, a contribution from the static pressure drop will be studied in detail. Also the author will first apply straight tube correlations to the whole length of the 
vertically oriented evaporators (Data set 9-13) to understand how big the error would be when vertical U-bend perturbation effects are not accounted for in the prediction.

Static pressure drop components are based on equations (2) and (3) from section 2.1:

Down-flow: $\quad \Delta P_{\text {static }}=-g D\left(\varepsilon \rho_{V}+(1-\varepsilon) \rho_{L}\right)$

Up-flow:

$$
\Delta P_{\text {static }}=g D\left(\varepsilon \rho_{V}+(1-\varepsilon) \rho_{L}\right)
$$

Void fraction, $\varepsilon$, vapor density, $\rho_{V}$, and liquid density, $\rho_{L}$, for equations (2) and (3) will all be calculated at the center of the U-bends using constant quality gradient along the whole length of the tube and accounting for the pressure and temperature changes of the refrigerant along the length of the evaporator (see Figure 30)

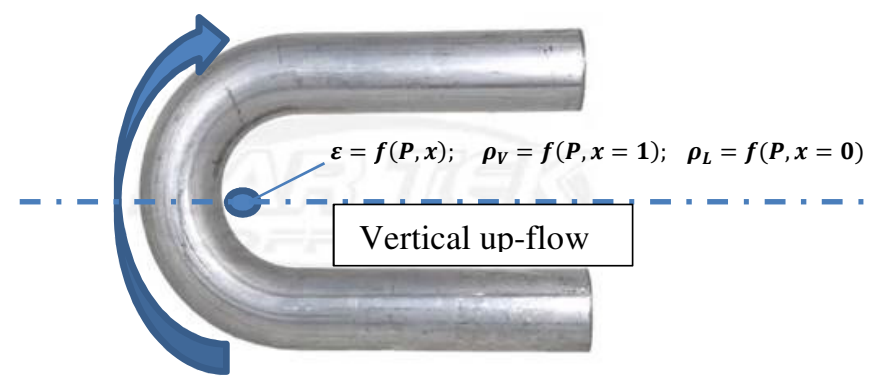

Figure 30: Location of property calculation for static pressure drop across a single vertical U-bend

Each data set numbered 9-13 in Table 5 has six vertical up-flow U-bends followed by a single horizontal U-bend at the top of the evaporator followed by six vertical down-flow U-bends at the second half of the evaporator. Figure 31 shows the calculated contribution of the static pressure drop from each of 12 vertical U-bends at respective quality along the 0.267 " internal diameter tube and internal U-bend radius of 0.530 ". Only one of the mass flow rate points with static pressure drop values is shown in Figure 31 because it is 
not a function of the mass flow rate per equations (3) and (2).The first six static pressure drop contributions are positive due to the up-flow conditions and last six are negative due to down-flow conditions.

As was found by Silva Lima \& Thome (2012) the gravitational effect is higher for lower qualities due to increased refrigerant densities at lower vapor quality.

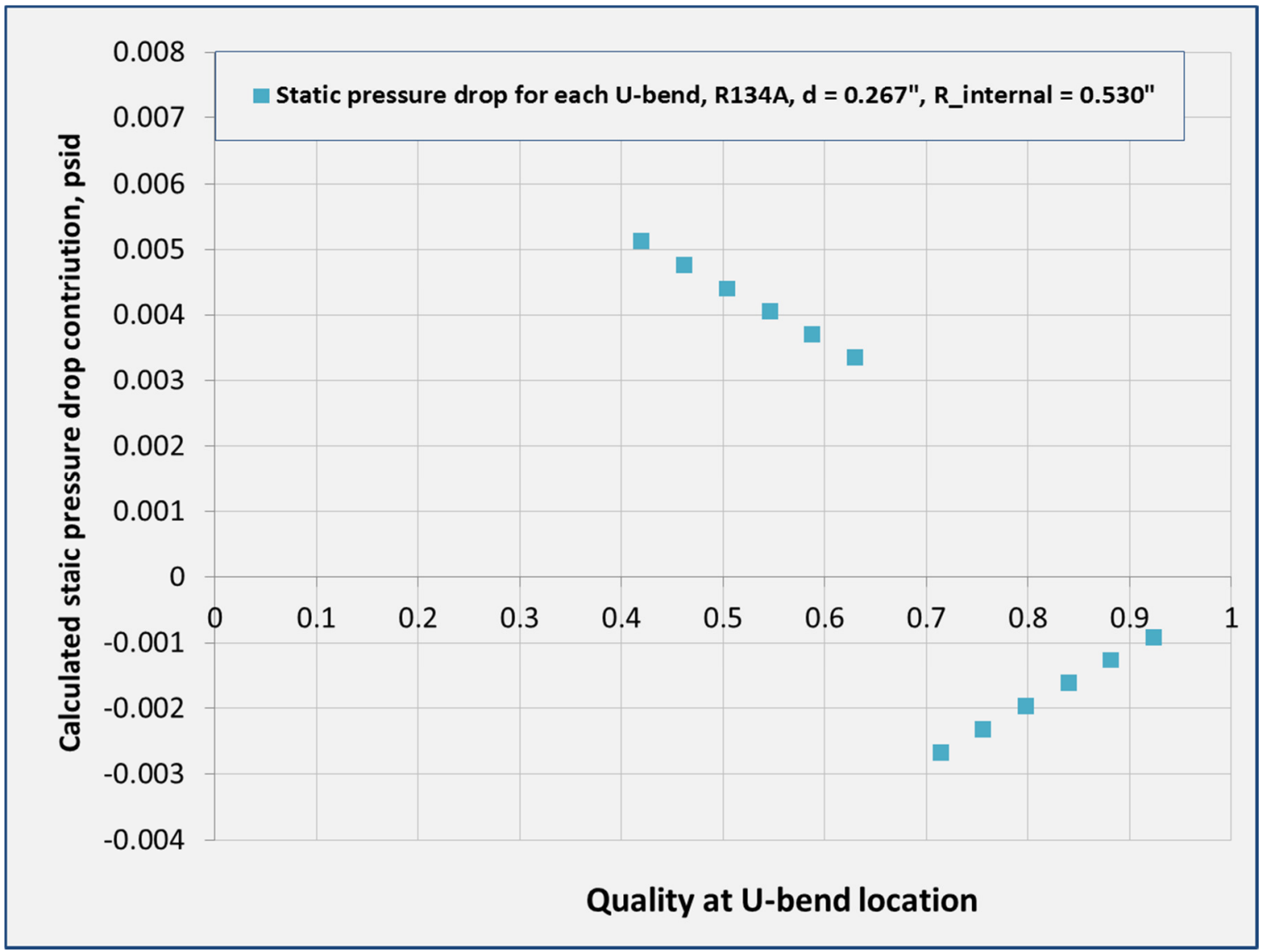

Figure 31: Calculated static pressure drop contribution for each of twelve vertical U-bends for 7.14 $\mathrm{lbm} / \mathrm{hr}$ mass flow rate with $\mathrm{R} 134 \mathrm{~A}, \mathrm{~d}=\mathbf{0 . 2 6 7 "}$ ", $\mathrm{R}$ _internal $=0.530^{\prime \prime}$ 
On Figure 32 a total contribution from all twelve vertical U-bends is shown for each of the Data sets 9 - 13. It is a very small contribution overall because half of all U-bends experience down-flow direction and, thus, have a negative contribution to the total. A sum of all individual U-bend static pressure drops is still over twenty times smaller than the total measured two-phase pressure drop through evaporator samples (Figure 32).

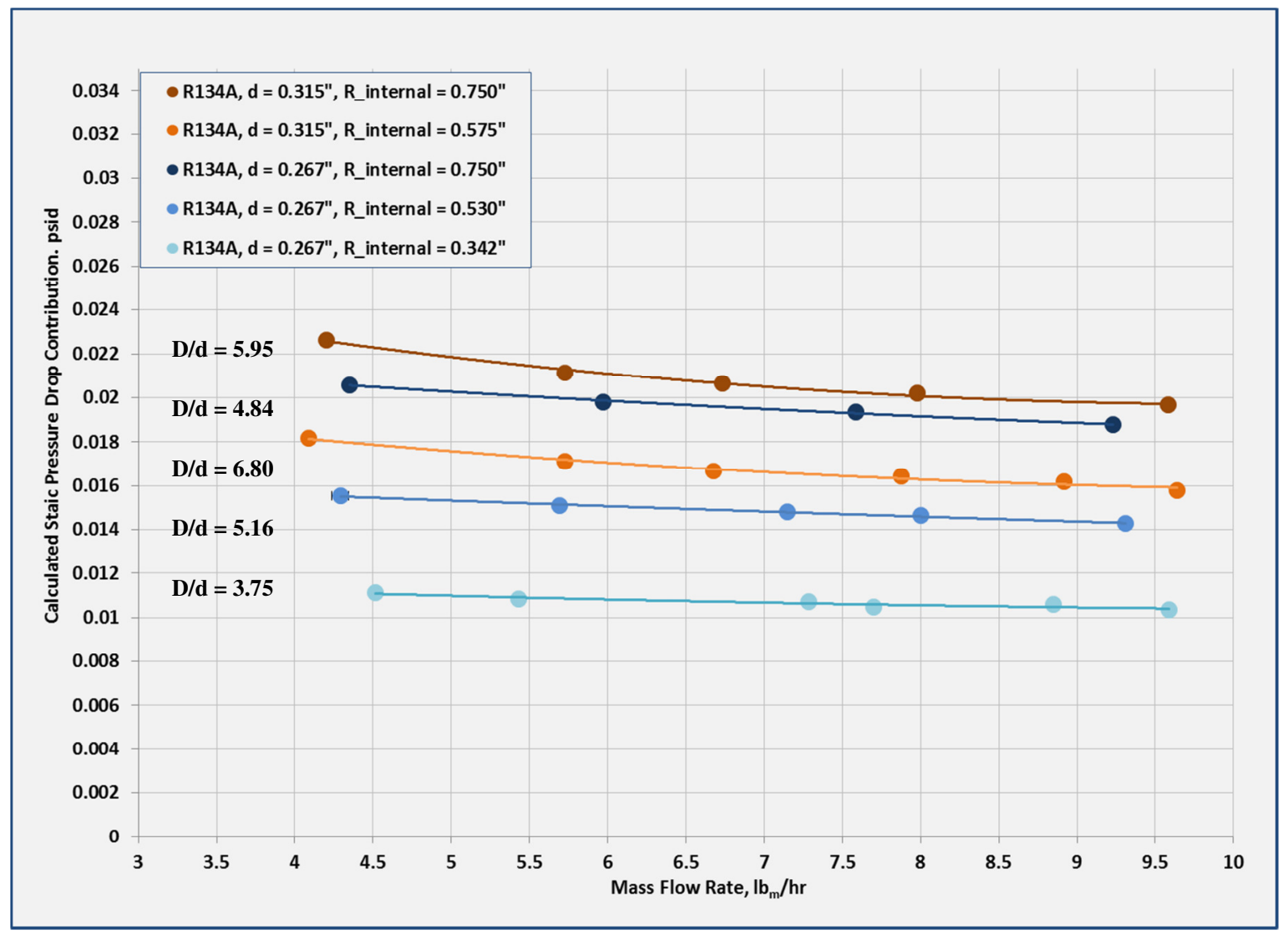

Figure 32: Calculated static pressure drop contribution to the total measured value for Data sets 913: Vertical Curvature Ratio Study.

Also from Figure 32 is can be noticed that even though very slightly, but the gravitational effects diminish at higher mass fluxes because the dependence of the total pressure drop 
from the mass flux is much higher than from the gravitational effects. This effect was originally described by Silva Lima \& Thome (2012) for their higher mass fluxes, where every portion of the total pressure drop has higher magnitude and gradient.

Next, Figures 33 and 34 show a simplified approach to predicting two-phase pressure drop for vertically oriented evaporators with multiple U-bends. And as mentioned before, this part of the analysis will not include the vertical U-bend flow perturbation effects contribution, but will include all other components as in equation (37):

$$
\begin{aligned}
\Delta P_{\text {measured }}= & \Delta P_{\text {static }}+\Delta P_{\text {momentum }} \\
& +\Delta P_{\text {frictional(straight tube along all length) }}
\end{aligned}
$$

Figure 33 represents performance of the adjusted MS\&H (1986) correlation (per equation (35)) and Figure 34 represents the performance of original Grönnerud (1979) correlation used for calculating $\Delta P_{\text {frictional(Straight tube along all length) }}$. 


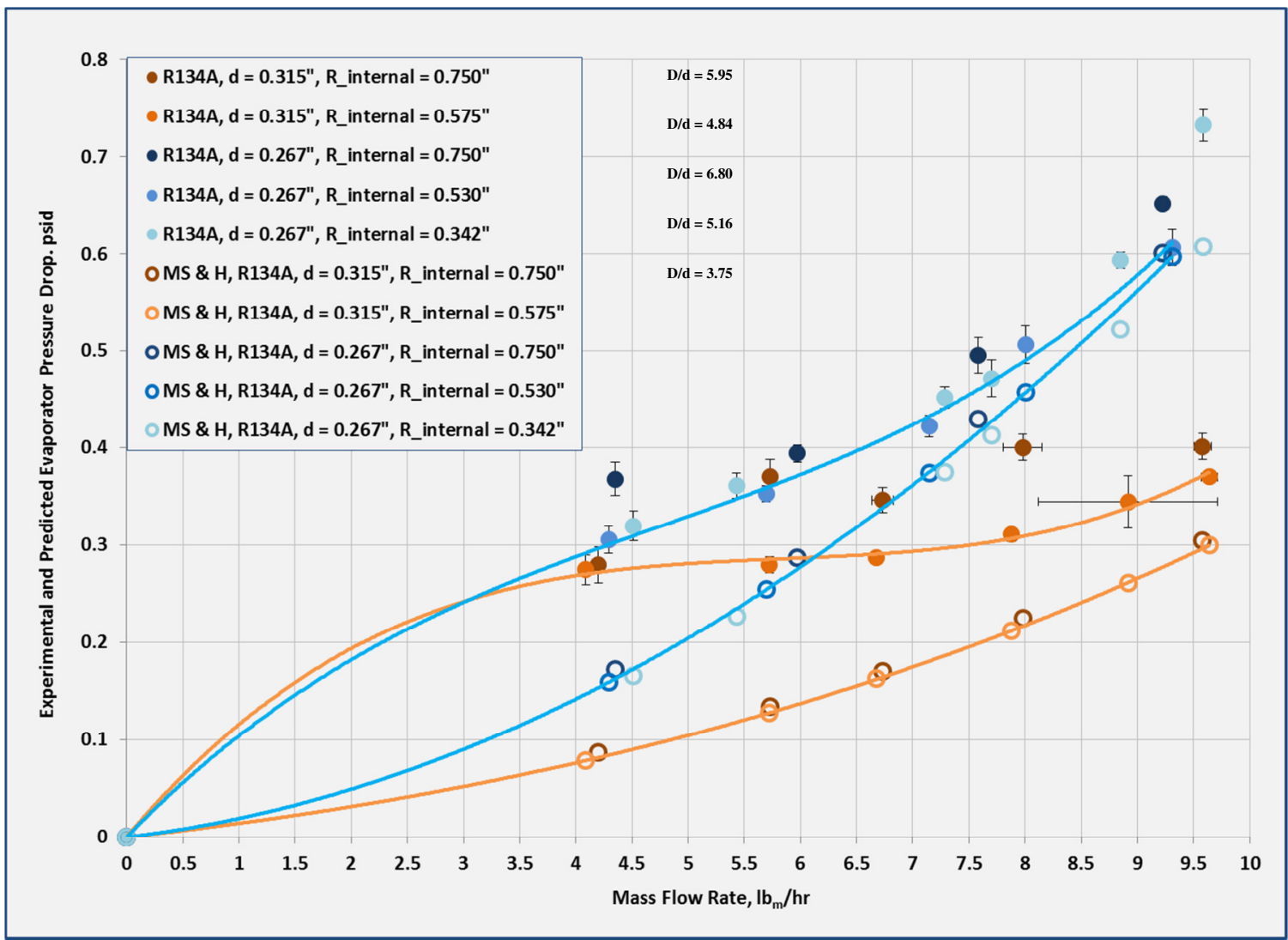

Figure 33: Experimental two-phase refrigerant pressure drop and prediction using MS\&H (1986) correlation for Data sets 9-13: Vertical Curvature Ratio Study. 


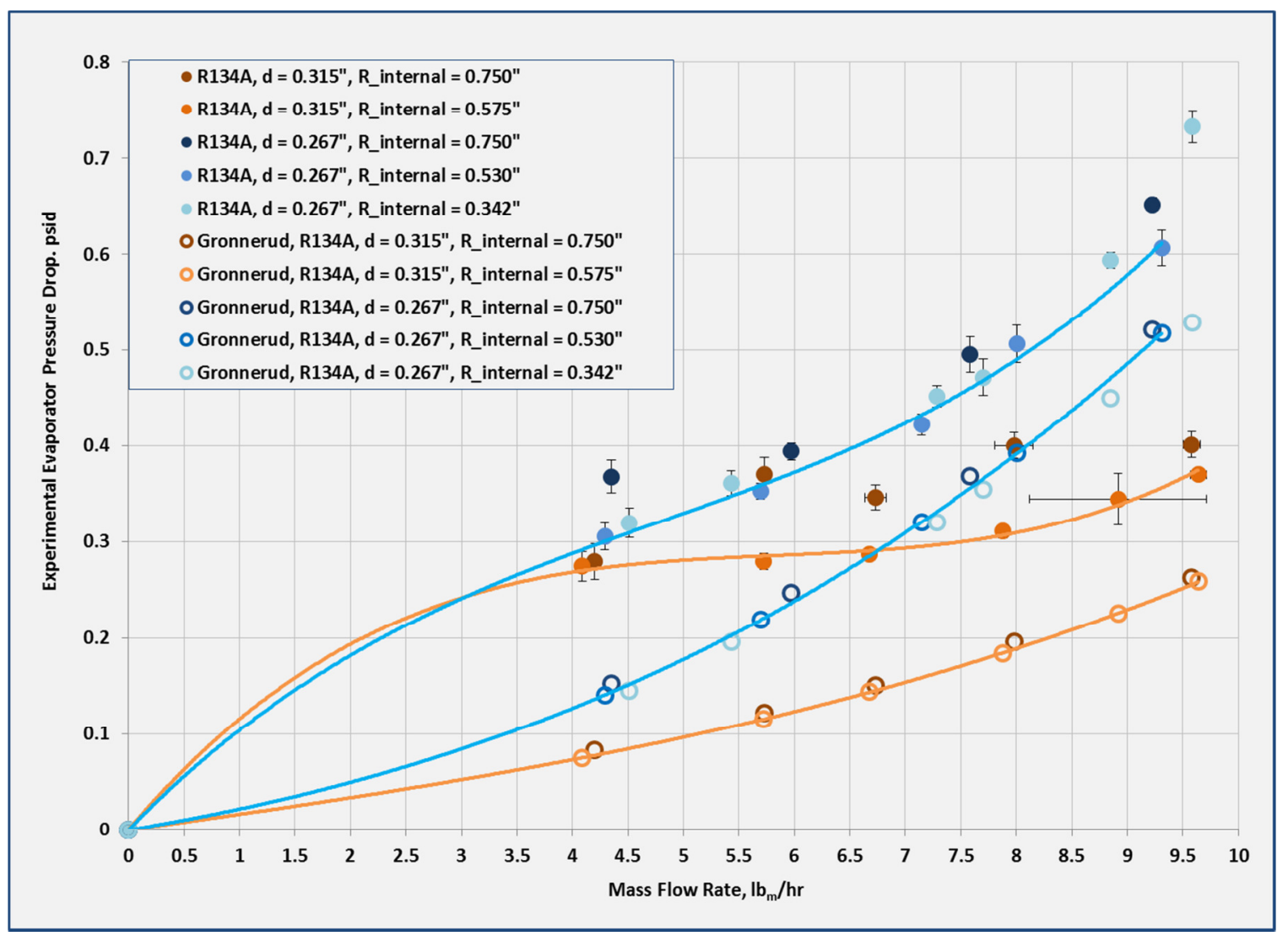

Figure 34: Experimental two-phase refrigerant pressure drop and prediction using Grönnerud (1979) correlation for Data sets 9-13: Vertical Curvature Ratio Study.

From Figures 33 and 34, it is evident that neither of straight tube correlations for frictional pressure drop can adequately predict the two phase pressure drop through the vertical U-bends with perturbation effects. Neither the slope nor the magnitude of any curve is represented accurately. However, the relative location of the curves for different internal tube diameters is representative of the measured data.

The main conclusion made from Figures 33 and 34 is that vertical U-bend regions of the evaporator tube should have a different correlation for predicting two-phase pressure drop, because if any simplified assumptions are made, such as assuming that frictional pressure drop along the whole tube in any geometry is adequately predicted by the 
straight tube models, a risk of under-predicting total pressure drop by as high as $60 \%$ is possible. For a household refrigerator sealed system design this could result in undersizing and underperforming of the design with further consequences in lower efficiency and higher energy usage by the refrigerator.

Thus, the next step in this chapter is to include a U-bend frictional pressure drop correlation by Silva Lima \& Tome (2012) in the total prediction per equation (36). 


\subsection{Wojtan (2005) Flow Pattern Map}

Wojtan flow pattern map facilitates the observation of flow pattern transitions at fixed mass velocities with increasing vapor quality along straight evaporator tubes. It is a function of several geometrical properties calculated using equations (B1) - (B6) in Appendix B, where equation (B1) represents the void fraction as a function of the mass flux (or mass velocity) in $\mathrm{kg} / \mathrm{m}^{2} \mathrm{~s}$. Wojtan et al. (2005) used several previous iterations of this flow pattern models built for multiple refrigerants as well as actual measured values for the void fraction along the tube. The authors of Wojtan flow pattern map have used a mass flux dependent correlation for void fraction in order to simplify and modulate their flow map and flow boiling heat transfer models. However, its dependence on the mass flux influences the location of the transition curves at low qualities. This influence is a disadvantage of the Wojtan flow pattern model, which otherwise is extremely advantageous to use due to it being simple and non-iterative.

For nearly a hundred data points taken for this study, the range of mass fluxes used is shown in Table 11. These mass flux ranges are fully representative of those currently used in the household refrigeration sealed systems.

Table 11: Mass Flux ranges for all experimental data

\begin{tabular}{|l|l|l|}
\hline Experimental Mass Flux, $\mathbf{k g} / \mathbf{m}^{\mathbf{2}} \mathbf{s}$ & R134A data & R600A data \\
\hline Maximum & 67.8 & 35.4 \\
\hline Minimum & 10.2 & 3.8 \\
\hline Average & 26.7 & 16.4 \\
\hline
\end{tabular}


The following Figures 35 - 36 and 37 - 38 show Wojtan flow pattern maps calculated and plotted for R134A and R600A refrigerants respectively. All maps are created based on three rounded mass fluxes per Table 11: 70, 30 and $10 \mathrm{~kg} / \mathrm{m}^{2} \mathrm{~s}$ for R134A and 35, 15 and $5 \mathrm{~kg} / \mathrm{m}^{2} \mathrm{~s}$ for R134A (these ranges allow understanding how the location of the pattern curves changes based on the mass flux they are calculated at in order to investigate how effective the maps are going to be for using flow patterns in two-phase pressure drop predictions at low flows). Also Figures 35 and 37 represent the tubes of largest internal diameter tested of $d=0.315$ inches; and Figures 36 and 38 represent the smallest internal diameter tubes of $\mathrm{d}=0.186$ inches.

Similarly to Figure 1, an example of Wojtan flow pattern map, the flow regions are marked as shown in Table 12.

Table 12: Wojtan flow pattern map graphical representations

\begin{tabular}{|l|l|}
\hline Symbol used on Wojtan flow pattern map & Flow pattern name \\
\hline I & Intermittent \\
\hline A & Annular \\
\hline Slug & Slug \\
\hline S & Stratified \\
\hline SW & Stratified-Wavy \\
\hline Slug+SW & Slug and Stratified-Wavy \\
\hline M & Mist \\
\hline D & Dryout \\
\hline
\end{tabular}

From all Wojtan flow pattern maps plotted on Figures 35 - 38 it is evident that the flow pattern boundaries are unclear mostly for regions above $100 \mathrm{~kg} / \mathrm{m}^{2} \mathrm{~s}$ for R134A and 70 $\mathrm{kg} / \mathrm{m}^{2} \mathrm{~s}$ for $\mathrm{R} 600 \mathrm{~A}$. Otherwise, there are no singularities along the whole range of qualities. A slight boundary separation is, however, evident for Stratified to Slug and Stratified-Wavy flow patterns. 


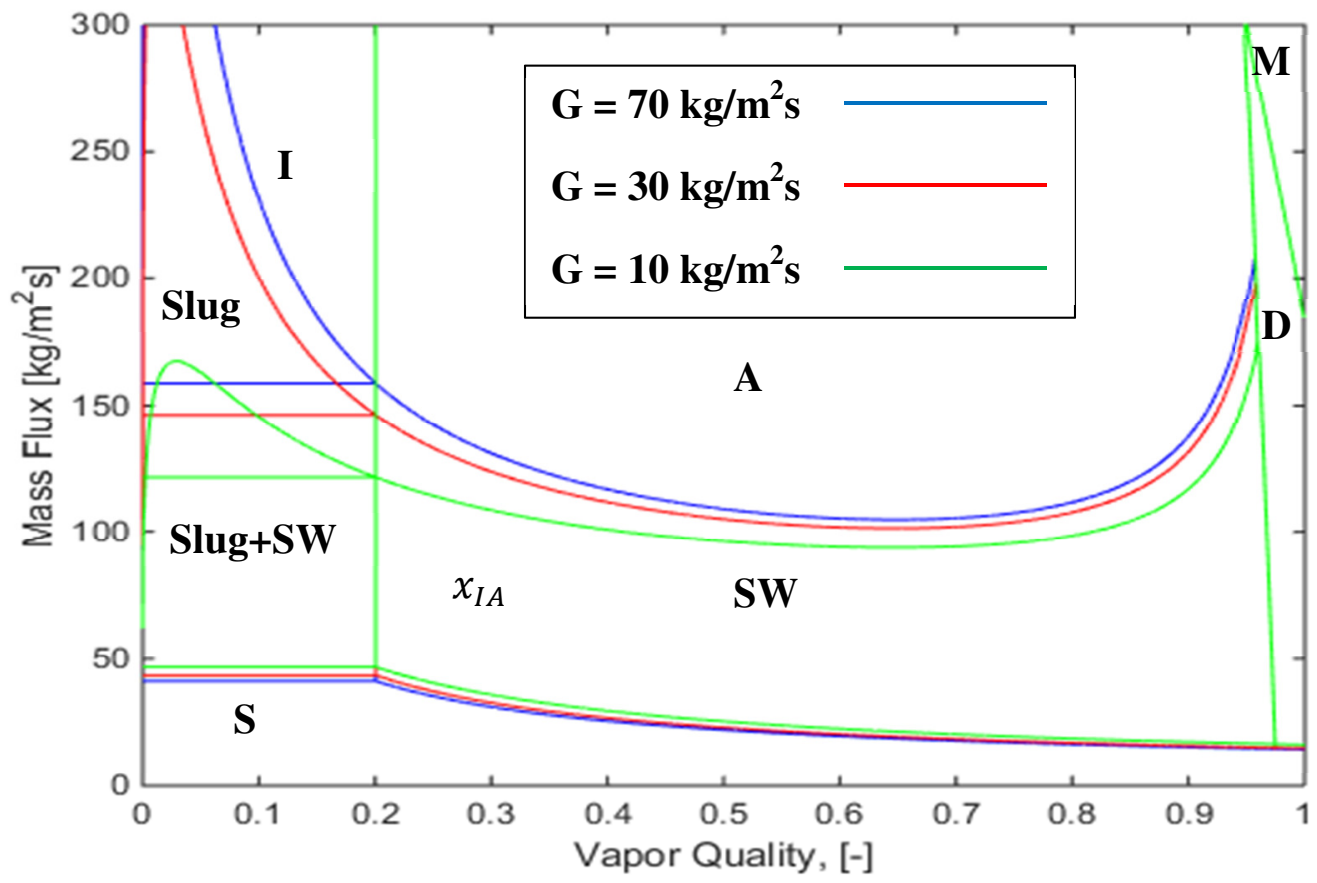

Figure 35: Wojtan flow pattern map for $\mathrm{d}=\mathbf{0 . 3 1 5}$ " tested for data set 5 per Table 5 calculated at fluxes of 70,30 and $10 \mathrm{~kg} / \mathrm{m} 2 \mathrm{~s}$ using R134A.

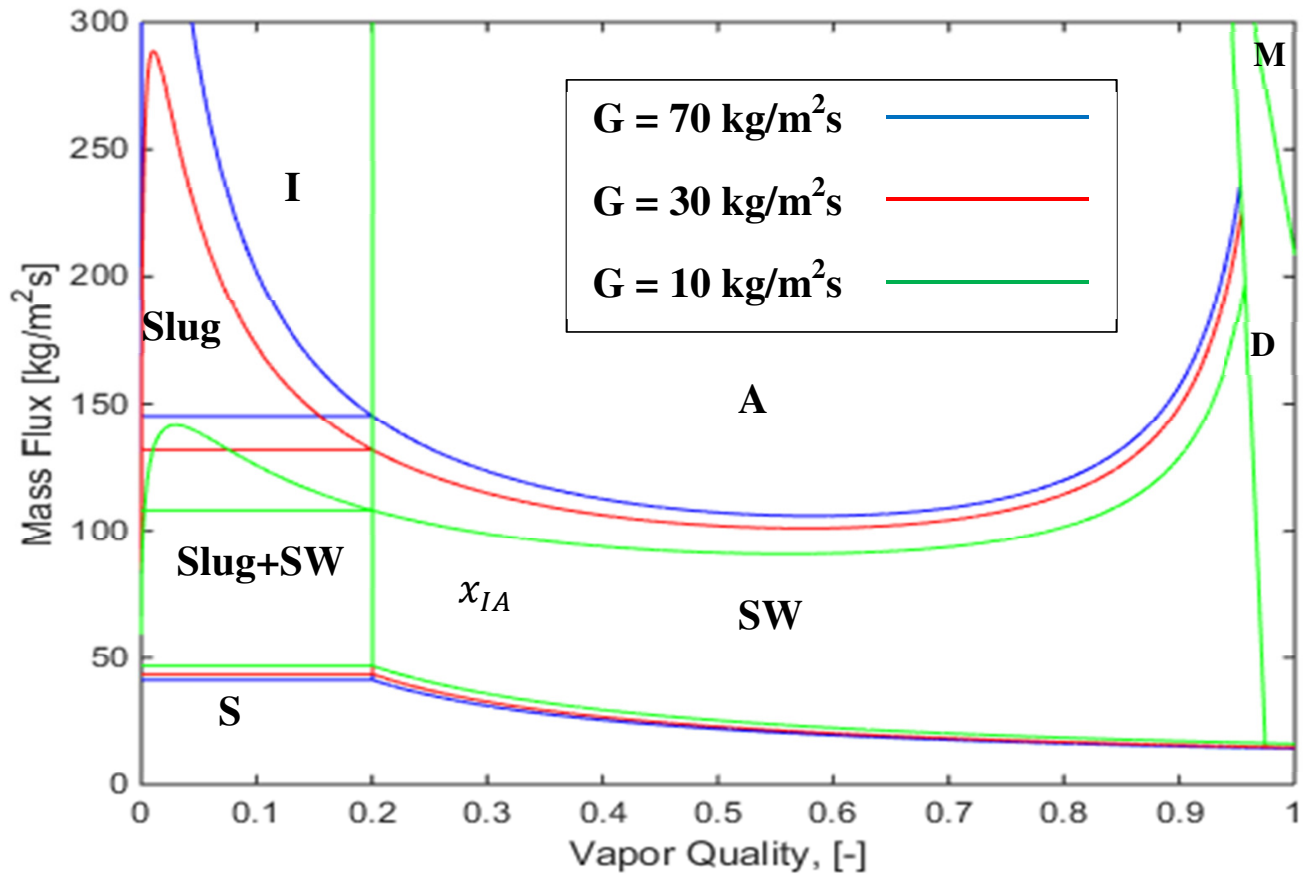

Figure 36: Wojtan flow pattern map for $\mathrm{d}=\mathbf{0 . 1 8 6}$ " tested for data set 7 per Table 5 calculated at fluxes of 70,30 and $10 \mathrm{~kg} / \mathrm{m}^{2}$ s using R134A. 


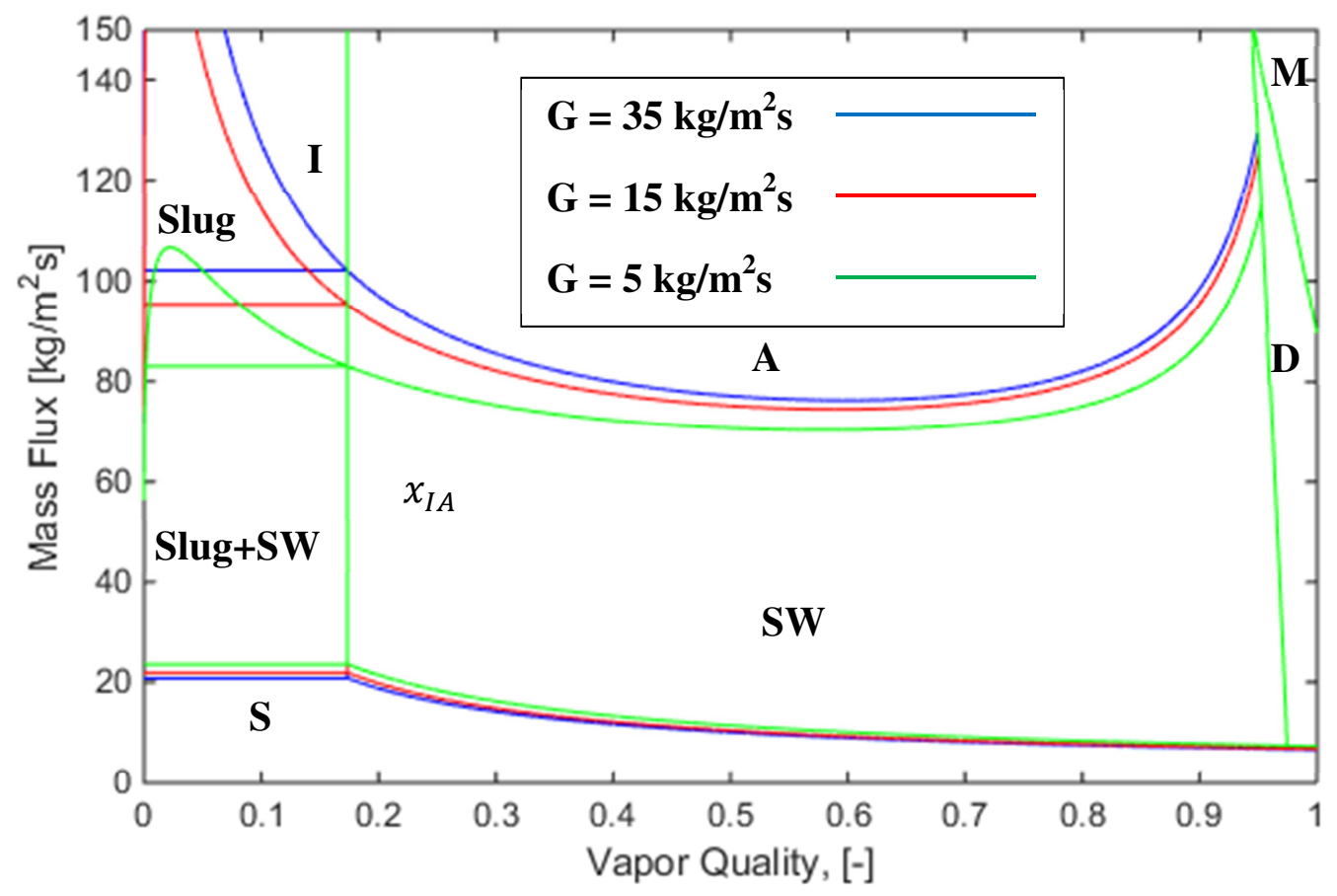

Figure 37: Wojtan flow pattern map for $\mathbf{d}=\mathbf{0 . 3 1 5}$ " tested for data set 2 per Table 5 calculated at fluxes of 35,15 and $5 \mathrm{~kg} / \mathrm{m}^{2}$ s using R600A.

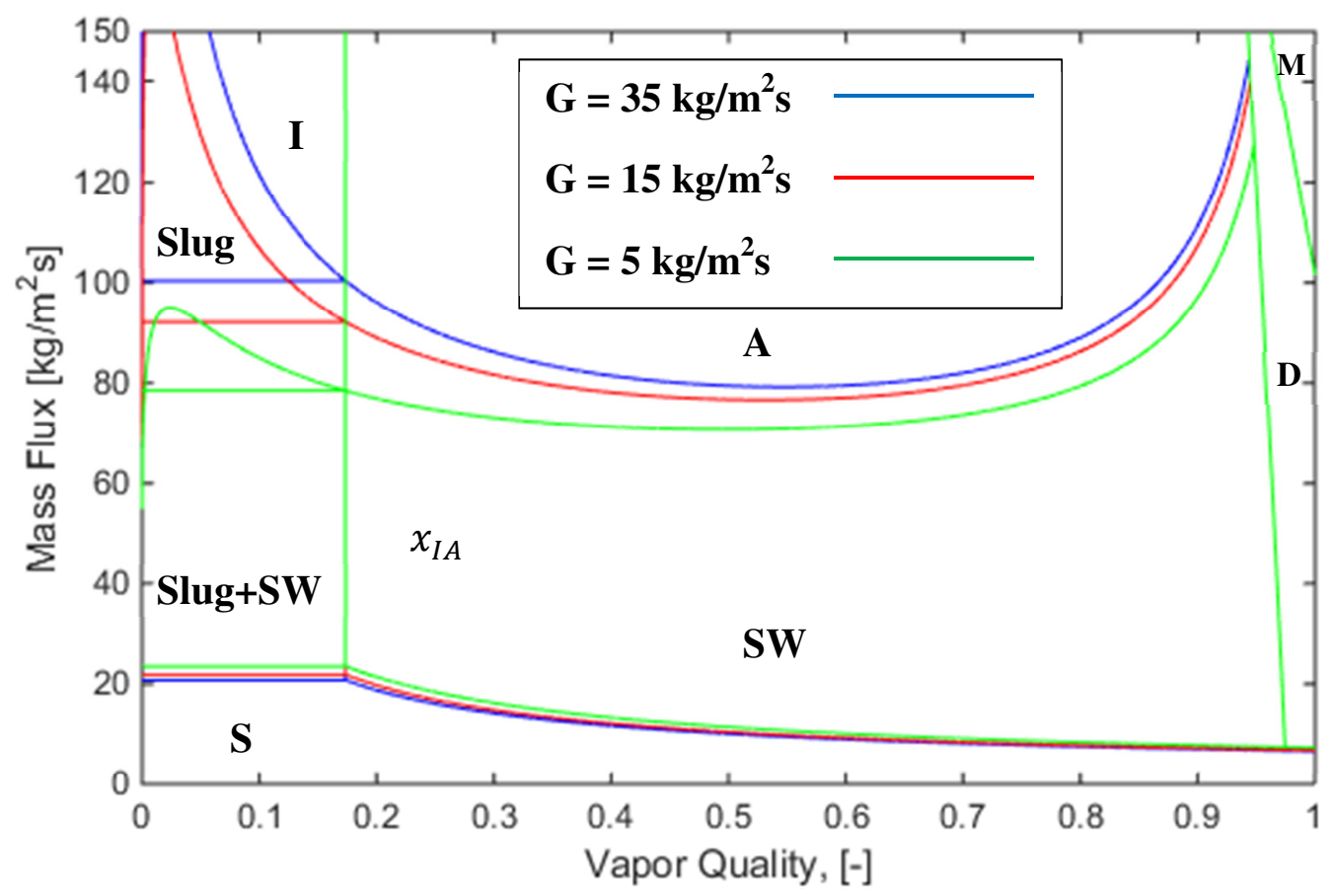

Figure 38: Wojtan flow pattern map for $\mathrm{d}=\mathbf{0 . 1 8 6}$ " tested for data set 8 per Table 5 calculated at fluxes of 35, 15 and $5 \mathrm{~kg} / \mathrm{m}^{2}$ s using R600A. 
Also an important simplifying finding can be reported using these Wojtan flow pattern maps. For the straight regions of the evaporators at low flows tested in this study, out of eight possible flow patterns, only four flow patterns are likely to occur along the whole range of vapor qualities.

Above approximately $45 \mathrm{~kg} / \mathrm{m}^{2} \mathrm{~s}$ for R134A ( $23 \mathrm{~kg} / \mathrm{m}^{2} \mathrm{~s}$ for R600A) the flow patterns occur in the following order:

- Slug/Stratified-Wavy for qualities of 0 to approximately 0.2 for R134A (0.18 for R600A)

- Stratified-Wavy for qualities of 0.2 to approximately 0.97 for R134A (0.18 0.97 for R600A)

- Dryout for the remainder of the quality range

And for mass fluxes below $45 \mathrm{~kg} / \mathrm{m}^{2}$ s for R134A ( $23 \mathrm{~kg} / \mathrm{m}^{2} \mathrm{~s}$ for R600A) the Stratified flow pattern continues for most of the quality region with possible Stratified-Wavy transition anywhere above approximately $15 \mathrm{~kg} / \mathrm{m}^{2} \mathrm{~s}$ for R134A $\left(8 \mathrm{~kg} / \mathrm{m}^{2} \mathrm{~s}\right.$ for R600A) and at qualities above $0.2(0.18$ for R600A). A very small portion at the end of the quality region could also enter the Dryout flow pattern.

Also from comparing Wojtan flow pattern maps for the same refrigerants but different internal tube diameters, it is evident that while the internal diameter had an effect on map boundaries at higher flows; at the lower flows, there is no noticeable dependence on the evaporator internal diameter. 
However, since in this study, as well as in common evaporators in household refrigerators, the inlet quality is about $0.3-0.4$, which based on the Wojtan flow maps eliminates the Slug/Stratified-Wavy pattern from consideration.

\subsection{Silva Lima \& Thome (2012) Frictional Pressure Drop, Horizontal Orientations}

Silva Lima \& Thome (2012), further referred to as SL\&T, correlation for straight horizontal tubes is the most complex out of the three reviewed in this study. It is developed based on Moreno Quibèn \& Thome (2007) correlations provided in detail in Appendix C. The authors adjusted frictional pressure drop constant for annular flow developed by Moreno Quibèn \& Thome (eq. (20)) based on a much larger data population. Annular flow pattern correlation is then used as the base for calculating pressure drop for the majority of the remaining two-phase flow patterns (see Appendix C for details).

SL\&T correlations differ for different regions of the Wojtan map, and consequently, Wojtan maps had to be developed for each of the experimental data sets first. Further, the pressure gradient was calculated with quality step of $10^{-4}$ along the tube where, as mentioned in previous section, the order of flow patterns per Wojtan map is either Stratified to Stratified/Wavy to Dryout or Slug-Stratified/Wavy to Stratified/Wavy to Dryout. 
To understand the flow pattern distribution at different mass fluxes across the total evaporator tube length, Figures 39 and 40 were developed. Both Figures show results for evaporators with internal diameters of $d=0.267$ inches. Figure 39 represents Data set 14 (with Data set 16 looking very similar) for R134A and Figure 40 represents Data set 15 (with Data set 17 looking very similar) for R600A. Both Figures show mass fluxes in the descending order. And as can be seen from the Wojtan map, examples in Figures 35-38, the percentage of the tube with Stratified-Wavy flow region decreases as mass flux decreases, this relationship is inverse for Stratified flow region. The Dryout portion for these flows is very small - under $3 \%$ of the total tube and occurs at the very end of the evaporator. The main difference between flow distributions along the same evaporator for two analyzed refrigerants is that the R134A flows are more likely to enter the Stratified flow region at lower flows.

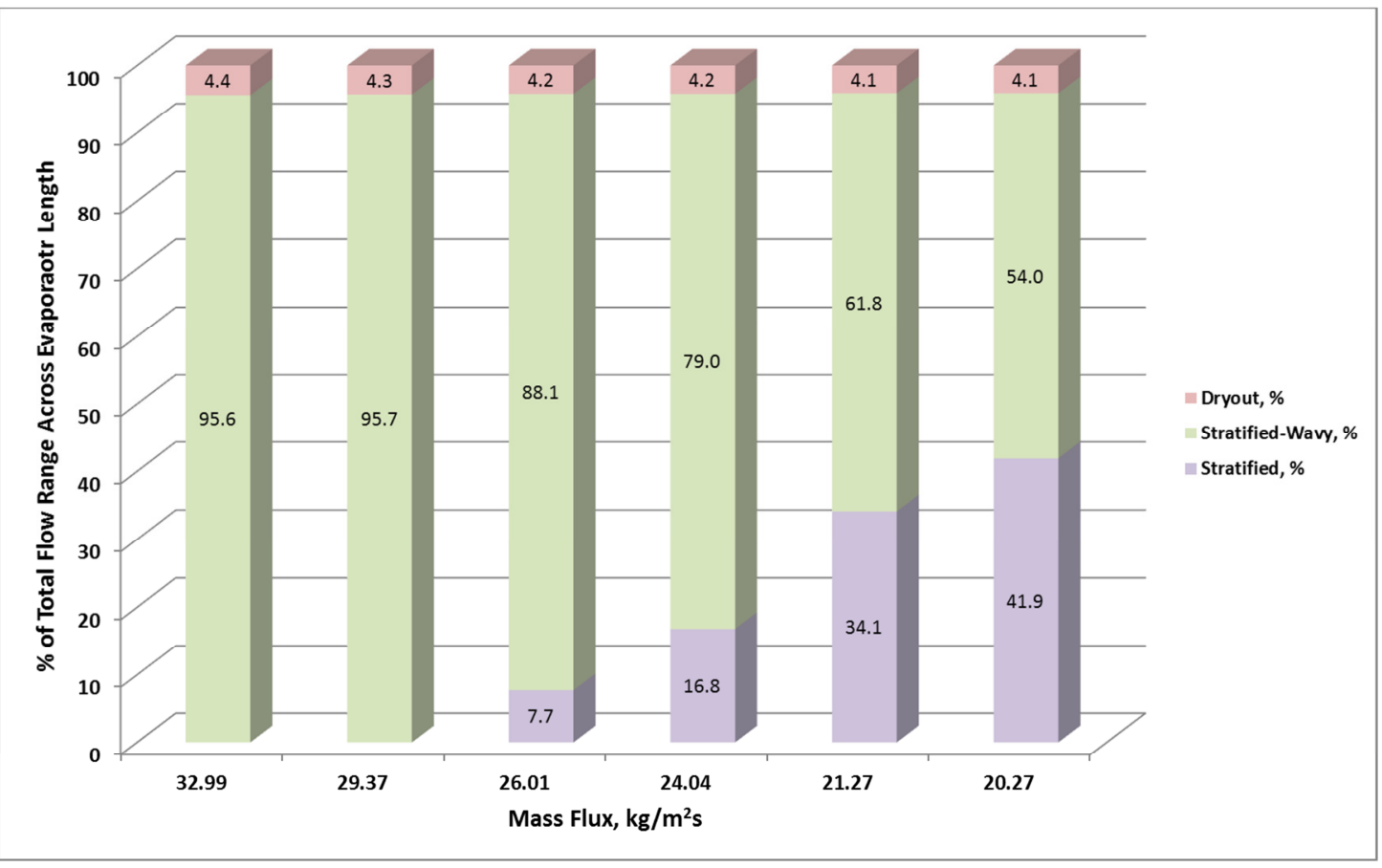

Figure 39: Percent breakdown between each flow pattern across evaporator length using Wojtan (2005) map at tested Mass Fluxes for Data sets 14, R134A (Data set 16 has a very similar result). 


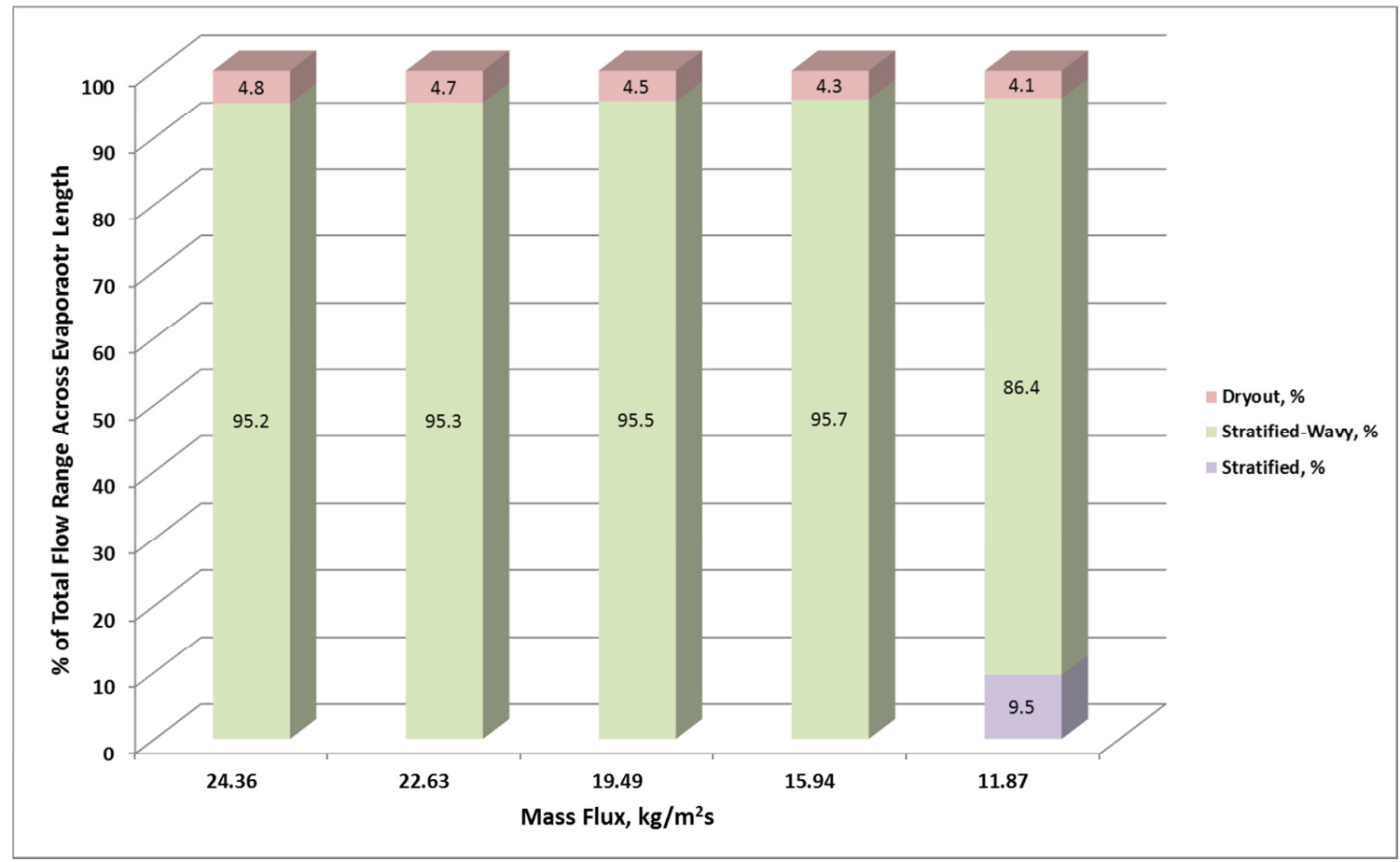

Figure 40: Percent breakdown between each flow pattern across evaporator length using Wojtan (2005) map at tested Mass Fluxes for Data sets 15, R600A (Data set 17 has a very similar result).

After the frictional pressure gradient was calculated for change in quality of $10^{-4}$ and with Wojtan flow pattern consideration, Figure 41 and 42 were developed. In Figure 41, as for Figure 39, the pressure gradient curves are shown for Data set 14 with R134A refrigerant and at tested mass fluxes; and in Figure 42, as for Figure 40, same is shown for Data set 15, R600A.

Both Figures have the expected trend of pressure gradient peaks increasing with increasing mass flux as was experimentally determined. Also all pressure gradients change slopes significantly closer to the Dryout region, where the refrigerant according to Wojtan maps provided above spends a very small amount of total evaporator length. Physically, of course, a Mist region does exist between the Dryout flow and the fully 
vapor flow, however, it is a very complex and fast process, which was not experimentally understood by Wojtan and his colleagues for low flows like these.

In comparison between Figures 41 and 42, refrigerant R134A has relatively lower frictional pressure gradients as predicted by SL\&T than R600A at similar mass fluxes, as was also shown with experimental data.

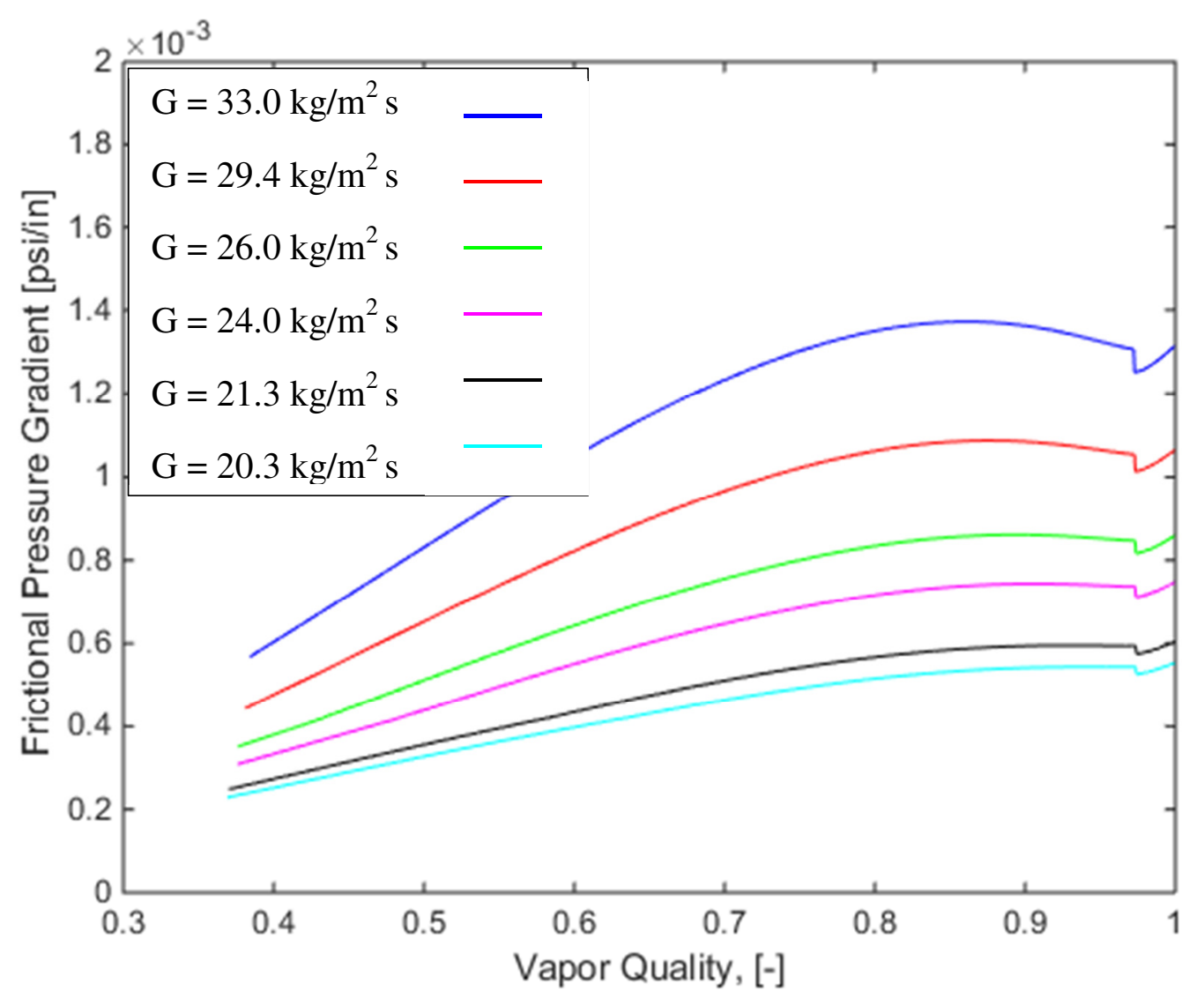

Figure 41: Frictional pressure gradient across full range of qualities using Silva Lima $\&$ Thome (2012) model at tested Mass Fluxes for Data sets 14, R134A (Data set 16 has a very similar result). 


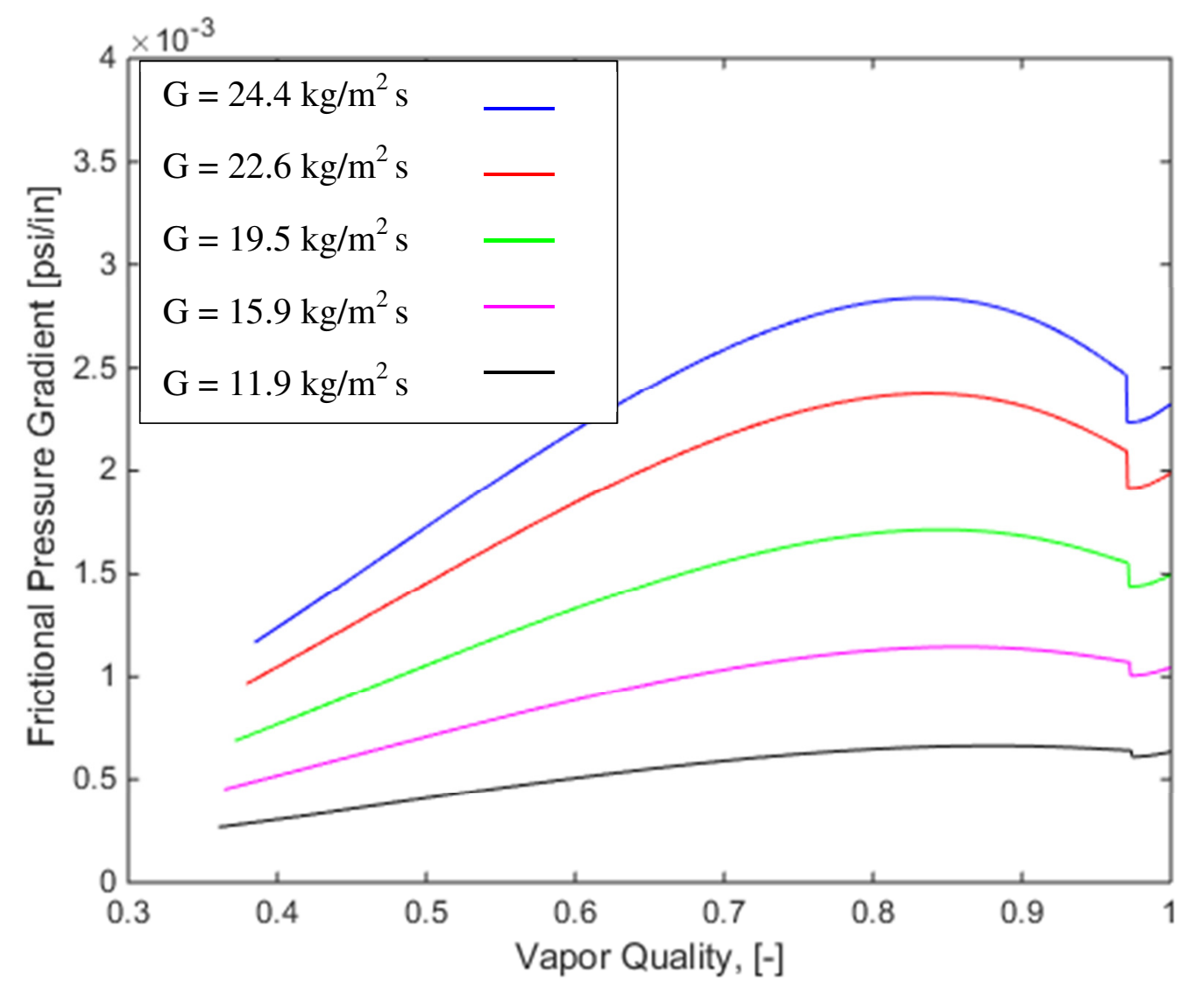

Figure 42: Frictional pressure gradient across full range of qualities using Silva Lima \& Thome (2012) model at tested Mass Fluxes for Data sets 15, R600A (Data set 16 has a very similar result).

Figure 43 below represents the performance of the SL\&T correlation in comparison to the experimental data for data sets 14-17, which, as previously discussed, behave largely as a straight horizontal tube. As before, for this data set, the total predicted pressure drop is a function of the frictional component found using SL\&T correlations and the momentum pressure drop values calculated previously. 


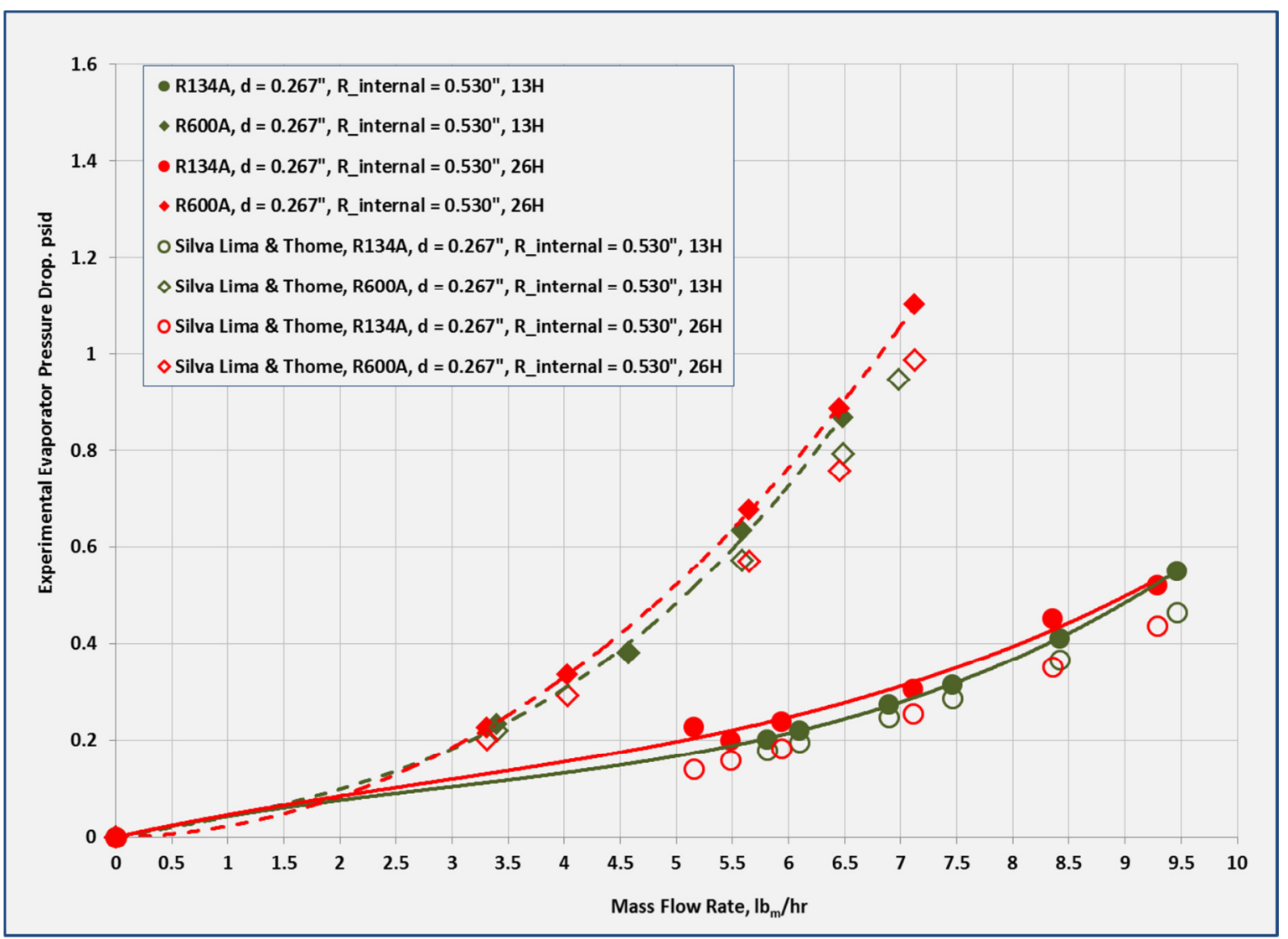

Figure 43: Experimental two-phase refrigerant pressure drop and prediction using Silva Lima \& Thome (2012) correlation for Data sets 14-17: Horizontal orientation study.

Figure 43 shows that SL\&T slightly under-predicts the experimental values with average error of $13.3 \%$ and standard deviation of error at $8.14 \%$. Figure 44 portrays this underestimation in a form of Predicted/Experimental data ratio. 


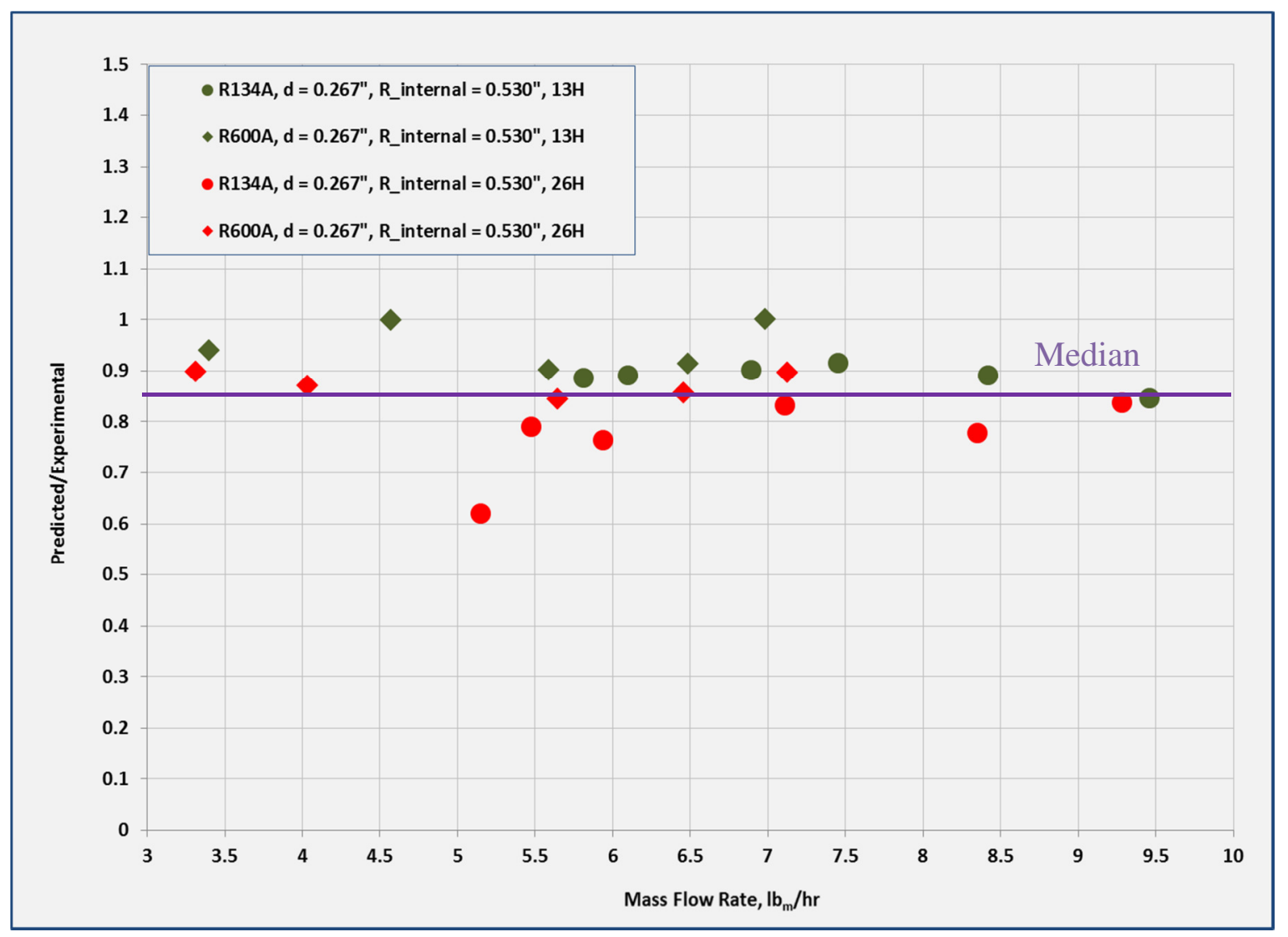

Figure 44: Ratio of predicted two-phase refrigerant pressure drop using Silva Lima \& Thome (2012) correlation to experimental data for Data sets 14-17: Horizontal orientation study.

This average performance might be explained by the fact that the authors of this correlation did not have data to check the performance of their model in Stratified region and the majority of the Stratified/Wavy region. The lowest mass flux data point available to Silva Lima \& Thome was $70 \mathrm{~kg} / \mathrm{m}^{2}$ s, while the experimental data obtained within this study all lays under this limit (see Table 11). The Wojtan flow map data bank also lacked data at extremely low flows which are presented here.

However, as was previously done for Müller-Steinhagen \& Heck (1986) model a multiplier could be found to adjust SL\&T correlation to better predict experimental data. 
Figures 45 and 46 show how well an adjusted SL\&T correlation performs, when total predicted frictional pressure drop at tested conditions is multiplied by value of 1.06 with offset of 0.032 added to the result. An average error drops down to $-0.83 \%$ with standard deviation of error at $8.4 \%$.

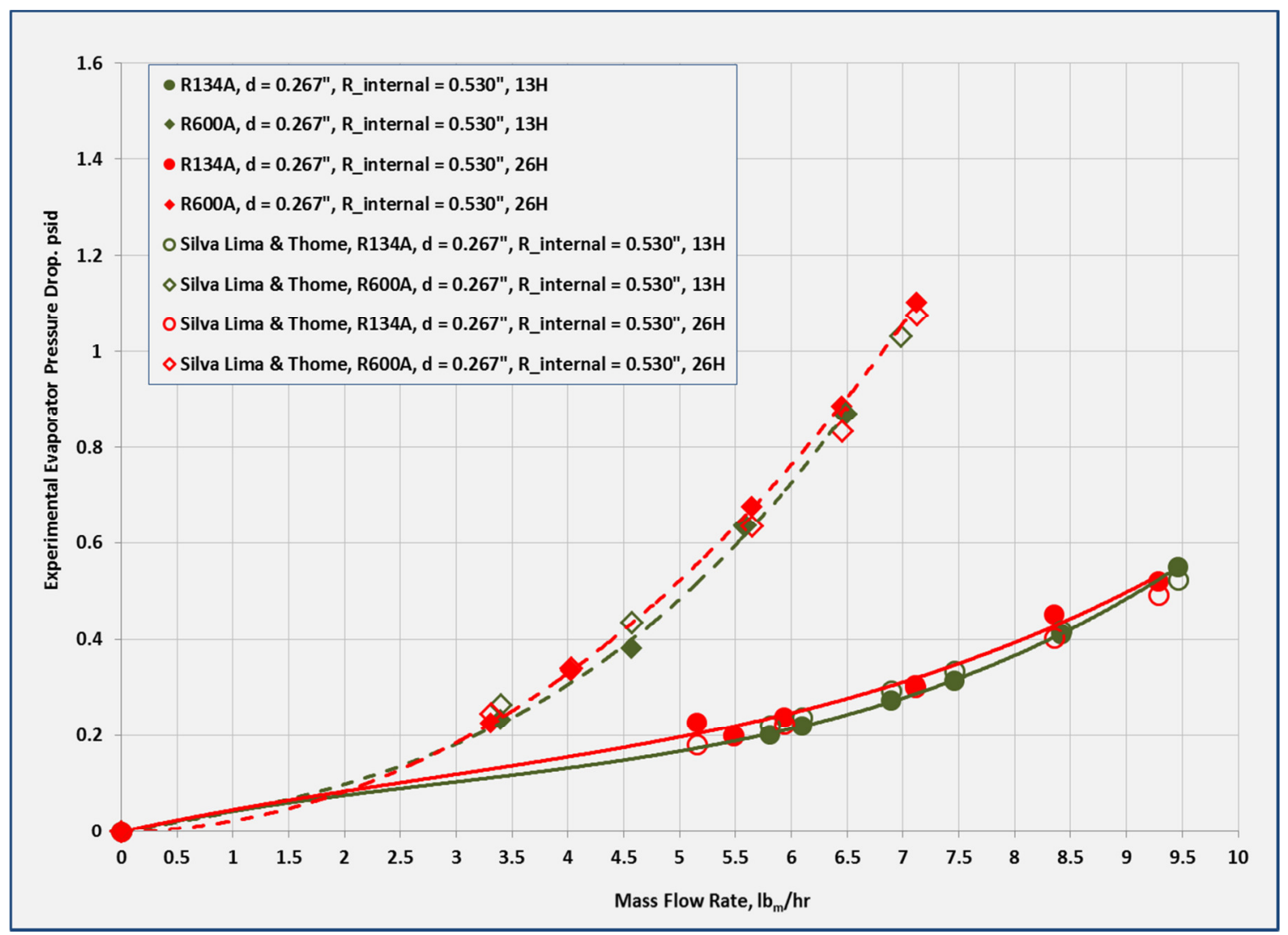

Figure 45: Experimental two-phase refrigerant pressure drop and prediction using Adjusted Silva Lima \& Thome (2012) correlation for Data sets 14-17: Horizontal orientation study. 


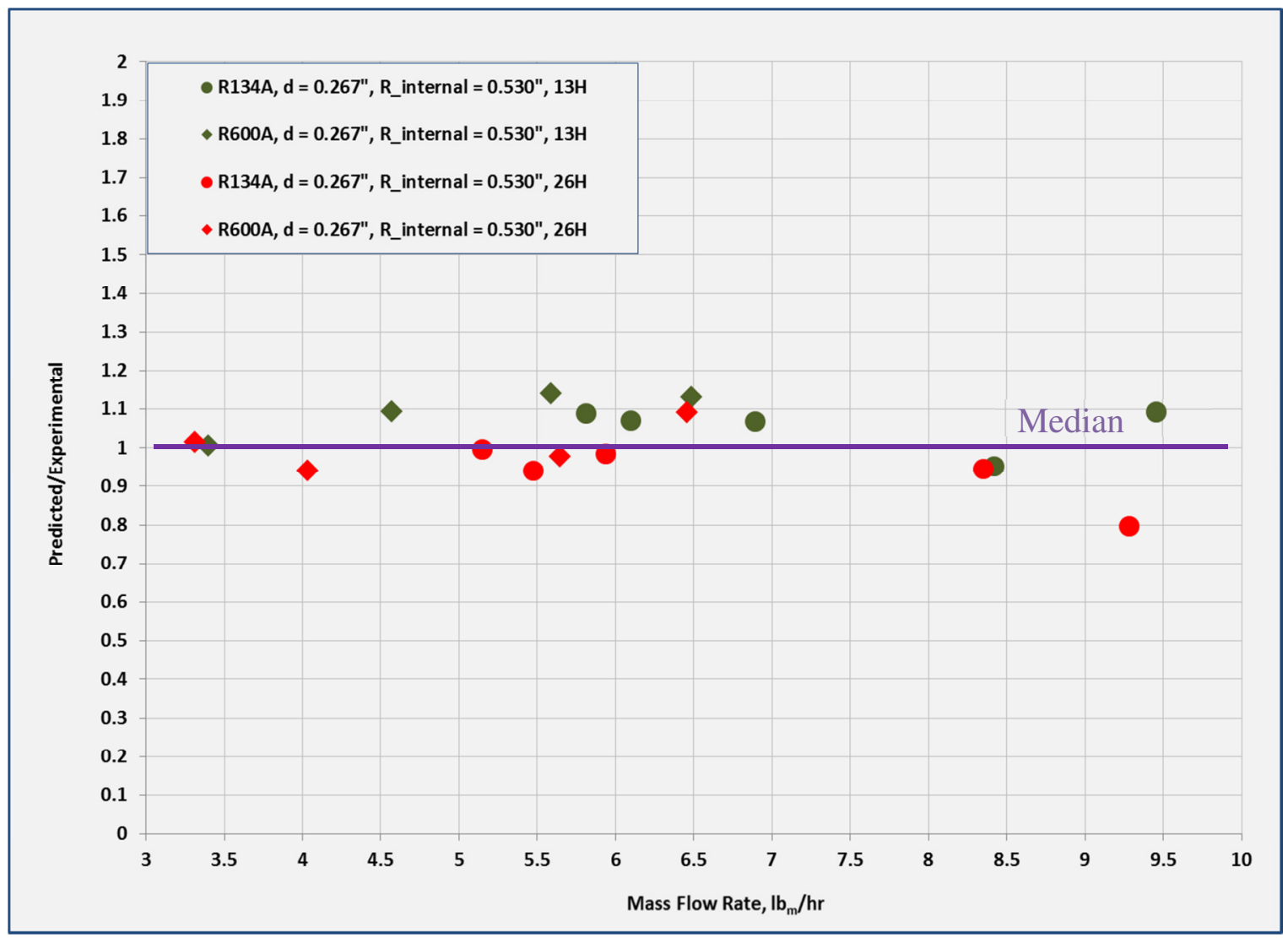

Figure 46: Ratio of predicted two-phase refrigerant pressure drop using Adjusted Silva Lima \& Thome (2012) correlation to experimental data for Data sets 14-17: Horizontal orientation study.

This completes the horizontal orientation and double U-bend study of this paper. Three two-phase frictional pressure drop models for straight horizontal evaporators were compared here and Figure 47 summarizes the results. Out of three reviewed predictive models, only one, Grönnerud model, was not adjusted due to its initial good performance. The other two models, Silva Lima \& Thome and Müller-Steinhagen \& Heck, which over predicted and under predicted the experimental data, respectively, had to be adjusted with separate multipliers resulting in very good predictions. However, it is understood, that the experimental data bank used for these adjustments is small ( 22 data points were taken for 
horizontal orientation and double U-bend study) and the confidence in these correlations could be increased by collecting more data.

Overall, the order of decreasing prediction accuracy for all three adjusted models (besides Grönnerud ) is Silva Lima \& Thome, Grönnerud, and Müller-Steinhagen \& Heck. When comparing the difficulty of implementation of each of reviewed correlations it is very apparent, that the newest model, Silva Lima \& Thome (2012) for straight tubes does not justify its complexity with good initial predictions, while the other two much simpler models performed at the same level of accuracy after some adjustments were made.

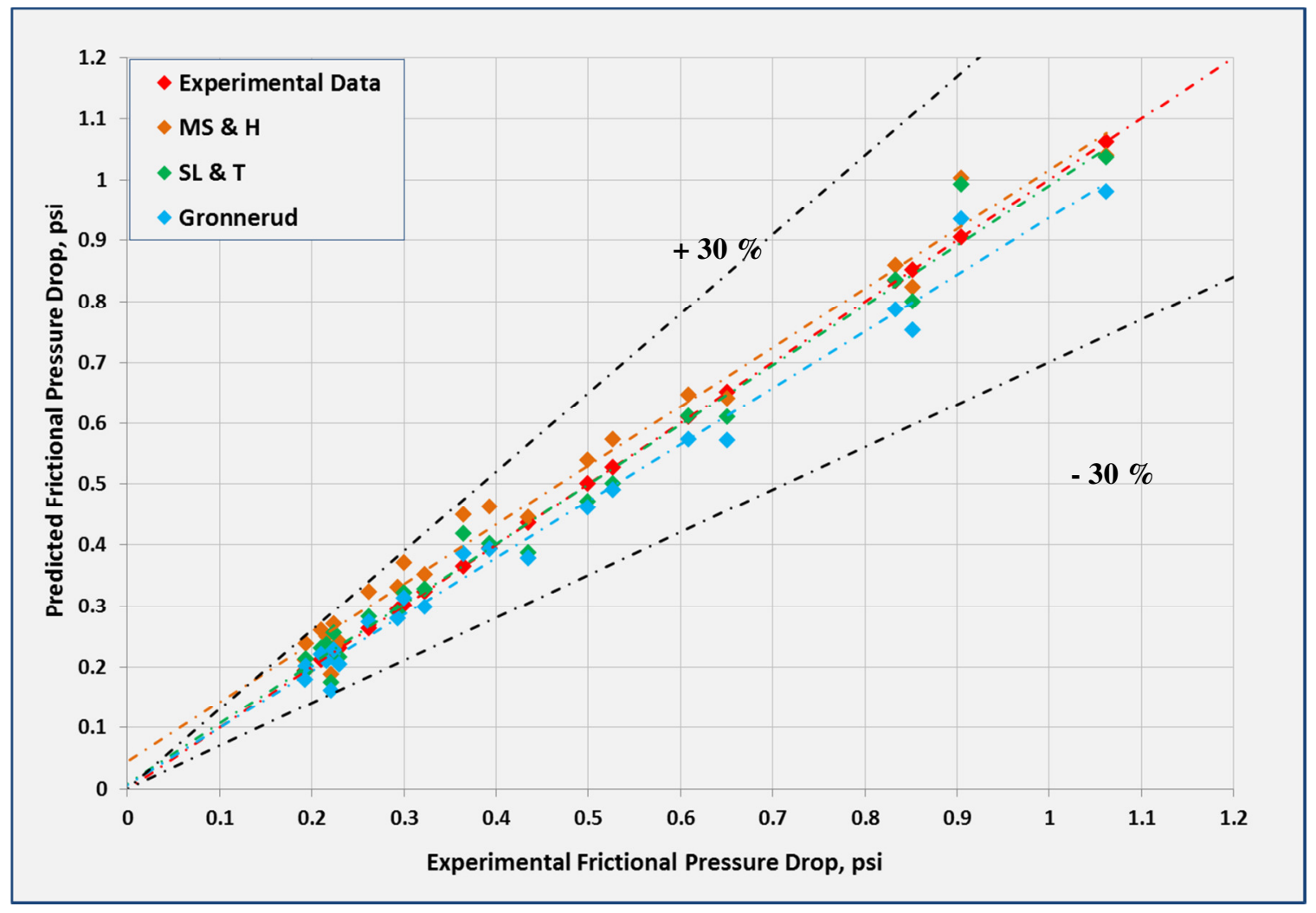

Figure 47: Overall predictive performance comparison between Grönnerud (1979), adjusted MüllerSteinhagen \& Heck (1986) and adjusted Silva Lima \& Thome (2012) correlations. 


\subsection{Vertical Orientation Study (Data sets 1-8)}

The next step in this research is to review the prediction of the SL\&T two-phase frictional pressure drop model for vertical U-bends. Data sets 1-13 in Table 5, which are parts of Vertical Orientation and Curvature Ratio studies in this paper, all contain thirteen vertical U-bends: first six with up-flow and last six with down-flow of two-phase refrigerant. Following Figures 48(A-B) to 51(A-B) represent the pressure gradient through the whole length of the evaporator as predicted by a combination of straight tube and U-bend SL\&T models. A complex MatLAB code was created in order to apply correct correlations to every point along the evaporator including single phase property changes, quality increase, flow orientation and direction (straight horizontal, U-bend upflow or U-bend down-flow) and flow pattern per Wojtan flow map described previously.

In order to understand how SL\&T pressure gradient prediction differs for different geometries of the evaporator four data sets are plotted in the following four figures. Figures 48(A-B)-49(A-B) and Figures 50(A-B)-51(A-B) represent the same evaporator geometries with largest and smallest internal tube diameters, respectively. Part A of each Figure represents pressure gradient over range of qualities seen by evaporators, and Part B of each Figure represents a percent breakdown of each flow pattern and location as per Wojtan maps. Both refrigerants, R134A and R600A, are also depicted per each of these geometries as per Table 13 below: 
Table 13: Data sets plotted on Figures 48(A-B)-49(A-B) and Figures 50(A-B)-51(A-B)

\begin{tabular}{|l|l|l|l|}
\hline Data set reference number & Refrigerant type & $\begin{array}{l}\text { Tube internal diameter d, } \\
\text { in }\end{array}$ & $\begin{array}{l}\text { Tube U-bend internal radius Rinternal, } \\
\text { in }\end{array}$ \\
\hline 1 & R134A & 0.315 & 0.575 \\
\hline 2 & R600A & 0.315 & 0.575 \\
\hline 7 & R134A & 0.186 & 0.530 \\
\hline 8 & R600A & 0.186 & 0.530 \\
\hline
\end{tabular}

In Figures 48 - 51 each U-bend appears as a spike in frictional pressure gradient, while straight portions of the evaporator have the same shape as was shown before with Figures 41 and 42 for horizontal evaporator orientations. The first six spikes are lower for each of the plotted data sets due to flow being directed in the up-ward direction along those Ubends. Last six pressure gradient spikes are slightly shorter for down-flow U-bends, however they increase as the refrigerant quality increases (higher frictional pressure drop for vapor state). Further, all figures show increased effect of the U-bends for higher flow velocities.

All vertical U-bends hold about $7.2 \%$ of the total length of evaporators. Thus, even though higher pressure drop occurs across vertical U-bends, their total effect is lowered by the adjacent long straight portions.

Also as for horizontal evaporator orientation, the inlet qualities (around 0.38) are above the Intermittent-Annular quality transition, $x_{I A}$, which is found to be under 0.2 (see Wojtan maps on Figures 35 - 38). This eliminates the possibility of Slug-Stratified/Wavy flow pattern per Wojtan map for all tested samples and flows. Thus, Part B of each Figure below consists of some combination of Straight Stratified, U-bend Stratified, Straight Stratified/Wavy, U-bend Stratified-Wavy and Straight Dryout. Since Dryout region is very short at the end of quality range, none of the vertical U-bends fell in that region. 


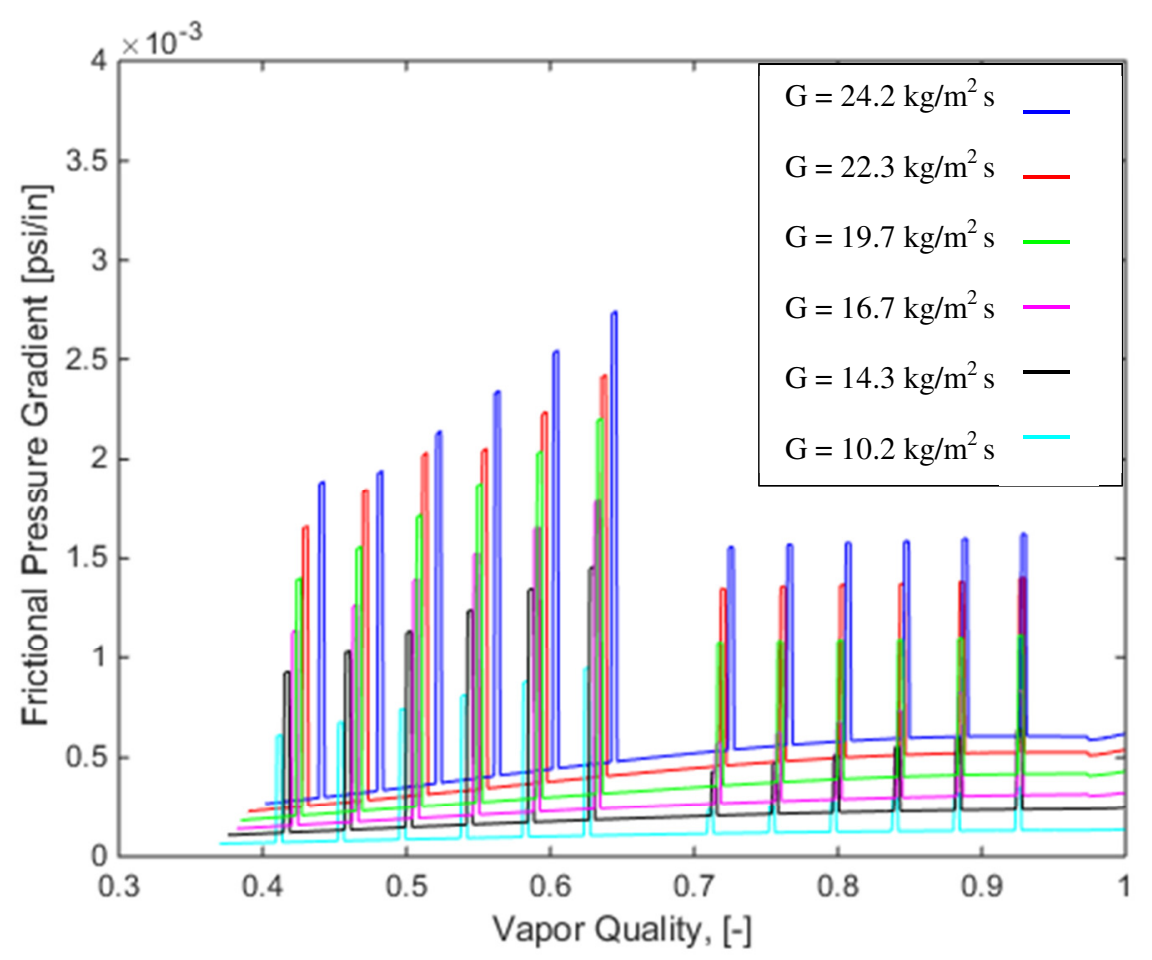

(A): Frictional pressure gradient across full range of qualities

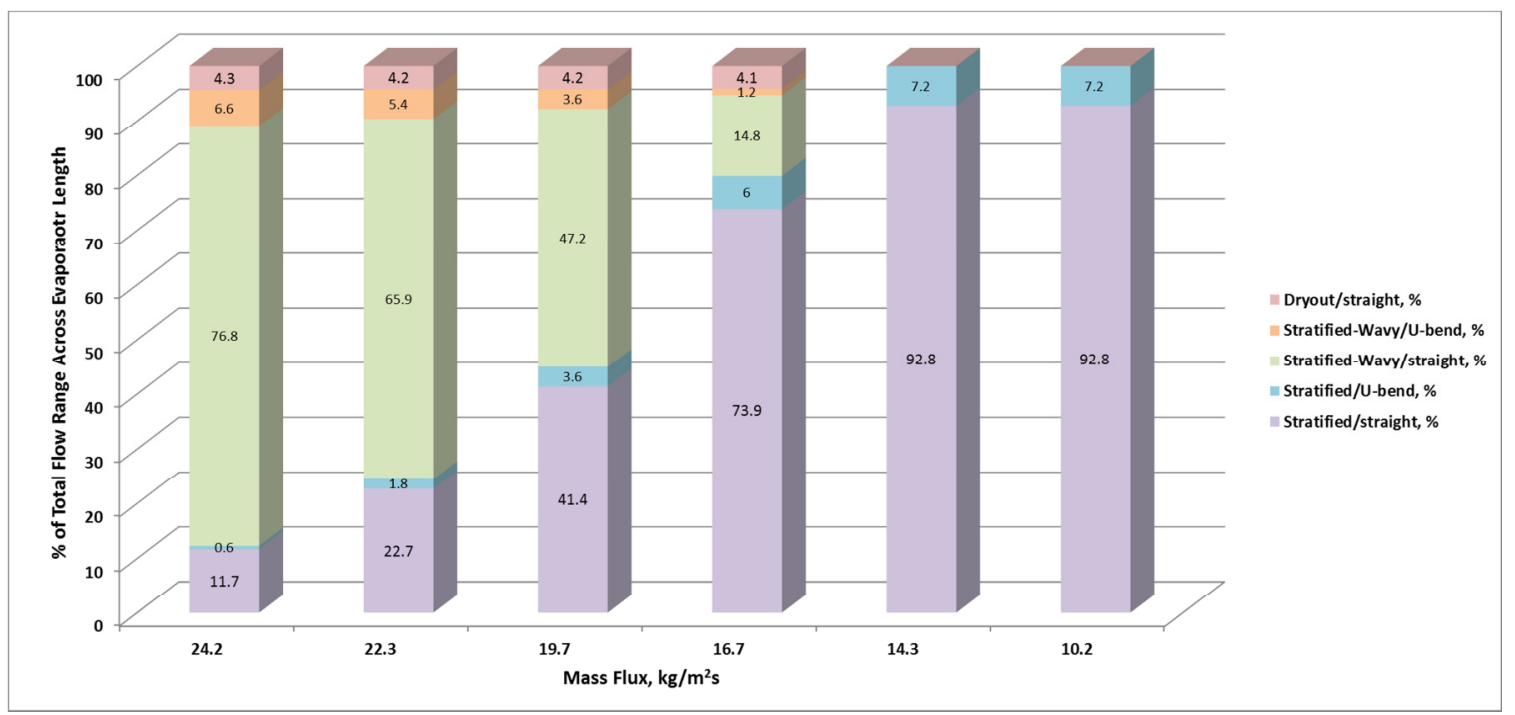

(B): Percent breakdown between each flow patterns and location across evaporator length

Figure 48(A-B): Silva Lima \& Thome (2012) frictional pressure gradient and percent breakdown between flow patterns and locations at tested Mass Fluxes for Data set 1, R134A. 


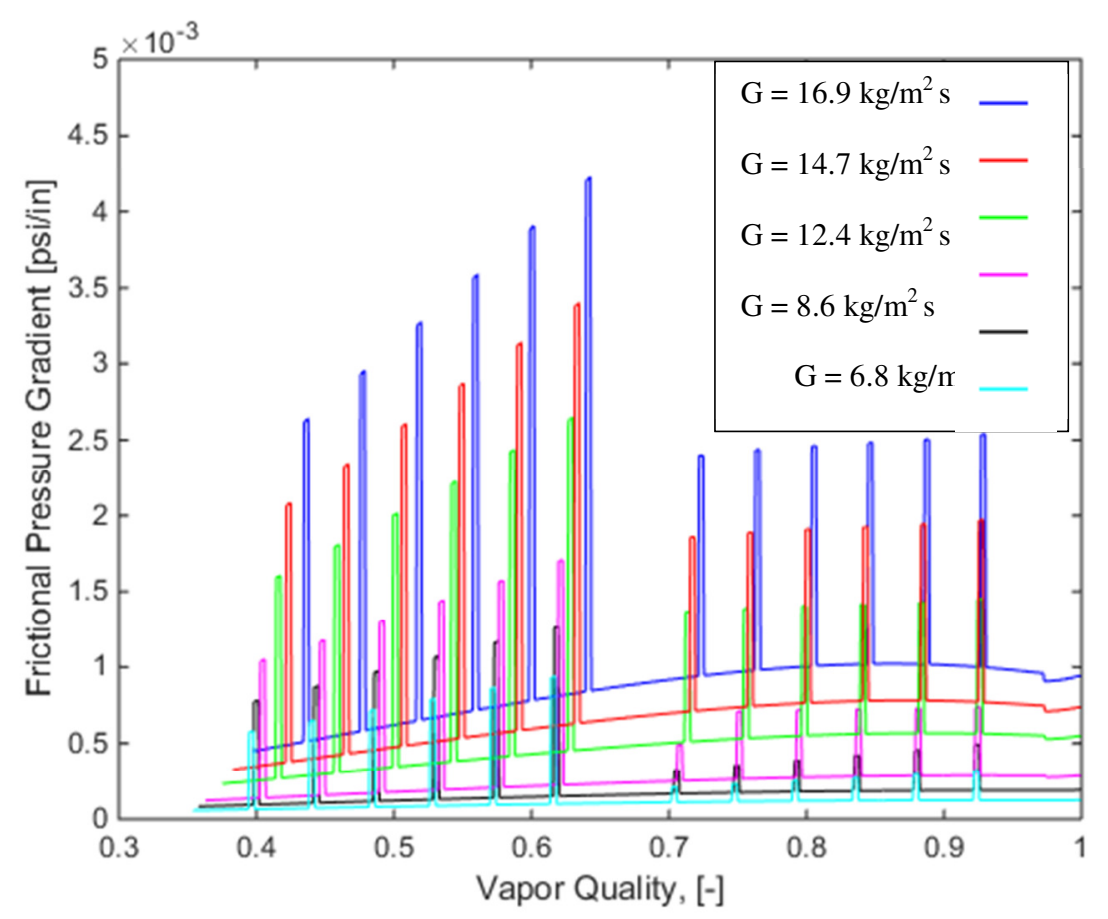

(A): Frictional pressure gradient across full range of qualities

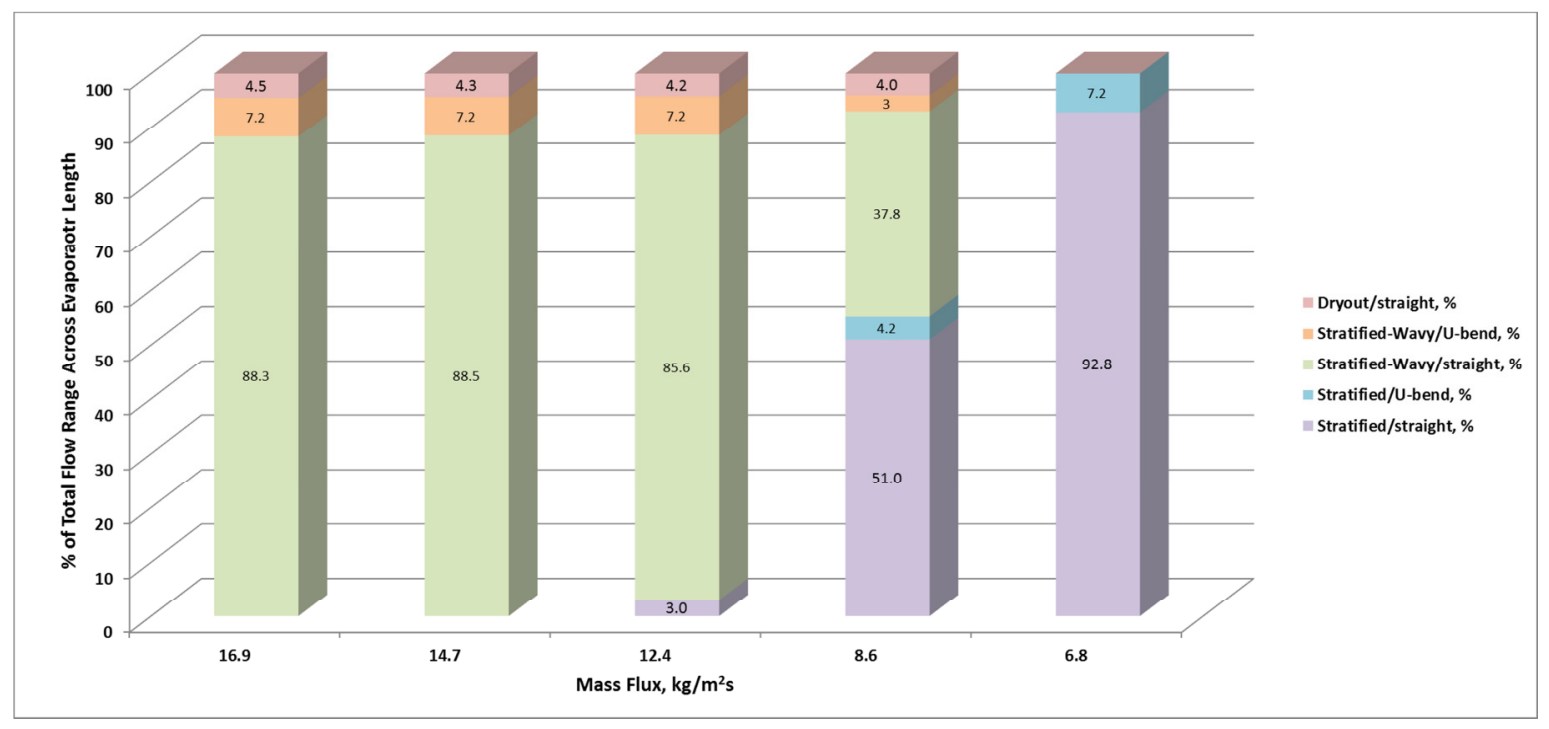

(B): Percent breakdown between each flow pattern and location across evaporator length

Figure 49(A-B): Silva Lima \& Thome (2012) frictional pressure gradient and percent breakdown between flow patterns and locations at tested Mass Fluxes for Data set 2, R600A. 


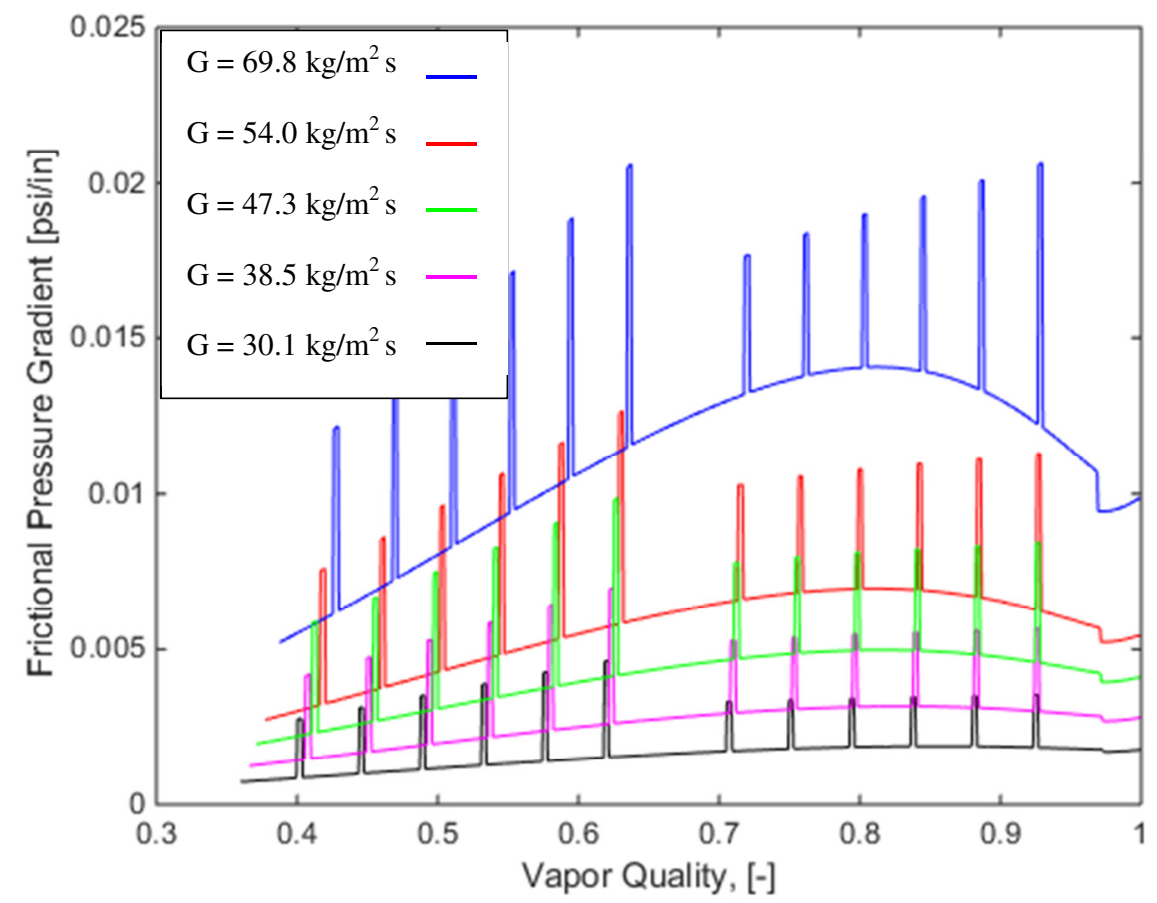

(A): Frictional pressure gradient across full range of qualities

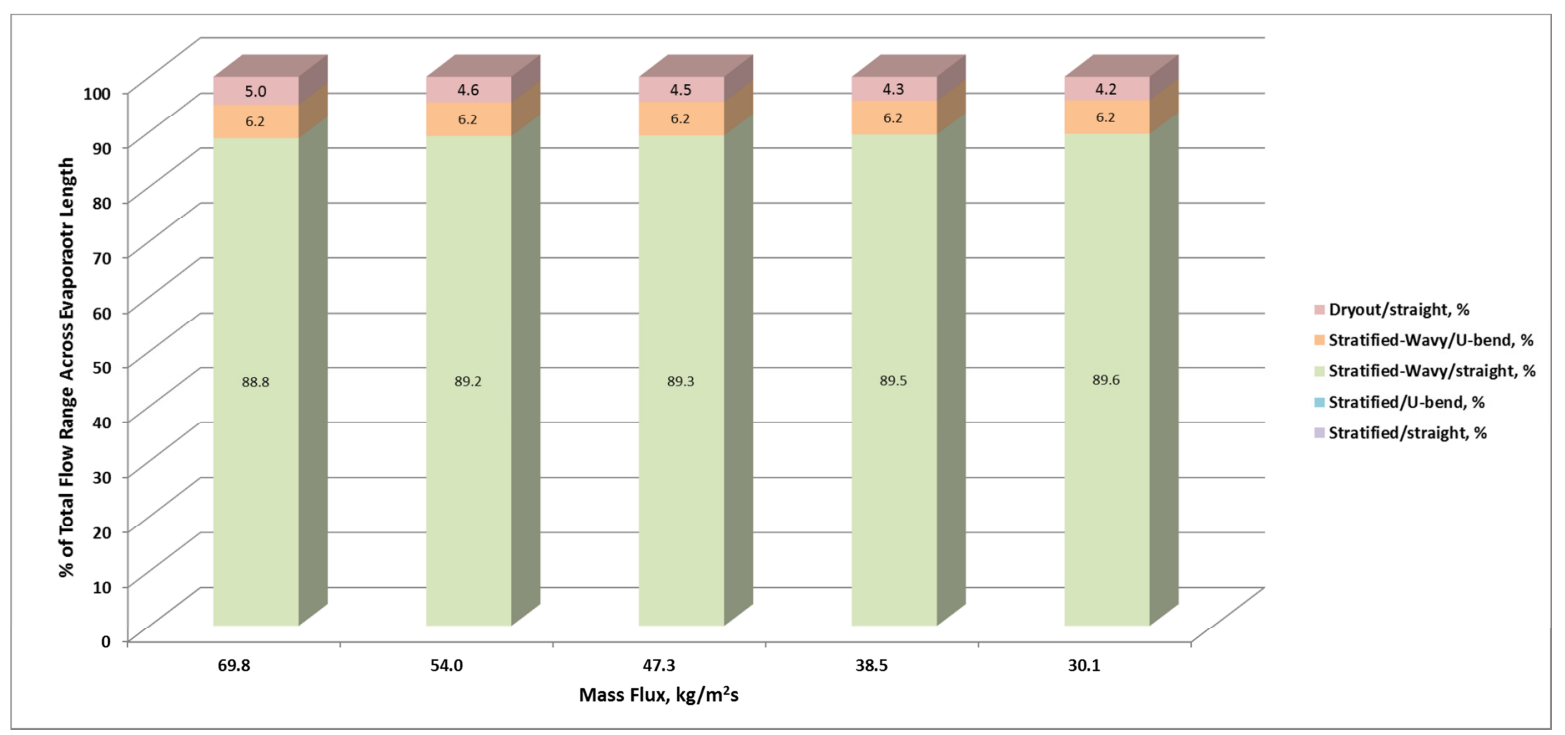

(B): Percent breakdown between each flow pattern and location across evaporator length

Figure 50(A-B): Silva Lima \& Thome (2012) frictional pressure gradient and percent breakdown between flow patterns and locations at tested Mass Fluxes for Data set 7, R134A. 


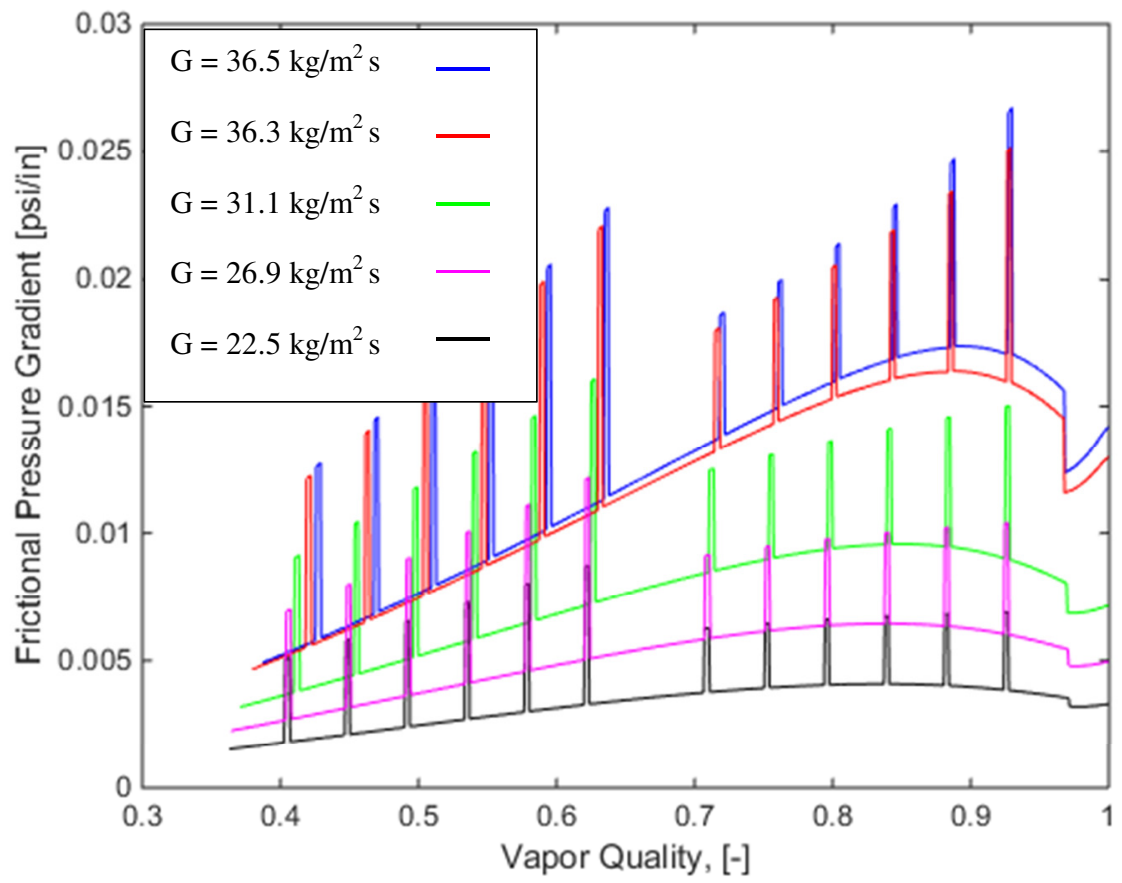

(A): Frictional pressure gradient across full range of qualities

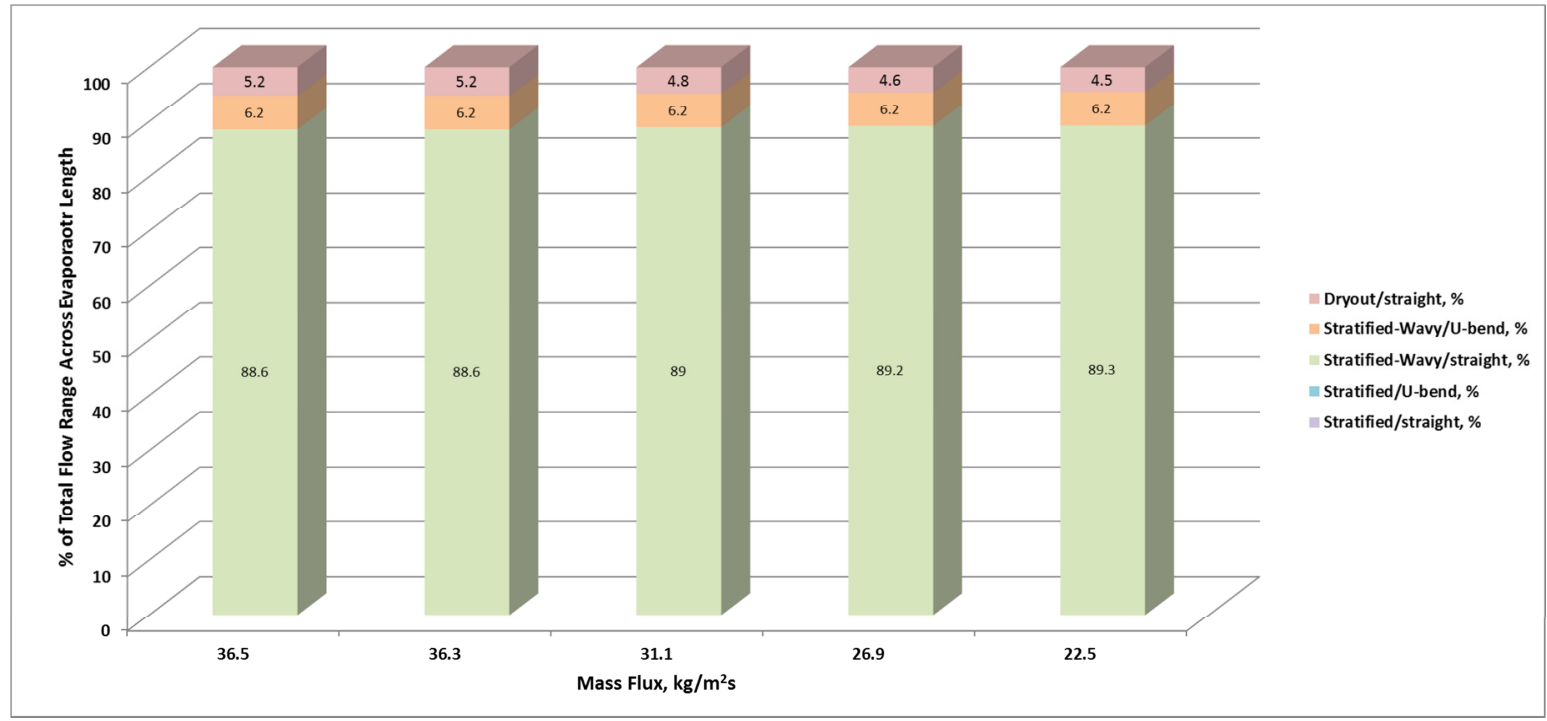

(B): Percent breakdown between each flow pattern and location across evaporator length

Figure 51(A-B): Silva Lima \& Thome (2012) frictional pressure gradient and percent breakdown between flow patterns and locations at tested Mass Fluxes for Data set 8, R600A. 
Next, after adding all SL\&T predicted pressure gradients across the length of evaporators, the result is shown for all tested vertical orientations and separated in two graphs; Figure 52 depicting Curvature Ratio study in particular, and Figure 53 depicting overall Vertical Orientation study. It is important to note that no correction factors found in the horizontal orientation study were used for predictions in Figures 52 and 53.

It was expected that SL\&T model for two-phase pressure drop will perform best among other models due to its obvious merits, such as extended U-bend related experimental data bank used for its creation, dependence on the flow patterns, relation to a flow direction, etc. However, Figures 52 and 53 show that for tested evaporator geometries and conditions, this correlation predicts with unsatisfactory accuracy. The slope as well as magnitude of the prediction is incorrect.

As before, the solid points on Figures 52 and 53 represent the experimental data and the hollow ones of the same shape and color represent respective prediction with correlation under analysis (SL\&T in this case). Figure 52 shows data collected under the curvature ratio study, while Figure 53 shows the remainder of vertical orientation results (there are some repetitions between these two Figures). 


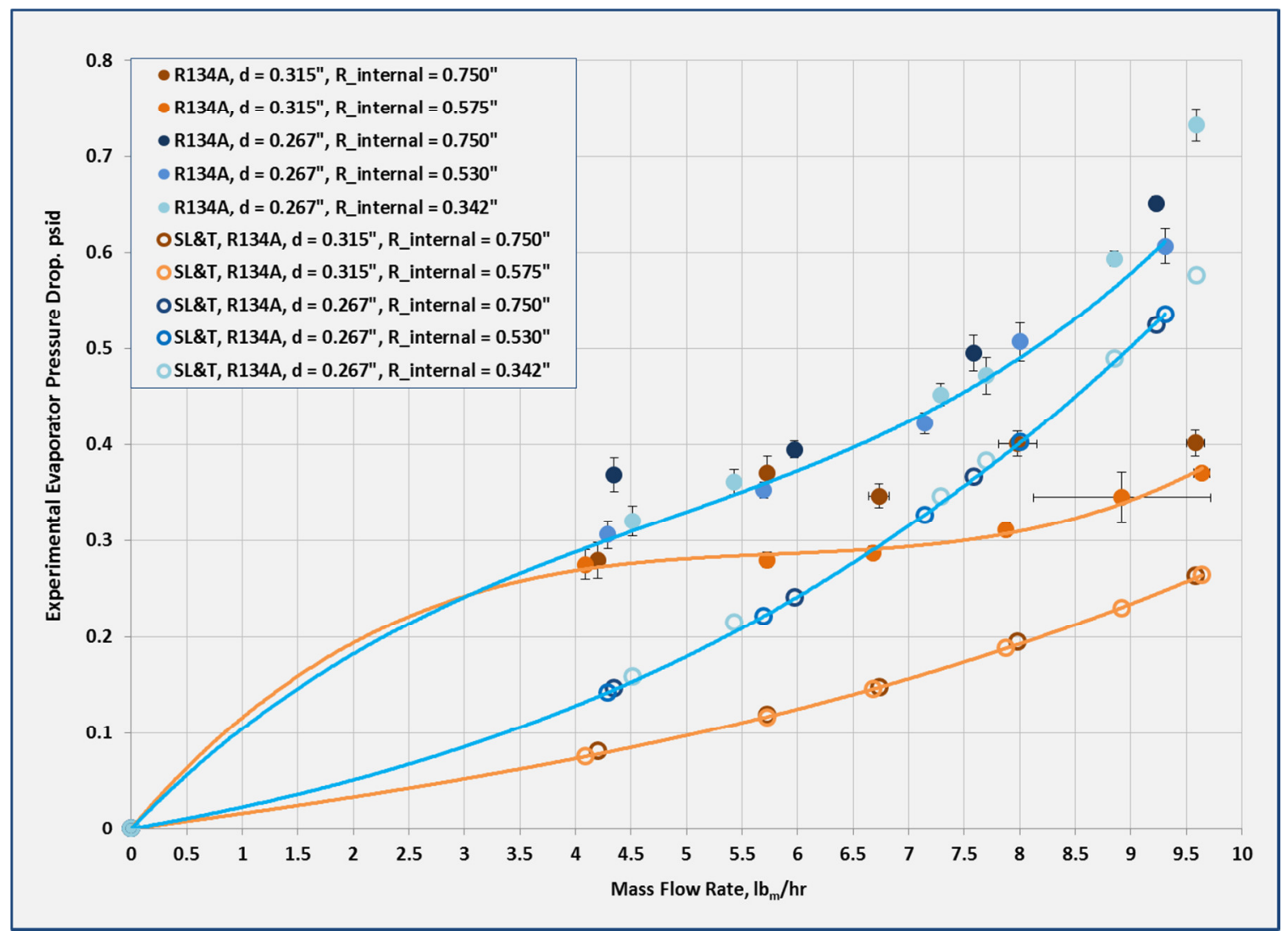

Figure 52: Experimental two-phase refrigerant pressure drop and prediction using Silva Lima \& Thome (2012) correlation for Data sets 9-13: Vertical Curvature Ratio study.

SL\&T correlation under predicts all data shown in Figure 52, which includes two of the largest internal diameter tubes tested within this study. Same performance is also evident from Figure 53 at large tube diameters; however smaller tube diameter data (0.186 inch) is over predicted. Only 0.243 inch diameter tube pressure drop is predicted well with SL\&T (green curve in Figure 54). 


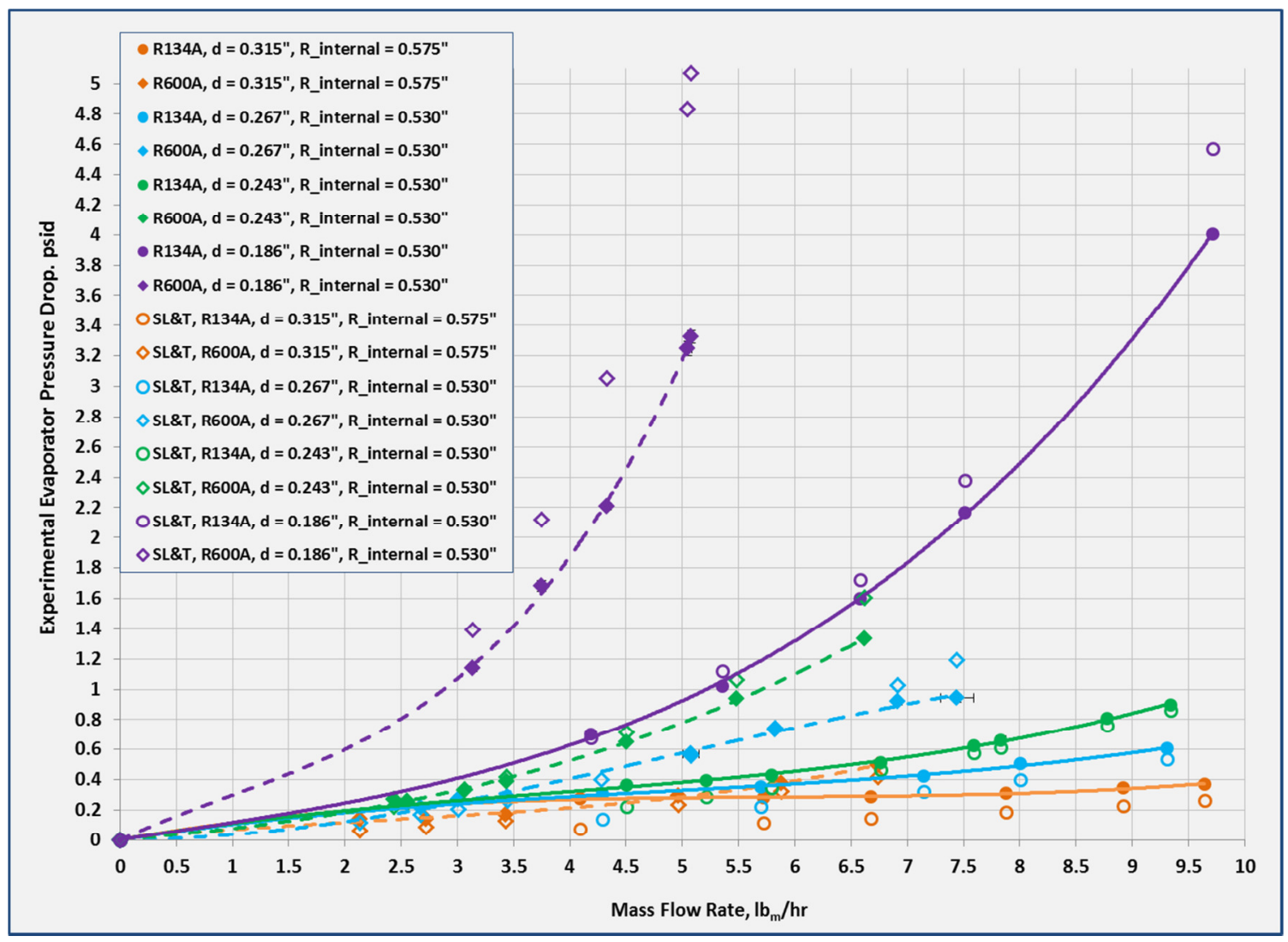

Figure 53: Experimental two-phase refrigerant pressure drop and prediction using Silva Lima \& Thome (2012) correlation for Data sets 1-8:Vertical Orientation study.

This diameter dependence, as well mass flux dependence (incorrect slope), point towards main variables within analyzed correlation that have high effect on the accuracy of the prediction. This finding allows an adjustment of the model in mass flux and internal diameter dependence. It is possible to calculate how a combination of offsets, powers and multipliers of mass flux and internal diameter (or other variables) could be used to minimize prediction errors of this (or similar) empirical model in tested conditions.

For comparison, adjusted Müller-Steinhagen \& Heck (1986) and original Grönnerud (1979) frictional pressure drop models were also applied to this Vertical Orientation (Data sets 1-8) even though they were not developed for U-bend flow, but only for straight horizontal tubes. From Figures 54 and 55 it can be seen that both of this 
correlations performed as well, if not better than Silva Lima \&Thome (2012). This can be partially explained by total length of the evaporator experiencing straight horizontal flows in comparison to its length experiencing U-bend flows. Total numeric U-bend pressure drop across all thirteen U-bends predicted by Silva Lima \& Thome (2012) is not high enough to distinguish its prediction from straight horizontal tube correlations like Müller-Steinhagen \& Heck (1986) and Grönnerud (1979). Thus, the accuracy of twophase flow predictions for vertical orientations of Silva Lima \& Thome (2012) does not benefit from distinguishing U-bend flows from the significant portion of the evaporator consisting of the straight horizontal tube.

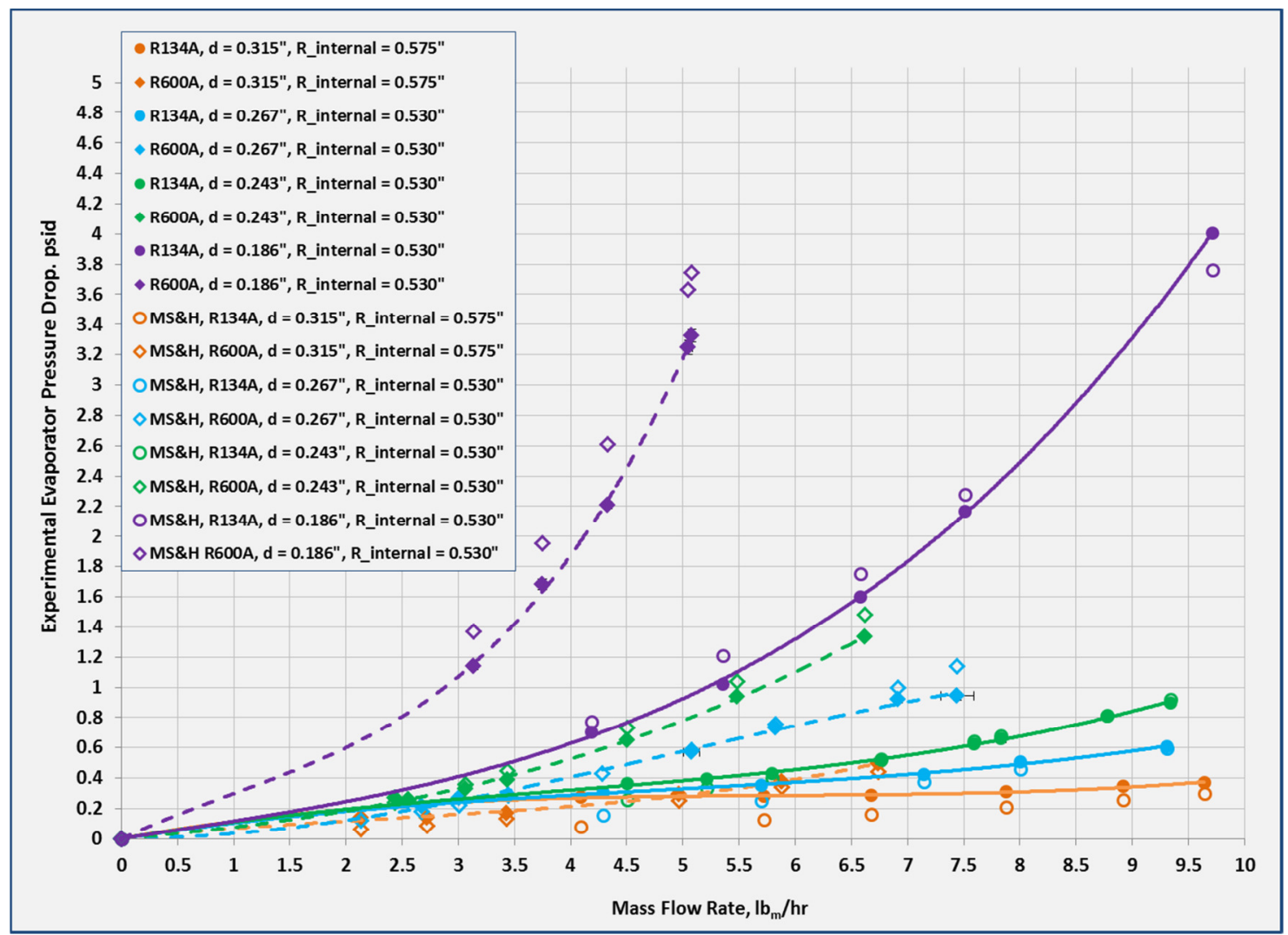

Figure 54: Experimental two-phase refrigerant pressure drop and prediction using adjusted MS\&H (1986) correlation for Data sets 1 - 8: Vertical Orientation Study. 


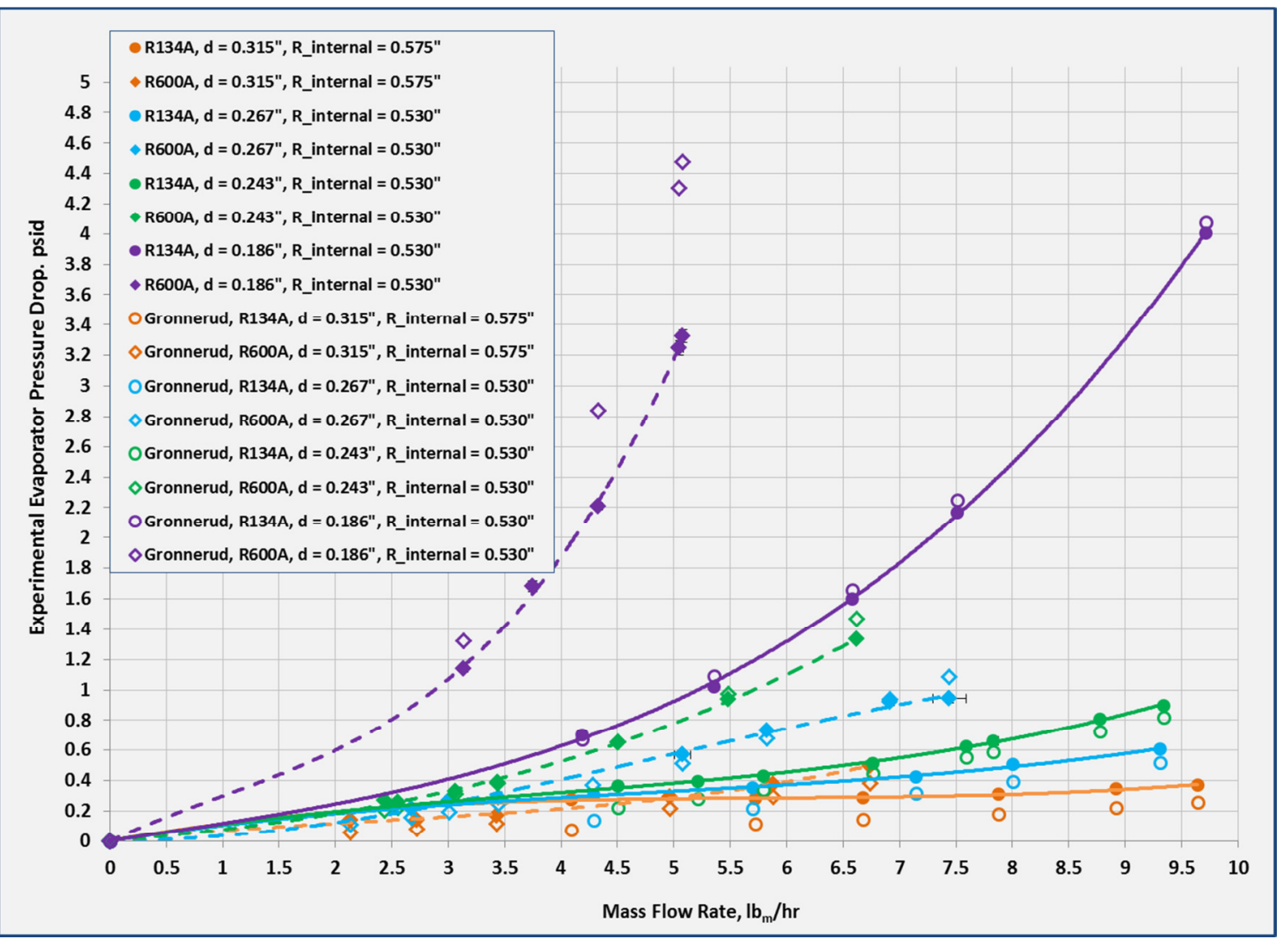

Figure 55: Experimental two-phase refrigerant pressure drop and prediction using Grönnerud (1979) correlation for Data sets 1 - 8.

A small accuracy analysis for all three correlations based on Vertical orientation Data sets $1-8$, the most complex configurations tested, will conclude analysis of experimental data and the performance of these three two-phase pressure drop frictional correlations.

Figure 56 shows a large spread in prediction errors of Silva Lima \& Thome (2012) model. $63.6 \%$ of all collected data is predicted within $\pm 30 \%$ error band. 


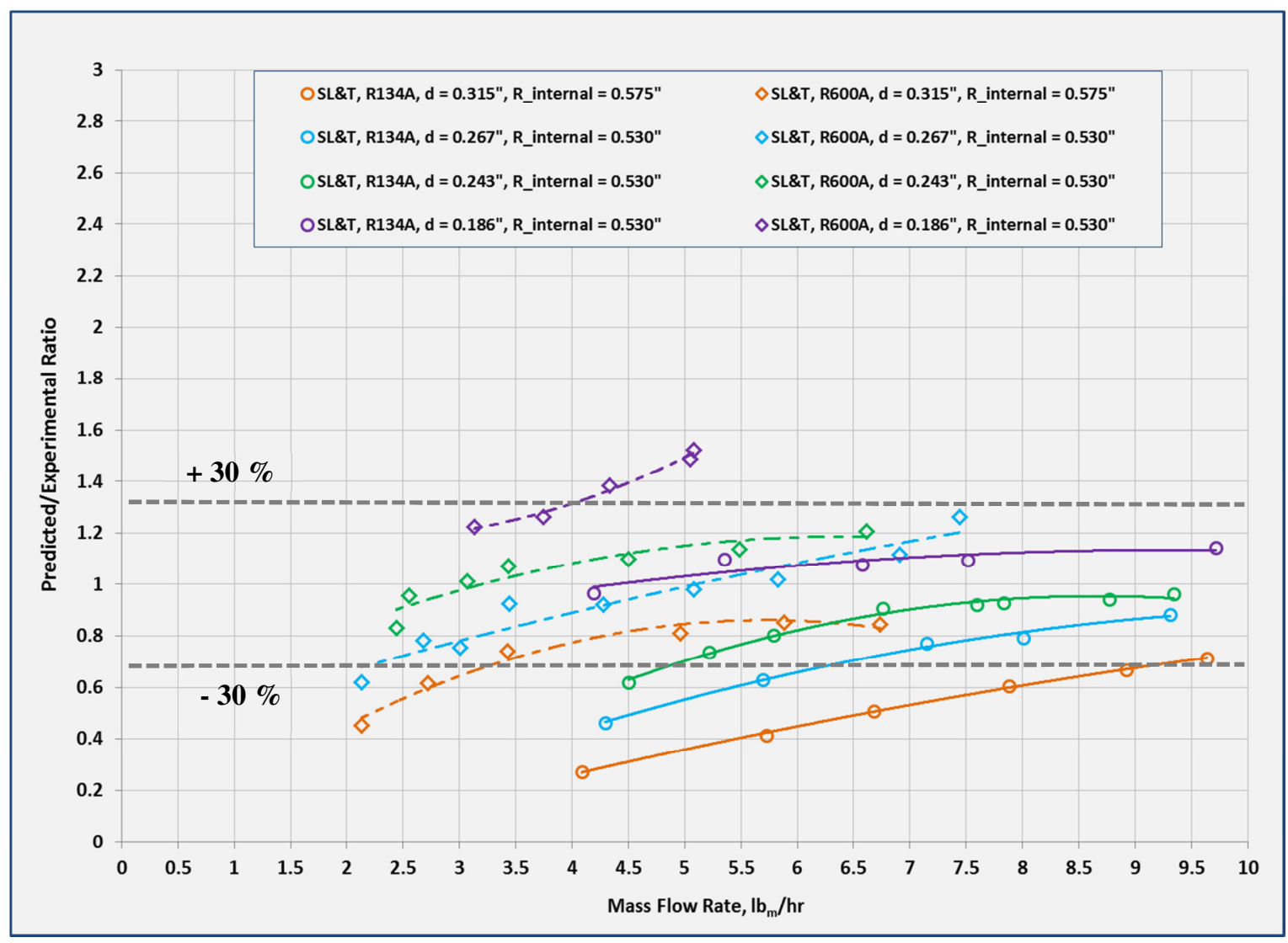

Figure 56: Ratio of predicted two-phase refrigerant pressure drop using Silva Lima \& Thome (2012) correlation to experimental data for Data sets 1 - 8: Vertical Orientation Study.

Similarly, Figures 57 and 58 show spread in prediction errors for Muller-Steinhagen \& Heck (1986) and Grönnerud (1979) models, respectively. $75.8 \%$ and $60.6 \%$ of all collected data is predicted within $\pm 30 \%$ error band Muller-Steinhagen \& Heck (1986) and Grönnerud (1979) models, respectively.

Most of the predictions that do not fall in the $\pm 30 \%$ error band are due to under predicting of the two-phase pressure drop through larger diameter tubes and lower flows. These are the conditions where pressure drop measurement is hardest, because of its magnitude being so close to the lower limit of the measurement devices. The mass fluxes at these conditions are the lowest (approaching single digits in metric units of $\mathrm{kg} / \mathrm{m}^{2} \mathrm{~s}$ ) 
and none of the reviewed models (or any other available empirical two-phase pressure drop models) had similar data available during their model development.

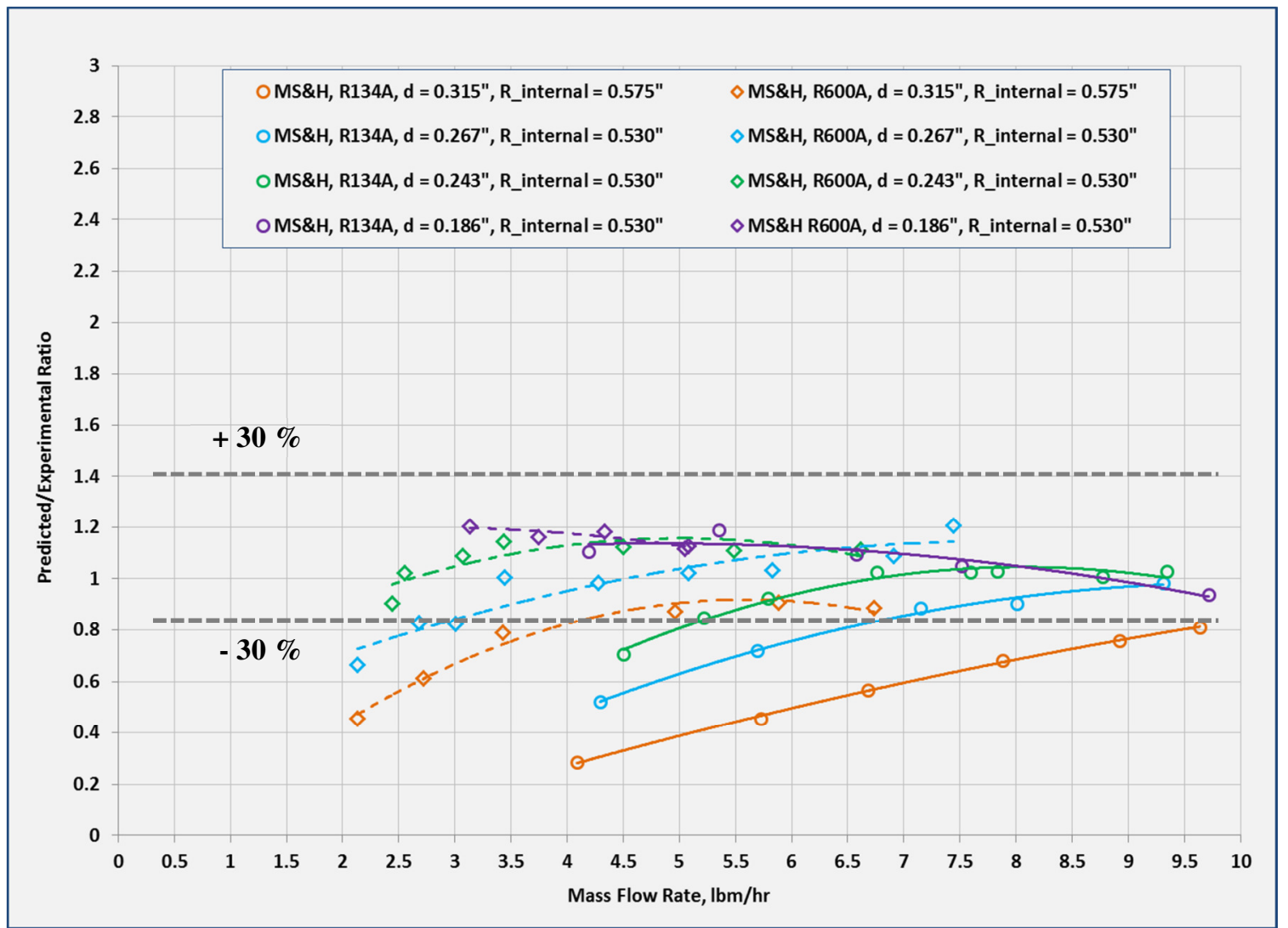

Figure 57: Ratio of predicted two-phase refrigerant pressure drop using adjusted Muller-Steinhagen \& Heck (1986) correlation to experimental data for Data sets 1 - 8: Vertical Orientation Study. 


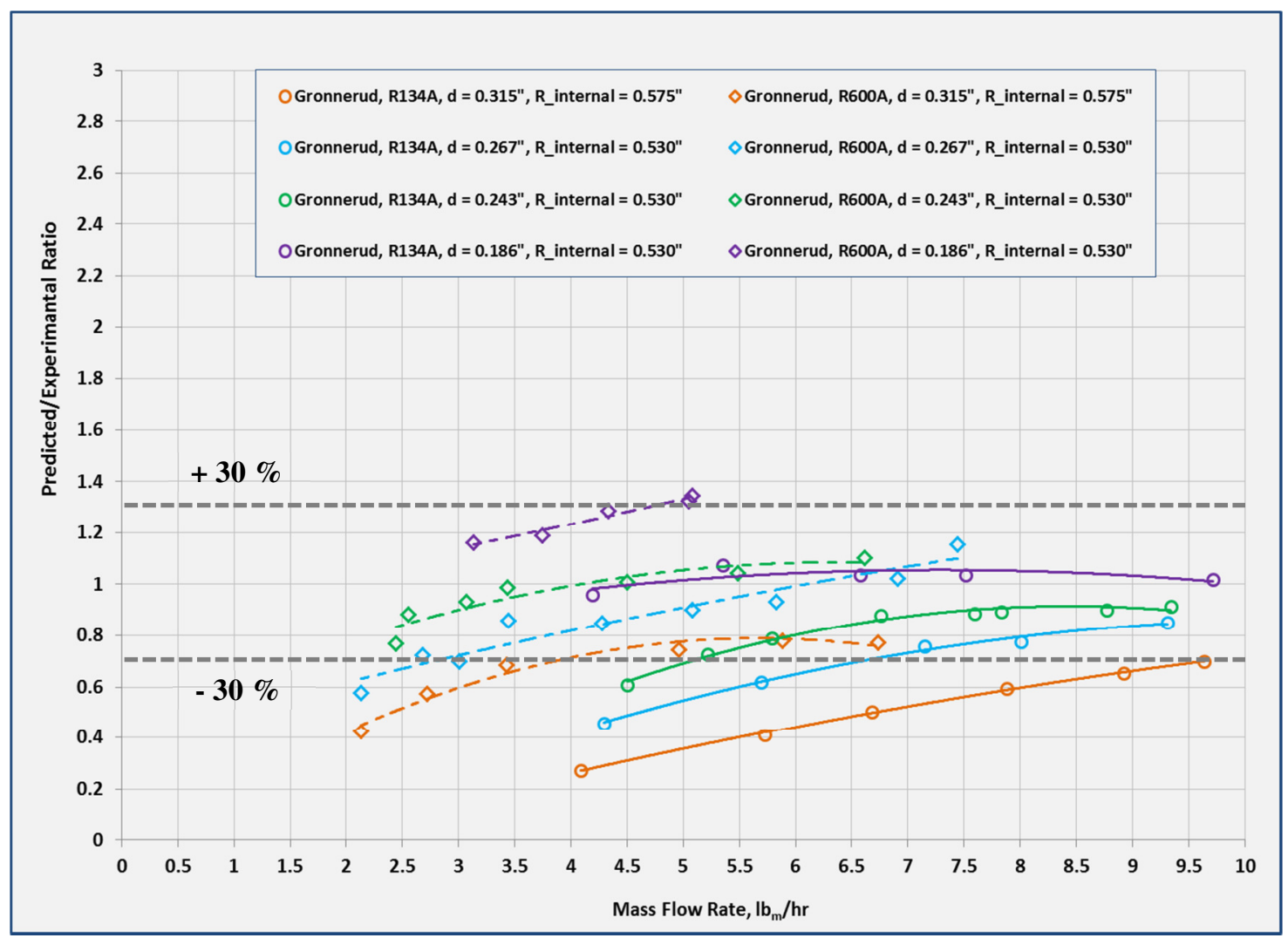

Figure 58: Ratio of predicted two-phase refrigerant pressure drop using Grönnerud (1979) correlation to experimental data for Data sets 1 - 8: Vertical Orientation Study.

All Figures 56 - 58 show the same trends in prediction error. They can easily be seen when quadratic trend lines are added to the error points. Thus, for all tested vertical samples the error increases with increasing mass flow rate and decreasing tube internal diameter. This goes for both refrigerants (R134A and R600A) which points towards strong dependence on the refrigerant physical properties as well. All of these trends could be potentially used to improve the performance of any or all of the reviewed models. 


\section{CONCLUSION AND FUTURE WORK}

The goal of the work was to possibly extend the range of application of three popular pressure drop models, Silva Lima \& Thome (2012), Müller-Steinhagen \& Heck (1986) and Grönnerud (1979), to accurately predict two-phase frictional pressure drop through the evaporator in a domestic refrigerator. The latter two models are frequently used and easy to implement. Silva Lima \&Thome model is one of the latest intricate models that uses Wojtan flow pattern maps and is extremely complex to use. This model has proven to have a very good accuracy for a large data bank, including refrigerants and other liquids at medium and higher flows. However, these models, as well as other two do not have a good accuracy for all tested geometries and orientations at low velocity flows $(<$ $70 \mathrm{~kg} / \mathrm{m}^{2} \mathrm{~s}$ ) reviewed in this paper.

At this time there are no available two-phase frictional refrigerant correlations with a good accuracy of predicting pressure drop for extremely low flows found in household refrigeration systems. Horizontal orientation with thirteen and twenty six horizontal Ubends was the only one to be well predicted by all reviewed correlations. MüllerSteinhagen \& Heck (1986) and Silva Lima \& Thome (2012) had to be slightly adjusted with multipliers and/or offsets in order to have nearly $100 \%$ of data within $\pm 30 \%$ error band. Several different samples with vertical orientations and multiple U-bends were predicted with $60.6 \%, 63.3 \%$ and $75.8 \%$ data falling within $\pm 30 \%$ accuracy band for 
Grönnerud, Silva Lima \& Thome and Müller-Steinhagen \& Heck correlations, respectively.

Furthermore, horizontal orientation tests with double the number of the U-bends showed that horizontal U-bends (at least in tested geometries) at low mass fluxes under $70 \mathrm{~kg} / \mathrm{m}^{2} \mathrm{~s}$ do not play a significant role in a total frictional pressure drop in horizontal evaporators. A Curvature Ratio study showed no two-phase frictional pressure drop dependence on the curvature ratio of the U-bends. The main geometrical properties affecting total two-phase frictional pressure drop in evaporators at low flows are an internal diameter of the tube and a total length of evaporator tube. And the main physical properties of the refrigerant flow affecting total two-phase frictional pressure drop in evaporators at low flows are the type of refrigerant and its mass flow rate.

Three components of the total pressure drop through the evaporator: momentum, static and frictional must all be included in calculations. Omitting momentum pressure drop and static pressure drop component could result in under-prediction by as much as $4.4 \%$ and $8.0 \%$, respectively. Omitting single phase property changes based on pressure decrease along the tube could lead to over-prediction by as much as $6 \%$ (Section 6.1).

The next steps in studying two-phase frictional pressure drop at low flows is taking a more intricate approach towards adjusting one or some of the reviewed models in order to extend their application to this range of flows. There is an obvious relationship between the prediction error by all reviewed models and at least three variables: mass flow rate, tube diameter and refrigerant physical properties (as discussed at the end of the analysis section). Refrigerant properties that might have some of the most significant effect are, 
perhaps, density and viscosity; however, the level of their influence needs to be further studied in the future work. All three of reviewed models have similar error dependence on these main factors and using current data bank of nearly 100 data points any or all of these models could be mathematically adjusted for a much improved performance. Furthermore, a brand new empirical correlation could be potentially considered for this region of flows; however, it may require an increase in the data bank size for good accuracy. As a part of this data collection and correlation analysis in horizontal application, Müller-Steinhagen \& Heck (1986) had a multiplier of 0.867 and Silva Lima \& Thome (2012) had a multiplier of 1.06 and 0.032 offset included in their models for a significant accuracy improvement.

Overall, even though none of the reviewed two-phase pressure drop models were able to accurately predict experimental data, the data itself is very useful for future designs of evaporators in domestic refrigerators since the flows, geometries and orientations tested here are being commonly used. 


\section{REFERENCES}

ASHRAE, 1993. 1993 ASHRAE Handbook Fundamentals, America Soiety of Heating, Refrigerating and Air Conditioning Engineers, Inc., Atlanta.

Bandel, J., 1973. Druckverlust und wärmeügang bei der verdampfung siedender kältemittel im durchströmten waagerechten rohr. Ph. D. thesis, University of Karlsruhe.

Bankoff, S. G., 1960. A variable density single-fluid model two-phase flow with particular reference to steam-water. J. Heat Transf. 11 (Series B), 265-272.

Baroczy, C. J., 1965. A symmetric correlation for two-phase pressure drop. Chem. Eng. Prog. Symp. Ser. 62 (44), 232-249.

Beattie, D. R. H., 1972. Two-phase flow structure and mixing length theory. Nucl. Eng. Des. 21, 46-64.

Biberg, D., 1999. An explicit approximation for the wetted angle in two-phase stratified pipe flow, Canadian J. Chem.Eng. 77(1999) 1221-1224

Calm, J. M. and Hourahan, G. C. 2001, Refrigerant Data Summary. Engineered Systems, 18(11):74-88

Chawla, J. M., 1967. Wärmeübergang and druckfall in waagerechten rohren bei der strömung von verdampfeden kältemitteln. 523. VDI-Forschungsh, Ch. Lg1-Lg2.

Chen, I. Y., Wang C.C. and Lin S.Y., 2004b. Measurements and correlations of frictional single-phase and two-phase pressure drops of 41-a flow in small u-type return bends, International Journal of Heat and Mass Transfer 47: 2241-9.

Chisholm, D., 1973. Pressure gradients sue to friction during the flow of evaporating two-phase mixtures in smooth tubes and channels. Int. J. Heat Mass Transf. 16, 347-358.

Cicchitti, A., Lombardi, C., Silvestri, M. Zavattarelli, G.S.R., 1960. Two-phase cooling experiments - pressure drop, heat transfer and burnout measurements, Energ. Nucl. 7 (6), 407-425. 
Domanski, P. A., and Hermes C. J. L. 2006.An improved two-phase pressure drop correlation for 180return bends. 3rd Asian Conference on Refrigeration and AirConditioning, Gyeonju, Korea, May 21-23.

Domanski, P.A. and Yachar David, 2006. Comparable Performance Evaluation of HC and HFC Refrigerants in an Optimized System.

Duckler, A.E., 1962. Two-Phase Flow, data analysis and correlation, Studies at University of Houston, Houston, TX,

Embraco, 2015. VEGD6H Compressor Technical Sheet,

Energy.gov. 2015. Estimating appliance and home electronic energy use, $<$ http://energy.gov/energysaver/estimating-appliance-and-home-electronicenergy-use>.

Friedel, L., 1979. Improved friction drop correlations for horizontal and vertical twophase pipe flow. In: European Two-Phase Flow Group Meeting, paper E2, Ispra, Italy.

Geary, D.F. 1975. Return bend pressure drop in refrigeration systems. ASHRAE Translations 81:250-64

Grönnerud, R., 1979. Investigation of liquid hold-up, flow-resistance and heat transfer in circulation type evaporators, Part iv: two phase flow reisistance in boiling refrigerants. In: Annexe 1972-1, Bull. de1'Inst du Froid.

Hart, j. Hamersma, P. J., Fortuin, J. M. H., 1989. Correlations predicting frictional pressure drop and liquis holdup during horizontal gas-liquid pipe flow with small liquid holdup. In. J. Multiphase Flow 15 (6), 947-964.

Hashizume, K., Ogiwara, H., Taniguchi, H., 1985. Flow pattern, void fraction and pressure drop of refrigerant two-phase flow in a horizontal pipe - 2: analysis of frictional pressure drop. Int. J. Multiphase Flow 11, 643-658.

Ito, H. 1959. Pressure losses in smooth pipe bends. Translations of the ASME, Series D, Journal of Basic Engineering March, 131-43

Ito, H. 1960. Pressure losses in smooth pipe bends. Trans. ASME, Series D, J. of Basic Engineering, march, pp. 131-43.

Kattan, N., and J.R. Thome, D. Favrat, 1998a. Flow boiling in horizontal tubes. Part 1: Development of siabatic two-phase flow pattern map, J. Heat Transfer 120 (1) (1998) 140-147. 
Kutateladze, S.S., 1948. On the transition to film boiling under natural convection, Kotloturbostroenie 3 (10).

Lockhart, R. W., Martinelli, R.C. 1949. Proposed correlation of data for isothermal twophase, two-component flow in pipes. Chem. Eng. Proce. 45 (1), 39-48.

Maclaine-cross, I. L. and Leonardi, E., 1996. Comparative Performance of Hydrocarbon Refrigerants.

Moreno Quibèn, J., and J.R. Thome. 2007a. Flow patern based two-phase frictional pressure drop model for horizontal tubes, Part 1: Diabatic and Adiabatic experimental study. International Journal of Heat Fluid Flow 28:1049-59.

Moreno Quibèn, J., and J.R. Thome. 2007b. Flow pattern based two-phase frictional pressure drop model for horizontal tubes, Part 2: New phenomenological model. International Journal of Heat Fluid Flow 28: 1060-72.

Müller-Steinhagen, H., and K. Heck. 1986. A simple friction pressure correlation for twophase flow in pipes. Chemical Engineering and Processing: Process Intensification 20:297-308.

Olujić, Z., 1985. Predicting two-phase flow friction loss in horizontal pipes. Chem. Eng. 24 (June), 45-50

Ould-Didi, M.B., Kattan, N., Thome, J.R., 2002. Prediction of two-phase pressure gradients of refrigerants in horizontal tubes. Int. J. Refrig. 25, 935-947.

Paliwoda, A. Generalized method of pressure drop and tube length calculation with boiling and condensing refrigerants within the entire zone of saturation, Int. J. Refrig. 1989 Vol. 12, November.

Pierre, B., 1964. Flow resistance with boiling refrigerants - Part 1. ASHRAE J. 6 (9), 5865.

Silva Lima, R.J., and J.R. Thome. 2010. Two-phase frictional pressure drops in adiabatic horizontal circular smooth u-bends and contiguous straight pipes (RP-1444), HVAC\&R Research 16:383-98.

Silva Lima, R.J., and J.R. Thome. 2012a. Two-phase frictional pressure drops in U-bends and contiguous straight tubes for different refrigerants, orientations, tube and bend diameters: Part 1. Experimental results (RP-1444), HVAC\&R Research 18:104771. 
Silva Lima, R.J., and J.R. Thome. 2012b. Two-phase frictional pressure drops in U-bends and contiguous straight tubes for different refrigerants, orientations, tube and bend diameters: Part 2. New models (RP-1444), HVAC\&R Research 18:1072-97.

EPA. 2010. SNAP Proposed Rule 17. 2010. Federal Register, Vol. 75, No, 89. $<$ http://www2.epa.gov/sites/production/files/201510/documents/rule_17_proposed_rule.pdf.>

Statista.com. 2015. Total unit shipments of core major household appliances in the U.S. from 2000 to 2017 (in millions). <http://www.statista.com/statistics/220180/unitshipments-of-core-major-appliances-in-the-us/>.

Steiner, D. Heat transfer to boiling saturated liquids, in: VDI-Wärmeatlas (VDI Heat Atlas), Verein Deutscher Ingenieure, VDi-Gessellschaft Verfahrenstechnik und Chemie-ingenieurwesen (GCV), Düsseldorf, 1993 (Translator: J.W. Fullarton).

Thome, J.R.S., 1964. Prediction of pressure drop during forced circulation boiling of water. Int. J. Mass Transf. 7, 709-724.

Wojtan, L., T. Ursenbacher, and J. R. Thome, 2005a. Investigation of flow boiling in horizontal tubes. Part 1: New diabatic two-phase flow pattern map. International Journal of Heat and Mass Transfer 48: 2955-69.

Wojtan, L., T. Ursenbacher, and J. R. Thome, 2005b. Investigation of flow boiling in horizontal tubes. Part 2: Development of new heat transfer model for stratifiedwavy, dryout and mist flow regimes. International Journal of Heat and Mass Transfer 48: 2970-85. 


\section{APPENDICES}

\section{NOMENCLATURE}

A

B1

$B 2$

C

$d$

D

De

F

Fr

$g$

G

K

$L$

$\dot{m}$

$N$

$P$

$R$

$Q$
$=$ cross-sectional area, $\mathrm{m}^{2}\left(\mathrm{in}^{2}\right)$

$=$ coefficient $(-)$

$=$ coefficient $(-)$

$=$ coefficient $(-)$

$=$ internal diameter, $\mathrm{m}$ (in)

$=$ bend diameter, $\mathrm{m}$ (in)

$=$ Dean number

$=$ friction factor $(-)$

$=$ Froude number $(-)$

$=$ acceleration of gravity, $\mathrm{m} / \mathrm{s}^{2}\left(\mathrm{in} / \mathrm{s}^{2}\right)$

$=$ mass flux, $\mathrm{kg} / \mathrm{m}^{2} \mathrm{~s}\left(\mathrm{lb} / \mathrm{ft}^{2} \mathrm{~h}\right)$

$=$ coefficient $(-)$

$=$ tube length, $\mathrm{m}$ (in)

$=$ mass flow rate, $\mathrm{kg} / \mathrm{s}(\mathrm{lbms} / \mathrm{s})$

$=$ number of data

$=$ pressure, $\mathrm{Pa}(\mathrm{psi})$

$=$ U-bend radius, $\mathrm{m}$ (in)

$=$ heat flux, W/m $\mathrm{m}^{2}\left(\mathrm{~W} / \mathrm{in}^{2}\right)$ 


$$
\begin{array}{ll}
\text { Re } & =\text { Reynolds number }(-) \\
t & =\text { Tube wall thickness (in) } \\
T & =\text { temperature, } \mathrm{K} \text { or }{ }^{0} \mathrm{C}\left({ }^{0} \mathrm{~F}\right) \\
u & =\text { velocity, } \mathrm{m} / \mathrm{s}(\mathrm{in} / \mathrm{s}) \\
\dot{V} & =\text { volumetric flow rate, } \mathrm{m}^{3} / \mathrm{s}\left(\mathrm{in}^{3} / \mathrm{s}\right) \\
W e & =\text { Weber number }(-) \\
x & =\text { vapor quality }(-) \\
z & =\text { axial position } \mathrm{m}(\mathrm{in})
\end{array}
$$

\begin{tabular}{|c|c|c|}
\hline$\beta$ & $=$ & coefficient $(-)$ \\
\hline$\delta$ & $=$ & film thickness, m (in.) \\
\hline$\Delta$ & $=$ & variation ( - ) \\
\hline$\varepsilon$ & $=$ & void fraction ( - ) \\
\hline$\theta$ & $=$ & angle, rad \\
\hline$\theta^{*}$ & $=$ & relative angle, rad \\
\hline$\vartheta$ & $=$ & coefficient $(-)$ \\
\hline$\mu$ & $=$ & dynamic viscosity, $\mathrm{Pa} \mathrm{s}$ \\
\hline$\Pi$ & $=$ & dimensionless number ( - ) \\
\hline$\rho$ & $=$ & density, $\mathrm{kg} / \mathrm{m}^{3}\left(\mathrm{lb} / \mathrm{in}^{3}\right)$ \\
\hline$\phi$ & $=$ & two-phase Grönnerud multiplier \\
\hline$\sigma$ & $=$ & surface tension, N/m (lb/in) \\
\hline
\end{tabular}

\section{Greek Symbols}

\section{Subscripts}

$$
\begin{array}{ll}
\text { crit } & =\text { critical } \\
\text { de } & =\text { dryout completion }
\end{array}
$$




$\begin{array}{ll}d i & =\text { dryout inception } \\ d r y & =\text { dry } \\ H & =\text { homogeneous } \\ i & =\text { index } \\ \text { in } & =\text { flow inlet } \\ \text { out } & =\text { flow outlet } \\ V & =\text { vapor or gas } \\ L & =\text { liquid }\end{array}$


Appendix A

\section{Description of databanks used to develop several popular two-phase pressure drop models}

\begin{tabular}{|c|c|c|c|c|c|c|}
\hline Source & $\begin{array}{c}\text { Refrigerant } \\
\text { tested }\end{array}$ & Orientation/conditions & $\begin{array}{c}\text { Saturation } \\
\text { temperature, } \\
{ }^{\circ} \text { F }\end{array}$ & $\begin{array}{l}\text { Mass flux, } \\
\mathrm{kg} / \mathrm{m}^{2} \mathrm{~s}\end{array}$ & $\begin{array}{c}\text { Inner } \\
\text { diameter, in }\end{array}$ & $\begin{array}{l}\text { Bend centerline } \\
\text { diameter, in }\end{array}$ \\
\hline $\begin{array}{l}\text { Müller- } \\
\text { Steinhagen \& } \\
\text { Heck, } 1986\end{array}$ & $\begin{array}{l}\text { R12, R11, } \\
\text { R22 }\end{array}$ & $\begin{array}{l}\text { Horizontal Straight, } \\
\text { Circular Adiabatic, } \\
\text { Smooth, vertical wpflow }\end{array}$ & N/A & $50-2490$ & $0.551,0.957$ & N/A \\
\hline $\begin{array}{l}\text { Quibèn and } \\
\text { Thome, Part 1, } \\
2007\end{array}$ & $\begin{array}{l}\text { R134A, R22, } \\
\text { R410A }\end{array}$ & $\begin{array}{l}\text { Horizontal straight, } \\
\text { Diabatic (heat flux 6.0- } \\
57.5 \mathrm{~kW} / \mathrm{m}^{2} \text { ) and } \\
\end{array}$ & 41 & $70-700$ & $0.315,0.543$ & N/A \\
\hline $\begin{array}{l}\text { Silva Lima \& } \\
\text { Thome, } 2010\end{array}$ & $\mathrm{R} 134 \mathrm{~A}$ & $\begin{array}{l}\text { Horizontal U-bends, } \\
\text { Horizontal Straight, } \\
\text { Circular Adiabatic, }\end{array}$ & $37-41$ & $155,310,518$ & 0.52 & 2.6 \\
\hline $\begin{array}{l}\text { Silva Lima \& } \\
\text { Thome Part } 1 \text {, }\end{array}$ & $\begin{array}{l}\mathrm{R} 134 \mathrm{~A}, \\
\mathrm{R} 410 \mathrm{~A}\end{array}$ & $\begin{array}{l}\text { Horizontal straight, } \\
\text { vertical upflow and }\end{array}$ & 41 and 50 & $150,300,500$ & $\begin{array}{l}0.527,0.421, \\
0.307\end{array}$ & $\begin{array}{l}\text { 2.602,2.157,1.5, } \\
1.248,0.976\end{array}$ \\
\hline
\end{tabular}


Appendix B

\section{Wojtan et al., 2005 Flow Pattern Map}

Seven step process of creating a Wojtan flow pattern map for a set of operational conditions is described as:

1. Dimensionless geometrical parameters $\varepsilon, A_{L D}, A_{V D}, h_{L D}, P_{i D}, Q_{s t r a t}$, representing cross-sectional vapor void fraction, cross-sectional area occupied by liquids and vapor phases, cross-sectional area occupied by vapor phase, vertical height of fluid, perimeter of the interface, and stratified flow angle of the tube perimeter (rad) respectively are calculated.

Cross-sectional vapor void fraction is found using Steiner (Steiner, 1993) version of the drift flux model of Rouhani and Axelsson for horizontal tubes (B1):

$$
\begin{aligned}
\varepsilon=\frac{x}{\rho_{V}}[[1+ & 0.12(1-x)]\left(\frac{x}{\rho_{V}}+\frac{1-x}{\rho_{L}}\right) \\
& \left.+\frac{1.18(1-x)\left[g \sigma\left(\rho_{L}-\rho_{V}\right]^{0.25}\right.}{G \rho_{L}{ }^{1 / 2}}\right]^{-1}
\end{aligned}
$$




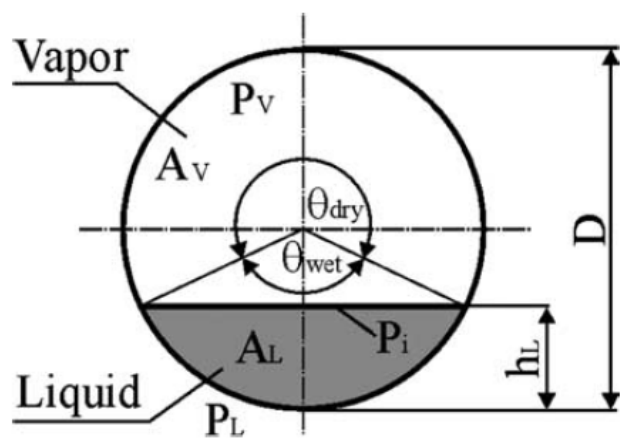

Figure 59: Stratified two-phase flow cross-section

$$
\begin{gathered}
A_{L D}=\frac{A(1-\varepsilon)}{d^{2}} \\
A_{V D}=\frac{A \varepsilon}{d^{2}} \\
h_{L D}=0.5\left(1-\cos \left(\frac{2 \pi-\theta_{\text {strat }}}{2}\right)\right) \\
P_{i D}=\sin \left(\frac{2 \pi-\theta_{\text {strat }}}{2}\right)
\end{gathered}
$$

where $Q_{\text {strat }}$, the stratified flow angle of tube perimeter $\left(Q_{w e t}\right.$ in Figure 1$)$ was evaluated in terms of void fraction by Biberg, 1999 to avoid any iterations, which significantly simplifies evaluation of the flow (Wojtan et. al, Part 1, 2004).

$$
\begin{aligned}
Q_{\text {strat }}=2 \pi-2\{ & \pi(1-\varepsilon)+\left(\frac{3 \pi}{2}\right)^{1 / 3}\left[1-2(1-\varepsilon)+(1-\varepsilon)^{1 / 3}-\varepsilon^{1 / 3}\right]-\frac{1}{200}(1 \\
& \left.-\varepsilon) \varepsilon[1-2(1-\varepsilon)]\left[1+4\left((1-\varepsilon)^{2}+\varepsilon^{2}\right)\right]\right\}
\end{aligned}
$$

2. The stratified-wavy to intermittent/annular, SW-I/A, transition $\left(G_{\text {wavy }}\right)$ is calculated using the adiabatic version of the original Kattan-Thome-Favrat (Kattan et. al, 1998) boundary from (Wojtan et. al, Part 1, 2004) as shown in equation (B7): 


$$
G_{\text {wavy }}=\left\{\frac{16 A_{V D}^{3} g d \rho_{L} \rho_{V}}{x^{2} \pi^{2}\left(1-\left(2 h_{L D}-1\right)^{2}\right)^{0.5}}\left[\frac{\pi^{2}}{25{h_{L D}}^{2}}\left(\frac{W e}{F r}\right)_{L}^{-1}+1\right]\right\}^{0.5}+50
$$

where $\left(\frac{W e}{F r}\right)_{L}$, is a ratio of Weber and Froude numbers for liquid (B8):

$$
\left(\frac{W e}{F r}\right)_{L}=\frac{\rho_{L} d^{2} g}{\sigma}
$$

Further, the stratified-wavy region is subdivided into three zones:

- Slug, S, zone for which $G>G_{\text {wavy }}\left(x_{I A}\right)$

- Slug/stratified-wavy, Slug/SW, zone for which $G_{\text {strat }}<G<G_{\text {wavy }}\left(x_{I A}\right)$ and $x<x_{I A}$

- Stratified-wavy zone, $\mathrm{SW}$, for $x \geq x_{I A}$

3. The stratified/stratified-wavy, S-SW, flow transition is calculated from the original Kattan-Thome-Favrat (Kattan et. al, 1998) boundary:

$$
G_{\text {strat }}=\left\{\frac{226.3^{2} A_{L D} A_{V D}^{2} \rho_{V}\left(\rho_{L}-\rho_{V}\right) \mu_{L} g}{x^{2}(1-x) \pi^{3}}\right\}^{1 / 3}
$$

with

$$
G_{\text {strat }}=G_{\text {strat }}\left(x_{I A}\right) \quad \text { at } \quad x<x_{I A}
$$

4. The intermittent-annular, I-A, two phase flow transition is also calculated from the original boundary and is extended down to intersection with $G_{\text {strat }}$.

$$
x_{I A}=\left\{\left[0.34^{1 / 0.875}\left(\frac{\rho_{V}}{\rho_{L}}\right)^{-1 / 1.75}\left(\frac{\mu_{L}}{\mu_{V}}\right)^{-1 / 7}\right]+1\right\}^{-1}
$$

5. The annular-dryout curve, A-D, is found using (B12). 


$$
\begin{aligned}
G_{\text {dryout }}=\left[\frac{1}{0.235}\right. & \left(\ln \left(\frac{0.58}{x}\right)\right. \\
& \left.+0.52)\left(\frac{D}{\rho_{V} \sigma}\right)^{-0.17}\left(\frac{1}{g D \rho_{V}\left(\rho_{L}-\rho_{V}\right)}\right)^{-0.37}\left(\frac{\rho_{V}}{\rho_{L}}\right)^{-0.25}\left(\frac{q}{q_{\text {crit }}}\right)^{-0.70}\right]^{0.926}
\end{aligned}
$$

The critical heat flux (B13), calculated using Kutateladze (Kutateladze, 1948) correlation provided by Wojtan in (Wojtan et. al, Part 1, 2004):

$$
q_{c r i t}=0.131 \rho_{V}^{0.5} h_{L V}\left(g\left(\rho_{L}-\rho_{V}\right) \sigma\right)^{0.25}
$$

where $h_{L V}$ is a tabulated latent heat of vaporization of the refrigerant.

6. And dryout-mist transition boundary, D-M, is calculated with (B14).

$$
\begin{aligned}
& G_{\text {mist }} \\
& =\left[\frac { 1 } { 0 . 0 0 5 8 } \left(\ln \left(\frac{0.61}{x}\right)\right.\right. \\
& \left.+0.57)\left(\frac{D}{\rho_{V} \sigma}\right)^{-0.38}\left(\frac{1}{g D \rho_{V}\left(\rho_{L}-\rho_{V}\right)}\right)^{-0.15}\left(\frac{\rho_{V}}{\rho_{L}}\right)^{0.09}\left(\frac{q}{q_{\text {crit }}}\right)^{-0.27}\right]^{0.943}
\end{aligned}
$$

7. Finally, the following conditions are applied to complete the map for higher vapor qualities region:

- If $G_{\text {strat }}\left(x_{i}\right) \geq G_{\text {dryout }}\left(x_{i}\right)$, then $G_{\text {dryout }}\left(x_{i}\right)=G_{\text {strat }}\left(x_{i}\right)$

- If $G_{\text {wavy }}\left(x_{i}\right) \geq G_{\text {dryout }}\left(x_{i}\right)$, then $G_{\text {dryout }}\left(x_{i}\right)=G_{\text {wavy }}\left(x_{i}\right)$

- If $G_{d r y}\left(x_{i}\right) \geq G_{m i s t}\left(x_{i}\right)$, then $G_{d r y}\left(x_{i}\right)=G_{m i s t}\left(x_{i}\right)$ (possible at high mass fluxes and low heat fluxes)] 


\section{Appendix C}

\section{Moreno Quibèn and Thome, 2007 pressure drop model for straight tubes}

A full outline of flow pattern based two-phase pressure drop correlations developed by Moreno Quibèn \& Thome, 2007 is provided further.

For annular flow (A) Moreno Quibèn and Thome's, 2007 data processing resulted in the pressure drop correlation (C1).

$$
(\Delta p)_{\text {annular }}=4 f_{\text {straight }- \text { annular }}\left(\frac{L}{d}\right) \frac{\rho_{V} u_{V}^{2}}{2}
$$

Here $f_{\text {straight-annular flow }}$ is an interfacial friction factor for straight tubes with annular flow proposed by Silva Lima \& Thome (Silva Lima \& Thome, Part 2, 2012), equation (20), and $u_{V}$ is a vapor phase velocity found using equation (22).

For Slug/Intermittent (Slug+I) flows Moreno Quibèn and Thome, 2007 developed a single correlation due to significant similarities in the frictional pressure drops between these two regimes.

$$
(\Delta p)_{\text {slug }+ \text { intermittent }}=\Delta p_{L}\left(1-\frac{\varepsilon}{\varepsilon_{I A}}\right)^{0.25}+(\Delta p)_{\text {annular }}\left(\frac{\varepsilon}{\varepsilon_{I A}}\right)^{0.25}
$$

In equation $(\mathrm{C} 2) \Delta p_{L}$ is a single-phase frictional liquid pressure drop, $\varepsilon_{I A}$ is a void fraction at the intermittent to annular transition boundary $x_{I A},(\Delta p)_{\text {annular }}$ is found using equation (C1) above with film thickness calculated at $\theta_{d r y}=0$. 
For Stratified-Wavy flow regime (SW) the parameter that defines the flow structure and the contact between the two-phase flow and the perimeter of the tube is $\theta_{d r y}$. See Figure 1. Quibèn and Thome state that it was determined experimentally that in these regimes the flow creeps up the sides of the tube to varying extend, which significantly affects the interfacial perimeters $P_{i}, P_{V}$ and $P_{G}$ and interfacial friction factor $f_{i}$. The authors range the value of $\theta_{d r y}$ from 0 at $G_{w a v y}(x)$ at annular flow to $\theta_{\text {strat }}$ for $G_{\text {strat }}(x)$ at stratified flow regime. Moreno Quibèn \& Thome, 2007 use the equation proposed by Wojtan et al. (Wojtan et. al, Part 1, 2005) based on experimental heat transfer data for SW region to mathematically describe this variation of $\theta_{d r y}$ across the SW region, (C3).

$$
\begin{gathered}
\theta_{d r y}=\left[\frac{\left(G_{\text {wavy }}-G\right)}{\left(G_{\text {wavy }}-G_{\text {strat }}\right)}\right]^{0.61} \theta_{\text {strat }} \\
f_{\text {tratified-wavy }}=\theta_{d r y}^{*} f_{V}+\left(1-\theta_{\text {dry }}^{*}\right) f_{\text {straight-annular }} \\
\theta_{d r y}^{*}=\theta_{d r y} / 2 \pi \\
f_{V}=\frac{0.079}{R e_{V}^{0.25}}
\end{gathered}
$$

where

and

(C6) and (C7) are two classical correlations used for single-phase flows.

All these components together allow calculation of the total two-phase frictional pressure drop for stratified/wavy flows, (C8).

$$
(\Delta p)_{\text {stratified-wavy }}=4 f_{\text {stratified-wavy }}\left(\frac{L}{d}\right) \frac{\rho_{V} u_{V}^{2}}{2}
$$


For Slug-Stratified Wavy (Slug+SW) regime the tube inner perimeter is wetted intermittently by the slug flow following by low amplitude waves. As the quality is increased the slug flow periods diminish completely and according to Wojtan flow pattern map are completely replaced by the stratified wavy flow at the $\mathrm{x}_{\mathrm{IA}}$, vapor quality at transition from intermittent to annular flow (see Figure 1). Moreno Quibèn \& Thome, 2007 chose to model this region using the frictional pressure drop correlation (C9).

$$
(\Delta p)_{\text {slug }+S W}=\Delta p_{L}\left(1-\frac{\varepsilon}{\varepsilon_{I A}}\right)^{0.25}+(\Delta p)_{\text {stratified-wavy }}\left(\frac{\varepsilon}{\varepsilon_{I A}}\right)^{0.25}
$$

In the above equation $(\Delta p)_{\text {stratified-wavy }}$ is a two-phase frictional pressure drop for stratified-wavy regime evaluated at actual vapor quality, (C8).

For Stratified (S) flow the dry angle and stratified angle are coincident. This regime occurs at very low mass fluxes, which are most common in household refrigerators and are going to be extensively analyzed within this study. No literature was found that covers low flows like these. Moreno Quibèn \& Thome, 2007 did suggest equations (C10)-(C12) could be used to determine frictional pressure drop in this region, but the equations were never checked experimentally. For $x \geq x_{I A}$ :

$$
f_{\text {stratified }}=\theta_{\text {strat }} f_{V}+\left(1-\theta^{*}{ }_{\text {strat }}\right) f_{\text {straight-annular }}
$$

where $\theta^{*}{ }_{\text {strat }}$ is once again equal to $\theta^{*}{ }_{\text {strat }} / 2 \pi$ and $f_{V}$ found using equation (C6). And as before, $f_{\text {straight-annular flow }}$ is evaluated using actual vapor qualities but using equation (20).

And the total frictional pressure drop was suggested by authors as (C11) and (C12). 


$$
(\Delta p)_{\text {stratified }\left(x \geq x_{I A}\right)}=4 f_{\text {stratified }}\left(\frac{L}{d}\right) \frac{\rho_{V} u_{V}^{2}}{2}
$$

$(\Delta p)_{\text {stratified }\left(x<x_{I A}\right)}$

$$
=\Delta p_{L}\left(1-\frac{\varepsilon}{\varepsilon_{I A}}\right)^{0.25}+(\Delta p)_{\text {stratified }\left(x \geq x_{I A}\right)}\left(\frac{\varepsilon}{\varepsilon_{I A}}\right)^{0.25}
$$

where $(\Delta p)_{\text {stratified }\left(x \geq x_{I A}\right)}$ is evaluated at actual vapor qualities above $x_{I A}$.

Dryout and Mist flow patterns developed by Wojtan et al., 2007 occur at very high vapor qualities for extremely low flows. Mist flow type is a possibility for higher end of the low flow range, while dryout is definitely expected under conditions considered in this study.

Thus, for Dryout flow (D) regime at lower flows the transition occurs from either stratified-wavy or annular flow regime. This flow regime was mathematically described by Quibèn and Thome using interpolation between the annular and mist flows. The dryout region occurs from the inception of dryout (vapor quality $x_{D I}$ ) at the top of the tube, to the completion of dryout (vapor quality $x_{D E}$ ) at the bottom of the tube and the total two-phase frictional pressure drop is found with (C13), where $(\Delta p)_{\text {annular/stratified-wavy }}\left(x_{D I}\right)$ is found using either equation (C1) or (C8) depending on the region from which the dryout inception has occurred.

$$
\begin{aligned}
(\Delta p)_{\text {dryout }}= & (\Delta p)_{\text {annular/stratified-wavy }}\left(x_{D I}\right) \\
& -\frac{x-x_{D I}}{x_{D E}-x_{D I}}\left[(\Delta p)_{\text {annular/stratified-wavy }}\left(x_{D I}\right)\right. \\
& \left.-(\Delta p)_{\text {mist }}\left(x_{D E}\right)\right]
\end{aligned}
$$

Value of $x_{D I}$ is found using correlation suggested by Wojtan et al. (Wojtan et. al, Part 1, 2004). 


$$
x_{D I}=0.58 e^{\left[0.52-0.235 W e_{V}^{0.17} F r_{V}{ }^{0.37}\left(\rho_{V} / \rho_{L}\right)^{0.25}\left(q / q_{c r i t}\right)^{0.70}\right]}
$$

where $W e_{V}=\frac{G^{2} d}{\rho_{V} \sigma}$ is a vapor Weber number and $F r_{V}=\frac{G^{2}}{\rho_{V}^{2} g d}$ and $q_{c r i t}$ is found using equation (B13). And value of $x_{D E}$ is found using correlation (C15):

$$
x_{D E}=0.61 e^{\left[0.57-5.8 \cdot 10^{-3} W e_{V}^{0.38} F r_{V}^{0.15}\left(\rho_{V} / \rho_{L}\right)^{-0.09}\left(q / q_{c r i t}\right)^{0.27}\right]}
$$

Important to note, that for low flows like studied in this paper, the values of $x_{D E}$ will result in numbers above 1 , and this is not physically feasible. For that reason, $x_{D E}$ was chosen to be equal to 1 here.

Even though Mist flow (M) pattern does not play a role for exceptionally low flows studied here, besides being calculated as a part of $(\Delta p)_{\text {dryout }}$ equation (C13).

Mist flow can be described as a continuous vapor flow mixed with droplets of liquid. Using homogeneous flow theory with an assumption that mist flow possesses mean flow physical properties, the mist frictional pressure drop is calculated using (C16).

$$
(\Delta p)_{m i s t}=2 f_{m}\left(\frac{L}{d}\right) \frac{G^{2}}{\rho_{m}}
$$

In equation $(\mathrm{C} 16) \rho_{m}=\rho_{L}\left(1-\varepsilon_{h}\right)+\rho_{V} \varepsilon_{h}$ is a homogeneous density with homogeneous void fraction $\varepsilon_{h}=\frac{1}{1+\frac{(1-x) \rho_{V}}{x \rho_{L}}}$ and new friction factor value $f_{m}=\frac{0.079}{R e_{m}{ }^{0.25}}$ which includes the homogeneous viscosity $\mu_{m}=x \mu_{V}+(1-x) \mu_{L}$ through the calculation of $R e_{m}=\frac{G d}{\mu_{m}}$. The value of homogeneous viscosity was determined by Cicchitti et al. (Cicchitti et. al, 1960). 
As mentioned before, $(\Delta p)_{\text {mist }}$ is used merely for linear interpolation to calculate Dryout region pressure gradients for extremely low flows and since in equation (C13), $(\Delta p)_{m i s t}\left(x_{D E}\right)$ is a function of the dryout completion, it is calculated using quality of 1. 


\section{Silva Lima \& Thome, 20012 pressure drop model for U-bends}

A full outline of flow pattern based two-phase pressure drop correlations developed by Silva Lima \& Thome, 2012 is provided here.

As for the frictional pressure drop through the straight horizontal tubes, the friction factor

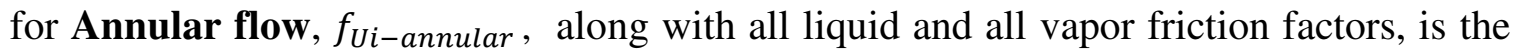
basis for all equations related to pressure drop through the U-bends.

$$
\Delta p_{U i-\text { annular }}=4 f_{U i-\text { annular }} \frac{L}{d} \frac{\rho_{V} u_{V}^{2}}{2}
$$

where

$$
L_{u}=\pi D / 2
$$

$L_{u}$ is the centerline length of the U-bend. $i$ index stands for the U-bend orientation: $H, V D, V U$ for horizontal, vertical downflow and vertical upflow respectively. $f_{U i-a n n u l a r}$ are found as following:

$$
\begin{gathered}
f_{U H-\text { annular }}=f_{\text {straight-annular }}\left(1+0.2\left(\frac{d}{D}\right)^{1.313} \mathrm{rmDe}_{V}{ }^{0.358}\right) \\
f_{U V D-\text { annular }}=f_{\text {straight-annular }}\left(1+0.5\left(\frac{d}{D}\right)^{1.339} \mathrm{Fr}_{2 \delta}{ }^{-0.193} \operatorname{Re}_{2 \delta}{ }^{0.555}\right) \\
f_{U V U-\text { annular }}=f_{\text {straight-annular }}\left(1+8\left(\frac{d}{D}\right)^{1.178} \mathrm{Fr}_{2 \delta} 0.196\left(\frac{u_{L}^{2}}{u_{V}^{2}} \frac{\rho_{V}}{\rho_{L}}\right)^{0.106}\right)
\end{gathered}
$$


In equations (D3)-(D5) $f_{\text {straight-annular }}, D e_{V}, F r_{2 \delta}, R e_{2 \delta}$ stand for straight tube friction factor by Quibèn \& Thome (20), vapor Dean number (D6), film Froude number (D7) and Reynolds number (D8) respectively. $\delta$ stands for film thickness (23).

$$
\begin{gathered}
D e_{V}=\frac{G d}{\mu_{V}} \frac{x}{\varepsilon} \sqrt{\frac{d}{D}} \\
F r_{2 \delta}=\frac{u_{L}^{2}}{g 2 \delta} \\
R e_{2 \delta}=\frac{2 G \delta}{\mu_{L}} \frac{(1-x)}{(1-\varepsilon)}
\end{gathered}
$$

For Slug and Intermittent Flows U-bend pressure drop found as:

$$
\Delta p_{U i \_s l u g+\text { intermittent }}=\Delta p_{\text {Ui_Liquid }}\left(1-\frac{\varepsilon}{\varepsilon_{I A}}\right)^{0.25}+\Delta p_{U i \_a n n u l a r}\left(\frac{\varepsilon}{\varepsilon_{I A}}\right)^{0.25}
$$

where

$$
\Delta p_{U i_{-} \text {Liquid }}=4 f_{\text {Ui_Liquid }} \frac{L}{d} \frac{\rho_{L} u_{L}^{2}}{2}
$$

with

$$
u_{L}=G / \rho_{L}
$$

In equations (D9) - (D10) the $\Delta p_{U i_{-} \text {annular }}$ is calculated using equation (D1) at the actual vapor quality, void fractions $\varepsilon$ and $\varepsilon_{I A}$ are found using (B1) at actual vapor quality and intermittent vapor quality respectively. $\Delta p_{U i_{-} \text {Liquid }}$ is a single-phase liquid pressure drop by Fanning with $u_{L 0}$ as a single-phase liquid velocity. $f_{U i}$ Liquid, a single-phase friction factor is found based on U-bend orientation using (D12) - (D14):

$$
\begin{aligned}
& f_{U H_{-} L i q u i d}=f_{\text {straight_Liquid }}\left(1+103.19 \cdot 10^{3}\left(\frac{d}{D}\right)^{2.405} D e_{L}^{-0.653}\right) \\
& f_{U V D_{-} \text {Liquid }}=f_{\text {straight_Liquid }}\left(1+717.7 \cdot 10^{5}\left(\frac{d}{D}\right)^{1.244} D e_{L}^{-1.461}\right)
\end{aligned}
$$




$$
f_{U V U_{-} \text {Liquid }}=f_{\text {straight_Liquid }}\left(1+4.09 \cdot 10^{3}\left(\frac{d}{D}\right)^{1.002} D e_{L}^{-0.381}\right)
$$

where

$$
f_{\text {straight_Liquid }}=0.079 / \operatorname{Re}_{L}{ }^{0.25}
$$

and

$$
D e_{L 0}=R e_{L} \sqrt{d / D}
$$

$f_{\text {straight_Liquid }}$ is a friction coefficient calculated using Blasius model for turbulent flow and a $D e_{L 0}$ is a single-phase liquid Dean number. $R e_{L}$ is found using (9a).

For Stratified-Wavy flow pattern frictional pressure drop is found as:

$$
\Delta p_{U i_{-} \text {stratified } / \text { wavy }}=4 f_{U i_{-} \text {stratified } / \text { wavy }} \frac{L}{d} \frac{\rho_{V} u_{V}^{2}}{2}
$$

with

$$
f_{U i \_s t r a t i f i e d / \text { wavy }}=\theta_{\text {dry }}{ }^{*} f_{U i \_ \text {Vapor }}+\left(1-\theta_{\text {dry }}{ }^{*}\right) f_{U i-\text { annular }}
$$

and

$$
\begin{gathered}
f_{U_{\text {U }} \text { Vapor }}=f_{\text {straight_Vapor }}\left(1+5.102 \cdot 10^{6}\left(\frac{d}{D}\right)^{1.109} D e_{V}^{-1.222}\right) \\
f_{U V D \_ \text {Vapor }}=f_{\text {straight_Vapor }}\left(1+8.39\left(\frac{d}{D}\right)^{1.278} D e_{V}^{0.057}\right) \\
f_{U V U_{-} \text {Vapor }}=f_{\text {straight_Vapor }}\left(1+47.1 \cdot 10^{3}\left(\frac{d}{D}\right)^{2.707} D e_{V}^{-0.507}\right)
\end{gathered}
$$

In (D18), the $\theta_{d r y}{ }^{*}$ is found with (C5), $f_{\text {straight_Vapor }}$ is a single-phase vapor friction factor calculated with (D22) using $R e_{V}$ as a function of a vapor true mean velocity (D23):

$$
\begin{aligned}
f_{\text {straight_Vapor }} & =0.079 / \operatorname{Re}_{V}{ }^{0.25} \\
\operatorname{Re}_{V} & =\frac{G d}{\mu_{V}} \frac{x}{\varepsilon}
\end{aligned}
$$

For Slug-Stratified Wavy regime frictional pressure drop is found as in (D24):

$$
\Delta p_{U i \_s l u g}+S W=\Delta p_{U i_{-} \text {Liquid }}\left(1-\frac{\varepsilon}{\varepsilon_{I A}}\right)^{0.25}+\Delta p_{\text {Ui_stratified } / \text { wavy }}\left(\frac{\varepsilon}{\varepsilon_{I A}}\right)^{0.25}
$$


(D24) is an interpolation between all liquid and stratified-wavy flow.

Mist Flow pattern frictional pressure drop can be calculated with (D25):

$$
\Delta p_{U i \_m i s t}=4 f_{U i \_m i s t} \frac{L}{d} \frac{G^{2}}{2 \rho_{m}}
$$

In (D25) $f_{U i}$ mist is calculated based on the U-bend orientation as:

$$
\begin{aligned}
& f_{U H_{-} m i s t}=f_{m}\left(1+300.35\left(\frac{d}{D}\right)^{1.623} D e_{m}{ }^{-0.189}\right) \\
& f_{U V U_{-} m i s t}=f_{m}\left(1+24.491\left(\frac{d}{D}\right)^{1.090} D e_{m}{ }^{0.011}\right)
\end{aligned}
$$

with

$$
D e_{m}=R e_{m} \sqrt{d / D}
$$

$\rho_{m}$ and $R e_{m}$, mist density and mist viscosity, are found identically as for equation (C16) and straight tube configuration. Unfortunately, Silva Lima \& Thome, were not able to define the friction factor for vertical down-flow, $f_{U V D_{-} m i s t}$, configuration, but did suggest the use of straight tube friction factor as defined earlier for (C16) with $f_{m}$.

Dryout Flow pattern frictional pressure drop according to Silva Lima \& Thome (Silva Lima \& Thome, Part 2, 2012):

$$
\Delta p_{U i_{-} \text {dryout }}=\Delta p_{U i_{-} j}\left(x_{d i}\right)-\frac{x-x_{D I}}{x_{D E}-x_{D I}}\left[\Delta p_{U i-j}\left(x_{D I}\right)-\Delta p_{U i_{m i s t}}\left(x_{D E}\right)\right]
$$

In (D29) index $j$ stands for the preceding flow pattern; for example, if the preceding flow pattern is annular: $\Delta p_{U i-j}=\Delta p_{U i-a n n u l a r}$ and equation (50) is used. $x_{D I}$, the dryout 
inception quality is found using $(\mathrm{C} 15)$ and $x_{D E}$, the dryout completion is found using (D30):

$$
x_{D E}=0.61 e^{\left[0.52-5.8 \cdot 10^{-3} W e_{V}^{0.38} F r_{V}{ }^{0.15}\left(\rho_{V} / \rho_{L}\right)^{-0.09}\left(q / q_{c r i t}\right)^{0.27}\right]}
$$

$W e_{V}$ and $q_{c r i t}$ found as for (C15), but $F r_{V}$ for U-bends is calculated as:

$$
F r_{V}=\frac{G^{2}}{\rho_{V}\left(\rho_{L}-\rho_{V}\right) g d}
$$

As for the straight tube correlation, the Stratified flow regime was not analyzed by the authors of this model, but they suggested the following correlations, which will also be analyzed using data from the current study:

$$
\begin{gathered}
\Delta p_{\text {Ui_stratified }\left(x \geq x_{I A}\right)}=4 f_{\text {Ui_stratified }\left(x \geq x_{I A}\right)} \frac{L}{d} \frac{\rho_{V} u_{V}{ }^{2}}{2} \\
\Delta p_{\text {Ui_stratified }\left(x<x_{I A}\right)} \\
=\Delta p_{\text {Ui_Liquid }}\left(1-\frac{\varepsilon}{\varepsilon_{I A}}\right)^{0.25}+\Delta p_{i_{-} \text {stratified }\left(x \geq x_{I A}\right)}\left(\frac{\varepsilon}{\varepsilon_{I A}}\right)^{0.25} \\
f_{\text {Ui_stratified }\left(x \geq x_{I A}\right)}=\theta_{\text {strat }}{ }^{*} f_{\text {Ui-Vapor }}+\left(1-\theta_{\text {strat }}{ }^{*}\right) f_{\text {Ui-annular }}
\end{gathered}
$$

As can be seen from (D32) and (D33), the frictional pressure drop through the U-bend in stratified flow is divided into two correlations relative to the transition quality from intermittent to annular flow, $x_{I A}$. 
Appendix E

Comparison of refrigerant properties and parameters affecting the measured energy consumption of domestic refrigerators for an idealized revised Rankine cycle operating between $-15^{\circ} \mathrm{C}\left(5^{\circ} \mathrm{F}\right)$ and $30^{\circ} \mathrm{C}\left(86^{\circ} \mathrm{F}\right)$ saturation temperatures (1996 Maclaine-cross and Leonardi, 1996).

\begin{tabular}{lcccc}
\hline Refrigerant & R12 & R134a & R600a & RC270 \\
\hline Chemical classification & CFC & HFC & HC & HC \\
$x_{1}$ Molar mass $(\mathrm{g} / \mathrm{mol})$ & 120.9 & 102.0 & 58.1 & 42.1 \\
$x_{2}$ Refrigerating effect $(\mathrm{J} / \mathrm{g})$ & 116.9 & 150.7 & 262.3 & 359.1 \\
$x_{3} 30^{\circ} \mathrm{C}$ sat. liquid volume $(\mathrm{L} / \mathrm{kg})$ & 0.773 & 0.844 & 1.835 & 1.636 \\
$x_{4} 30^{\circ} \mathrm{C}$ sat. vapour volume $(\mathrm{L} / \mathrm{kg})$ & 23.59 & 27.11 & 95.26 & 62.41 \\
$x_{5} 30^{\circ} \mathrm{C}$ sat. vapour viscosity $(\mu \mathrm{Pas})$ & 12.95 & 12.48 & 7.81 & 9.07 \\
$x_{6}$ Condenser pressure $(\mathrm{kPa})$ & 743.2 & 770.7 & 403.6 & 827.0 \\
\hline 1. Evaporator pressure $(\mathrm{kPa})$ & 181.9 & 163.6 & 89.2 & 206.0 \\
2. $x_{7}$ Condenser gauge $x_{6}-101.3(\mathrm{kPa})$ & 641.9 & 669.4 & 302.3 & 725.7 \\
3. COP 0 K suction superheat & 4.69 & 4.62 & 4.69 & 4.88 \\
4. COP 20 K suction superheat & 4.71 & 4.71 & 4.82 & 4.79 \\
5. Compressor discharge temp. $\left({ }^{\circ} \mathrm{C}\right)$ & 39.3 & 36.6 & 30.0 & 52.7 \\
6. Effective displacement $(\mathrm{L} / \mathrm{kJ})$ & 0.79 & 0.81 & 1.52 & 0.65 \\
7. Cond. loss par. $x_{7}^{2} x_{4} x_{5} /\left(x_{2} x_{6}\right)(\mu \mathrm{Pas})$ & 1.45 & 1.31 & 0.64 & 1.00 \\
8. 15 $5^{\circ} \mathrm{C}$ sat. liquid $k / \mu(\mathrm{kJ} / \mathrm{kgK})$ & 0.278 & 0.293 & 0.496 & 0.792 \\
9. Liquid molar volume $x_{1} x_{3}(\mathrm{~mL} / \mathrm{mol})$ & 93.5 & 86.1 & 106.7 & 68.8 \\
10. Leakage speed $x_{3} x_{7} /\left(x_{4} x_{5}\right)(1 / \mathrm{ns})$ & 1.62 & 1.67 & 0.75 & 2.10 \\
\hline
\end{tabular}




\title{
CURRICULUM VITAE
}

\author{
NAME: $\quad$ Anna Fenko \\ CONTACT: anna.fenko@yahoo.com \\ Work: 502-452-3381 \\ Cell: 850-420-7161 \\ 5022 Lea Ann Way \\ Louisville, KY, 40219 \\ DOB: $\quad$ March 14, 1987 \\ EDUCATION \\ \& TRAINING: $\quad$ M.S. Mechanical Engineering (exp. 12/2015) \\ University of Louisville \\ 2011-Present \\ B.S. Mechanical Engineering- With honors \\ University of Florida \\ 2010-2012
}

\section{WORK EXPERIENCE:}

GE Appliances, Louisville, KY

Edison Engineering Development Program

$4^{\text {th }}$ Rotation: Refrigeration Advanced Systems

$3^{\text {rd }}$ Rotation: Closing Care Advanced Systems

$2^{\text {nd }}$ Rotation: Refrigeration Production

$1^{\text {st }}$ Rotation: Microwave Oven
January 2013-Present

July 2014-July 2015

January 2014-Jul 2014

July 2013-Jananuary 2014

January 2013-July 2013 
Cummins, Inc., Turbo-technologies Group, Columbus, IN

May 2012-August 2012

Product Engineer Intern

UF Research and Education Engineering, Shalimar, FL Engineer Assistant

May 2011-August 2011

RESEARCH EXPERIENCE:

Undergraduate Research, UF, Gainesville, FL September 2012-December 2012

Magnetic abrasive finishing of the inside of the fuel injector tube at UF Nano-scale Manufacturing Lab

Undergraduate Research, UWF, Pensacola, FL

August 2009-December 2009

Mathematical modeling of the change of algae growth in 12 local lakes depending on a level of nutrients

COMPUTER SKILLS/ LANGUAGES:

Knowledgeable: SolidWorks, MATLAB, Microsoft Word, Excel, PowerPoint

Basic Understanding, MiniTab, Pre-E, LabVIEW

Proficient in Ukrainian and Russian 